LinKÖPING StUdies IN SCIENCE AND TECHNOLOGY.

DisSERTATION, NO. 1858

\title{
Automated layup and forming of prepreg laminates
}

\author{
Andreas Björnsson
}

Division of Manufacturing Engineering

Department of Management and Engineering

Linköping University

58183 Linköping

Sweden 
ISBN 978-91-7685-510-2

ISSN 0345-7524

Copyright (C) Andreas Björnsson, 2017

Published and distributed by:

Division of Manufacturing Engineering

Department of Management and Engineering

Linköping University

58183 Linköping

Sweden

Printed by

LiU-Tryck, Linköping 2017 
"Utan tvivel är man inte klok."

Tage Danielsson [1] 



\section{ABSTRACT}

Composite materials like carbon fiber-reinforced polymers (CFRPs) present highly appealing material properties, as they can combine high strength with low weight. In aerospace applications, these properties help to realize lightweight designs that can reduce fuel consumption. Within the aerospace industry, the use of these types of materials has increased drastically with the introduction of a new generation of commercial aircraft. This increased use of CFRP drives a need to develop more rational manufacturing methods.

For aerospace applications, CFRP products are commonly manufactured from a material called prepreg, which consists of carbon fibers impregnated with uncured polymer resin. There are two dominant manufacturing technologies for automated manufacturing using prepreg, automated tape layup and automated fiber placement. These two technologies are not suitable for all types of products, either due to technical limitations or a combination of high investment costs and low productivity. Automation alternatives to the two dominant technologies have been attempted, but have so far had limited impact. Due to the lack of automation alternatives, manual manufacturing methods are commonly employed for the manufacturing of complex-shaped products in low to medium manufacturing volumes.

The research presented in this thesis aims to explore how automated manufacturing systems for the manufacturing of complex CFRP products made from prepreg can be designed so that they meet the needs and requirements of the aerospace industry, and are suitable for low to medium production volumes. In order to explore the area, a demonstrator-centered research approach has been employed. A number of demonstrators, in the form of automated manufacturing cells, have been designed and tested with industrial and research partners. The demonstrators have been used to identify key methods and technologies that enable this type of manufacturing, and to analyze some of these methods and technologies in detail. The demonstrators have also been used to map challenges that affect the development of enabling methods and technologies.

Automated manufacturing of products with complex shapes can be simplified by dividing the process into two steps. Thin layers of prepreg are laid up on top of each other to form flat laminates that are formed to the desired shape in subsequent forming operations. The key methods and technologies required to automate such a system are methods and technologies for automated prepreg layup, the automated removal of backing paper and the forming of complex shapes. The main challenges are the low structural rigidity and tacky nature of prepreg materials, the extensive quality requirements in the aerospace industry and the need for the systems to handle a wide array of prepreg shapes.

The demonstrators show that it is possible to automate the manufacturing of complexshaped products using automated layup and forming of prepreg laminates. Tests using the demonstrators indicate that it is possible to meet the quality requirements that apply to manual manufacturing of similar products. 



\section{SAMMANFATTNING}

Polymera kolfiberkompositer erbjuder en eftertraktad kombination av låg vikt och hög styrka som kan bidra till lättviktskonstruktioner som t.ex. kan leda till bränslebesparingar för passagerarflygplan. Inom flygindustrin har användningen av denna materialtyp ökat kraftigt med introduktionen av en ny generation flygplan som till mer än hälften består av kompositmaterial. Den ökade användningen av polymera fiberkompositer medför ett ökat behov av rationella produktionsmetoder.

Inom flygindustrin tillverkas ofta polymera kolfiberkompositprodukter av så kallat prepreg-material som består av kolfibrer impregnerade med en plast. Det finns två huvudalternativ för automatisk tillverkning av prepreg-baserade produkter, automatisk tejpläggning eller automatisk fiberplacering. De två alternativen har tekniska begränsningar och är förknippade med mycket höga investeringskostnader vilket gör att det finns produkter som de inte kan tillverka eller som inte är kostnadseffektiva att tillverka med dessa två metoder. Andra automatiska alternativ har utvecklats, men har inte nått någon större industriell implementering. Bristen på automatiserade tillverkningsalternativ leder till att produkter med komplex form, och som tillverkas i små och medelstora volymer ofta tillverkas manuellt.

Forskningen som presenteras i denna avhandling syftar till att undersöka hur automatiska tillverkningsceller för tillverkning av polymera kolfiberkompositprodukter med komplex form kan utformas så att de uppfyller de krav som gäller för tillverkningen av produkter för flygindustrin och är lämpliga för låga och medelhöga tillverkningsvolymer. En demonstratorcentrerad forskningsmetod har använt för att utforska området och ett flertal demonstratorer har byggts och testats tillsammans med partners från industrin och andra forskningsorganisationer. Demonstratorerna, som är kompletta tillverkningsceller, har använts för att identifiera metoder och utrustning som är nödvändiga att utveckla för att automatisera denna typ av tillverkning och för att undersöka några metoder och tillhörande utrustning mer i detalj. Demonstratorerna har också använts för att kartlägga faktorer som påverkar hur metoder och utrustning utformas.

Automatisk tillverkning av produkter med komplex form kan förenklas genom att dela upp tillverkningen i två steg. Först läggs prepreg-ark ihop till ett laminat som formas till produktens form i ett efterföljande steg. För att automatisera denna typ av tillverkning behöver nyckelmetoder och nyckelutrustning för hopläggning av laminat, borttagning av skyddspapper samt formning av laminat till komplexa former utvecklas. Viktiga faktorer som påverkar utformningen av tillverkningscellerna är prepreg-materialens låga styvhet och klibbiga yta, de höga kvalitetskrav som gäller för tillverkning av flygplanskomponenter samt att systemen måste hantera en stor mängd olikformade prepreg-ark. Demonstratorerna visar att det är möjligt att automatisera tillverkningen av polymera kolfiberprodukter med komplex form genom automatisk uppläggning och formning av plana laminat. Tester med demonstratorerna pekar på att det är möjligt att tillverka produkterna i enlighet med de kvalitetskrav som finns för manuell tillverkning av liknande produkter. 



\section{ACKNOWLEDGMENTS}

The work presented in this thesis would not have been possible without tremendous efforts from a great number of people. First, I would like to thank my three supervisors for providing me the opportunity, and for helping me to explore this interesting field of research: Docent Kerstin Johansen, for recruiting me to a $\mathrm{PhD}$ position and showing me the way to become a scientist within the field of manufacturing engineering; Professor Mats Björkman, for always trusting me to explore the areas that I have found most interesting, and Dr. Marie Jonsson, for contributing with great technical knowledge and critical reviews on technical as well as methodological aspects of my work.

Most of the research results presented herein stem from the development of a number of demonstrators. The development has been a collaborative effort, and I would like to thank all the partners that have contributed to the demonstrators with both time and resources. It is impossible to mention all involved in the demonstrators, but some who have significantly contributed to the presented research are discussed below. A big thanks to Jan Erik Lindbäck at Saab Aerostructures, who with his strong engagement, curiosity and great technical knowledge, has continuously supported the work and made this an enjoyable and rewarding job. I am also indebted to Tomas Andersson and Mikael "Mille" Petersson, also from Saab Aerostructures, who with their extensive knowledge in prepregbased manufacturing have made valuable contributions to the development and testing of the demonstrators. Also, Sebastian von Gegerfelt and Daniel Eklund from Swerea SICOMP and Peter Karlsson and Per Johansson at the university workshop have, with their inventiveness and engineering skills, made important technical contributions to the demonstrators. I would also like to thank all the students that have helped the development of the demonstrators move forward by developing and testing some of the methods and technologies employed in the demonstrators.

The presented research has been funded by grants from the Swedish Governmental Agency for Innovation Systems, the Swedish National Space Board and the Swedish Foundation for Strategic Research. The funding organizations are gratefully acknowledged for their support.

During my years as a $\mathrm{PhD}$ student I have been fortunate to be surrounded with great colleagues and our discussions on research, teaching and life in general have made work very enjoyable. A special thank you to Kristofer Elo for providing the template used in this thesis.

Finally, I would like to thank my wonderful family and my fantastic friends who have supported me in my research endeavor. Without your understanding, kind concern and encouragement this thesis would not have been possible. My deepest gratitude goes to my wife Jenny. You are the true meaning of my life!

Brinkabo, April 2017

Andreas Björnsson 



\section{APPENDED PAPERS}

Paper I

Björnsson A. \& Johansen K. (2012) “Composite Manufacturing: How Improvement Work Might Lead to Renewed Product Validation" in Proceedings of the Swedish Production Symposium 2012 (SPS12), 6th-8th November 2012, Linköping, Sweden, peer-reviewed.

Paper II

Björnsson A. Lindbäck J. E. \& Johansen K. (2013). “Automated Removal of Prepreg Backing Paper - A Sticky Problem" in Proceedings of the SAE 2013 Aero Tech Congress and Exhibition, 24th-26th September 2013, Montreal, Canada, peer-reviewed.

Paper III

Björnsson A. Jonsson M. \& Johansen K. (2015). "Automation of composite manufacturing using off-the-shelf solutions; three cases from the aerospace industry" in Proceedings of the $20^{\text {th }}$ International Conference on Composite Materials (ICCM20), 19th-24th July 2015, Copenhagen, Denmark.

\section{Paper IV}

Björnsson A. Lindbäck J.E. Eklund D. \& Jonsson M. (2016) "Low-cost Automation for Prepreg Handling - Two Cases from the Aerospace Industry" SAE International Journal of Materials and Manufacturing 9(1), peer-reviewed.

\section{Paper V}

Björnsson A. Jonsson M. Lindbäck J.E. Åkermo M. \& Johansen K. (2016) "Robotforming of prepreg stacks - development of equipment and methods" in Proceedings of the 17th European Conference on Composite Materials (ECCM17), 26th-30th June 2016, Munich, Germany.

\section{Paper VI}

Björnsson A. Jonsson M. Eklund D. Lindbäck J. E. \& Björkman M. (?). “Getting to grips with automated prepreg handling" submitted for review to Production Engineering Research and Development.

\section{Paper VII}

Björnsson A. Jonsson M. \& Johansen K. (?) “Automated material handling in composite manufacturing using pick-and-place systems - a review" submitted for review to Robotics and Computer-Integrated Manufacturing. 


\section{OTHER PUBLICATIONS}

Lindbäck J. E. Björnsson A. \& Johansen K. (2012) "New Automated Composite Manufacturing Process: Is it possible to find a cost effective manufacturing method with the use of robotic equipment?" in Proceedings of the Swedish Production Symposium 2012 (SPS12), 6th-8th November 2012, Linköping.

Björnsson A. Johansen K. \& Alexandersson D. (2013) "Three-Dimensional Ultrasonic Cutting of RTM Preforms - A Part of a High Volume Production System" in Proceedings of the 19th International Conference on Composite Materials (ICCM19), 28th July - 2nd August 2013, Montreal, Canada.

Björnsson A. Thuswaldner M. \& Johansen K. (2014) “Automated Composite Manufacturing Using Off-The-Shelf Automation Equipment - A Case from the Space Industry" in Proceedings of the 16th European Conference on Composite Materials (ECCM16), 22nd-26th June 2014, Seville, Spain.

Björnsson A. (2014) "Enabling Automation of Composite Manufacturing through the Use of Off-The-Shelf Solutions" Licentiate Thesis, Linköping University. 


\section{TABLE OF CONTENTS}

1 Introduction. 1

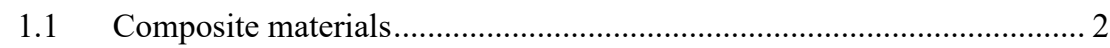

1.2 Composite material applications ....................................................... 3

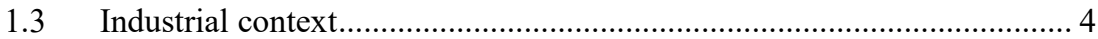

1.4 Automation of composite manufacturing................................................ 5

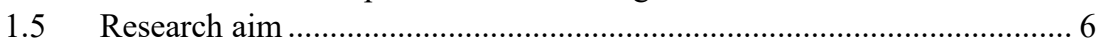

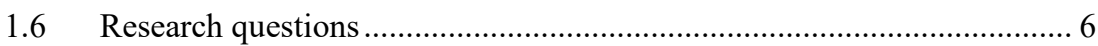

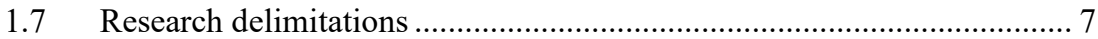

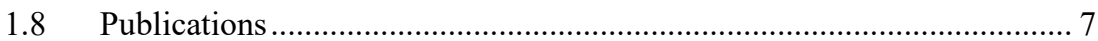

2 Research Method.

2.1 A general outlook on research........................................................... 12

2.2 Established research designs and methods............................................. 14

2.3 Analyzing the data................................................................................ 19

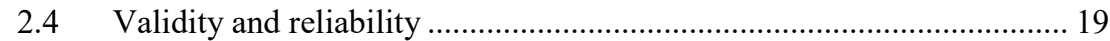

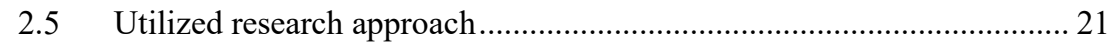

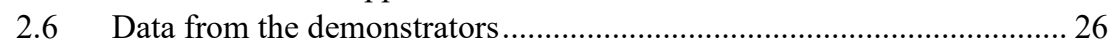

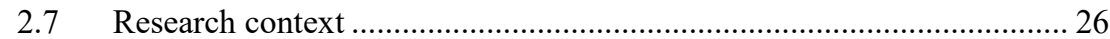

3 Manufacturing systems, au tomation and flexibility . 29

3.1 Automation of manufacturing systems ................................................. 30

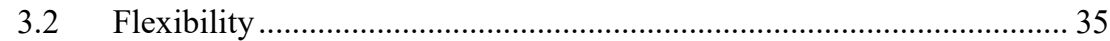

4 Manufacturing of composite products . 39

4.1 Historical use of composite materials .................................................... 40

4.2 Composite materials and their constituents......................................... 41

4.3 Manual manufacturing methods........................................................... 43

4.4 Forming of prepreg laminates .................................................................. 47

4.5 Automated Tape Laying and Fiber Placement...................................... 49

4.6 Pick-and-place solutions for prepreg layup............................................. 53

4.7 A review of automated material handling ................................................ 54

4.8 Examples of pick-and-place solutions for prepreg layup........................ 58

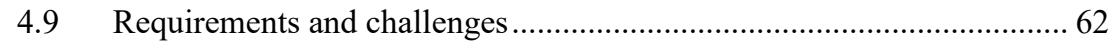

4.10 Alternative automation approaches........................................................ 63

5 Demonstrators. $\quad \mathbf{6 5}$

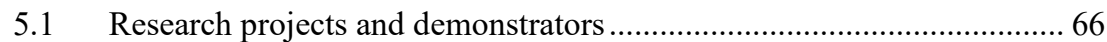

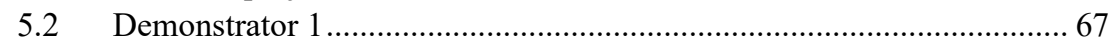

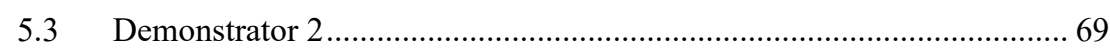

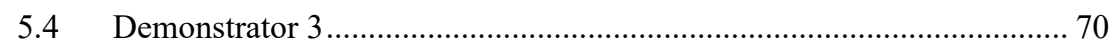

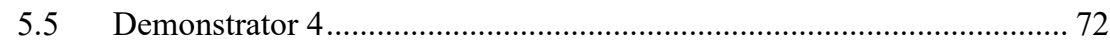

5.6 Connection between the demonstrators and appended papers............... 73 
6 Enabling methods and technologies.

6.1 The current use of automated solutions ................................................... 76

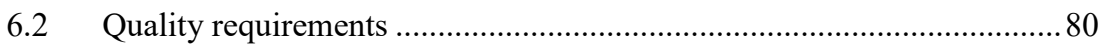

6.3 Key enabling methods and technologies identified ...............................8 82

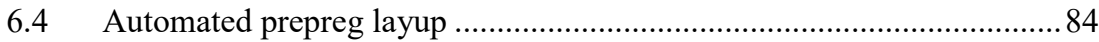

6.5 Automated forming of prepreg laminates............................................ 101

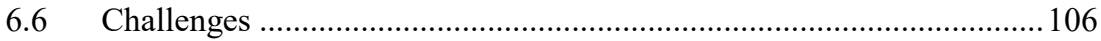

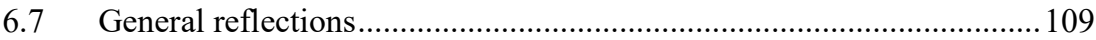

7 Conclusion and discussion. $\quad 113$

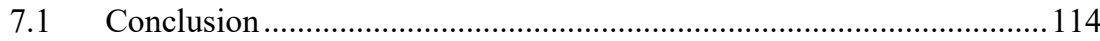

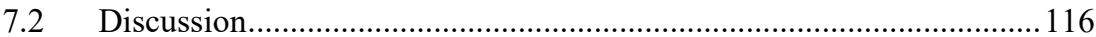

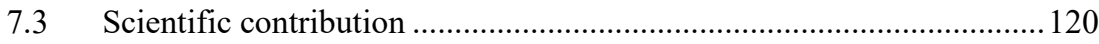

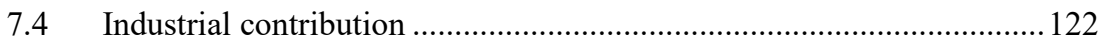

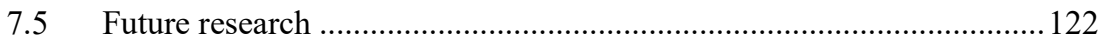




\section{LIST OF FIGURES}

Figure 1: Examples of reinforcements and matrixes …………..................................... 2

Figure 2: The global demand for carbon fiber .............................................................. 4

Figure 3: The global demand for CFRPs ................................................................. 4

Figure 4: The global demand for carbon composites by application.................................. 5

Figure 5: The revenue from carbon composites divided by application.............................. 5

Figure 6: The industry as a laboratory research design ……………………………..... 14

Figure 7: A typical research cycle in action research .................................................... 15

Figure 8: The four research strategies in systems development research......................... 16

Figure 9: The five stages of systems development ..................................................... 16

Figure 10: Demonstrator-centered research................................................................. 18

Figure 11: Specifying the system borders for the demonstrator ...................................... 22

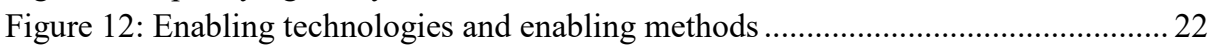

Figure 13: A typical workflow when developing a demonstrator .....................................2 23

Figure 14: The eleven flexibility types and their mutual relationships .............................36

Figure 15: Upton's framework for identifying and analyzing different flexibility types 38

Figure 16: Prepreg made from unidirectional carbon fibers............................................ 42

Figure 17: Process for manufacturing a CFRP part from prepreg using layup ................ 43

Figure 18: Manual layup of prepreg plies on a mold.................................................... 44

Figure 19: Illustration of bridging .............................................................................. 45

Figure 20: A two-step approach to prepreg layup ......................................................... 46

Figure 21: An illustration of the vacuum forming method.............................................. 48

Figure 22: Manual forming of a prepreg laminate............................................................ 48

Figure 23: Prepreg layup onto mold using ATL …………………………………...... 50

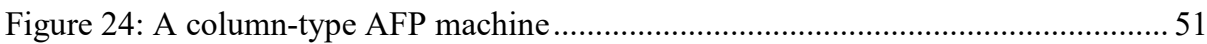

Figure 25: A laminate with a tapered edge .................................................................. 53

Figure 26: Overview of gripping technologies .............................................................. 56

Figure 27: 2D pick up to 3D placement.................................................................... 57

Figure 28: The layout of the cell developed by Newell et al...........................................5 59

Figure 29: The removal and reattachment process of the backing paper ......................... 59

Figure 30: A timeline showing the four demonstrators presented in this thesis............... 67

Figure 31: A flowchart showing the scope of Demonstrator 1........................................ 68

Figure 32: An illustration of how the conceptual demonstrator might be realized .......... 68

Figure 33: Prototype gripper for the handling of prepreg plies ........................................ 68

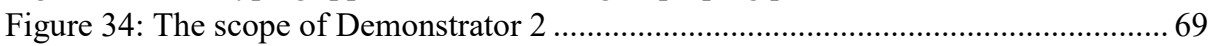

Figure 35: The layout of Demonstrator 2 .................................................................. 70

Figure 36: The end effector developed for automated layup of prepreg plies................. 70

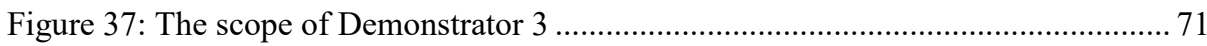

Figure 38: An illustration of the demonstrator product ................................................ 71

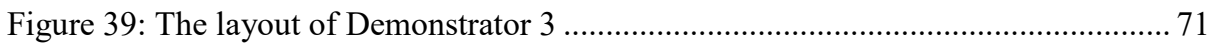

Figure 40: The scope of Demonstrator 4 ………………………………………........ 72

Figure 41: Flowchart showing the manufacturing of an integrated structure................... 79

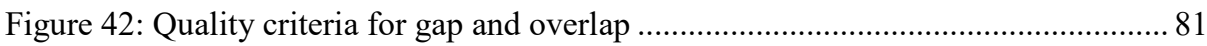

Figure 43: Examples of vacuum suction cups ........................................................... 85 
Figure 44: The outlines of the plies in the ply book for Demonstrator 1 .......................87

Figure 45: The distribution of vacuum cups and the division into zones ........................87

Figure 46: The end effector developed for Demonstrator 1 ....................................... 87

Figure 47: The extend and retract function and the two sides with vacuum cups ...........88

Figure 48: The end effector used for prepreg layup in Demonstrator 2 ...........................8

Figure 49: Examples of plies from the ply book in Demonstrator 3 ..............................89

Figure 50: The reconfigurable end effector developed in Demonstrator 3 ......................90

Figure 51: The dual-arm solution for prepreg layup developed in Demonstrator 3.........90

Figure 52: Sequential laydown using the dual-arm solution........................................... 91

Figure 53: The sequence used to pick up and secure a good grip of the backing paper ..97

Figure 54: The tool with vacuum cup and clamp integrated into the end effector ..........97

Figure 55: The tool used for removing the backing paper, as a separate end effector.....97

Figure 56: Tool for removal of backing paper using a rolling motion............................98

Figure 57: Sequence for removal of long backing papers..............................................99

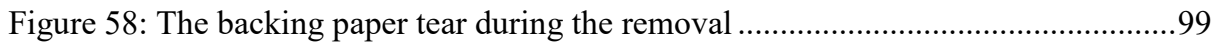

Figure 59: An illustration of how the backing paper is cut ..........................................99

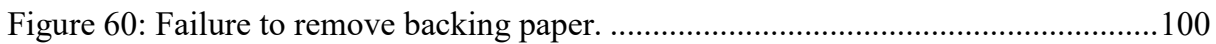

Figure 61: A cross-section of the mold used for the robot forming ................................ 102

Figure 62: The robot-forming solution developed for Demonstrator 3 ........................102

Figure 63: The wide rubber rolls and the tools used for forming the internal radius......103

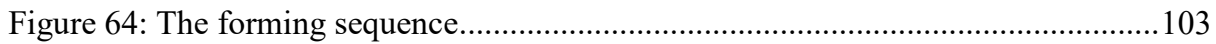

Figure 65: $\Omega$-shaped beam formed from a seven-layer laminate................................. 105

Figure 66: Illustration of joints between plies within the laminate ...............................108

\section{LIST OF TABLES}

Table 1: Connection between papers and research questions ....................................

Table 2: The five possible levels of automation in a production plant ................................ 31

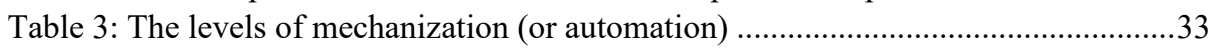

Table 4: Benefits, advantages, goals and reasons for implementing automation .............34

Table 5: Sources presenting work related to 2D or 3D material handling .......................55

Table 6: Sources describing systems for automated composite handling ..........................57

Table 7: Summary of the four demonstrators presented in the thesis ..............................66

Table 8: The connection between the demonstrators and the appended papers...............73

Table 9: The operations performed to cut plies using an automated cutting machine.....78

Table 10: Fraction of manual layup in relation to total time for manufacturing beams...78

Table 11: A comparison between the end four end effectors. 


\section{INTRODUCTION}

The research presented in this thesis explores automated alternatives for manufacturing of composite products for the aerospace industry. In this first chapter, the research area is briefly introduced and important terms are defined. The chapter provides an account for the research aim and the research questions as well as important delimitations. It also presents the papers that are appended to the thesis and outline their connection to the research questions. 


\subsection{COMPOSITE MATERIALS}

The term composite materials, or composites for short, includes a great range of different materials. Merriam-Webster [2] provides a general definition that describes a composite as " a solid material which is composed of two or more substances having different physical characteristics and in which each substance retains its identity while contributing desirable properties to the whole" [2]. Broad definitions of the term, such as the one provided by Merriam-Webster, usually highlight two distinct characteristics for composite materials. Firstly, composite materials are made up of two or more materials that have been combined so that the constituent materials contribute with their unique characteristics to form a new material with the desired properties [3-5]. Secondly, definitions often highlight the fact that the constituent materials, combined to form a composite, retain their physical and chemical properties [3,5]. These types of broad definitions include an ample array of material combinations, ranging from papier-mâché to steel-reinforced concrete.

The two major constituents in a composite material are called reinforcement and matrix. The main function of the reinforcement is to provide strength and stiffness to the material and to carry external loads. The reinforcement is surrounded by the matrix, which transfers and distributes external load to the fibers and protects the fibers against the surrounding environment. Figure 1 shows some examples of materials that can be used as reinforcement and matrix. As highlighted in Figure 1, this thesis only considers the polymer matrixes reinforced with fibrous materials, often denominated as fiberreinforced polymers (FRP), and in particular polymer materials reinforced with carbon fibers (CFRPs).

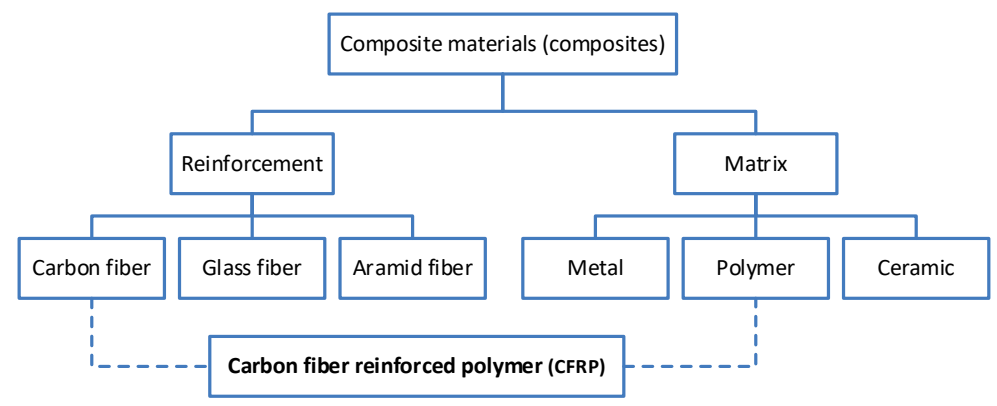

Figure 1: Examples of different reinforcements and matrixes that can be combined into a composite material. In this case carbon fiber-reinforced polymers (CFRPs). Figure from [6].

In addition to choosing from a multitude of materials to combine into a composite material, there are also different forms and shapes of reinforcement to choose from, and the manufacturing process itself has a clear influence on the material properties of the final product. All the options present an opportunity to design a composite material with characteristics adapted to specific applications. Some combinations, for example long carbon fibers in a unidirectional arrangement embedded in an epoxy matrix, yield materials with high strength and stiffness in combination with low density. In aerospace 
and automotive applications, these combinations provide a possibility for lightweight designs that can accomplish fuel savings and thereby reduced environmental impact.

Fibers and polymers can be handled as two separate materials that are mixed during the final stage of the manufacturing process, as is the case with many injection methods such as resin transfer molding (RTM). Another alternative is to purchase a raw material from a supplier where the fibers and the matrix are already mixed. One group of premixed composite materials where long fibers have been pre-impregnated with a polymer matrix are called prepreg material, or simply prepreg for short. Most of the manufacturing methods presented in this thesis use prepreg as raw material.

\subsection{COMPOSITE MATERIAL APPLICATIONS}

The use of composite materials, like clay reinforced with straw and laminated wood, has a long history, while the history of fiber-reinforced polymers is much shorter. Some of the earliest reports on the use of high-performance fiber-reinforced polymers are from the late 1930s [7]. In the early 1950s, following the development of fiber and resins, glass fiber-reinforced polymers saw a steep increase in use for a variety of applications [7]. Within the aerospace industry, one of the first major applications of advanced composites was fiberglass rotors for helicopters [8]. A decade later, in the mid-1960s, improved manufacturing techniques for manufacturing high-performance carbon fibers marked the start for carbon fiber-reinforced polymers [9]. Initially, carbon fibers were expensive and thus only used for high-tech and high-cost applications such as military aircraft. The introduction of fiber-reinforced polymer composites in the aerospace industry has occurred gradually, first used in military aircraft and later in civil aviation. New types of materials were first introduced in non-critical parts such as interiors, and based on those experiences, were later introduced into primary aircraft structures [8]. The two most recently launched commercial aircraft from Boeing and Airbus, the 787 and the A350, both contain more than 50\% composite materials $[8,10]$. The use of composite materials, in particular CFRPs, has increased within the automotive sector with the introduction of BMW's electric cars, the i3 and i8, which both rely on carbon fiber composites to reduce the weight of the vehicles.

The use of composite materials in general, and in particular carbon fiber-reinforced polymers, has increased dramatically over the last years and the sector is predicted to continue to grow. In an annual market report, Witten et al. [11] present the historical data as well as forecast the future composite demand. The report presents a good view of the current market, and some of the highlights are summarized below. The global demand for pure carbon fibers is presented in Figure 2, while the global demand for carbon fiber-reinforced polymers is presented in Figure 3. Carbon fibers are almost exclusively used to strengthen other materials, i.e. as the reinforcing constitute in composite materials. In 2015, carbon fibers with a polymer matrix generated approximately $65 \%$ of the total revenues from composite materials reinforced with carbon. Other matrix materials that are reinforced with carbon fibers are ceramics, metals and carbon. Between 2010 and 2015, the annual growth rate of CFRPs was $12.3 \%$ [11]. 


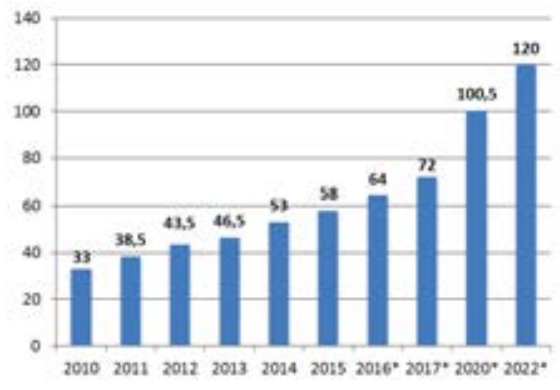

Figure 2: The global demand for carbon fiber in 1,000 tons based on [11].

Figures for 2016-2022 are estimates.

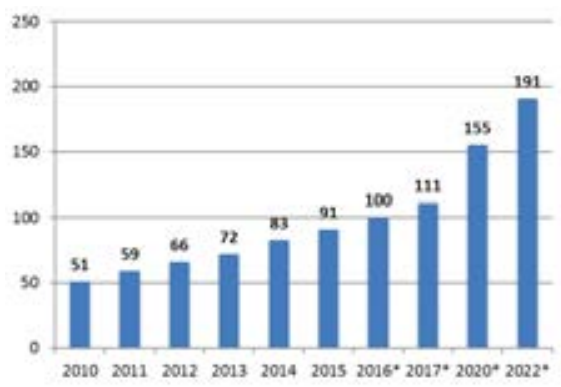

Figure 3: The global demand for CFRPs in 1,000 tons based on [11].

Figures for 2016-2022 are estimates.

Looking at the different manufacturing methods used to produce components from carbon fiber-reinforced polymers, layup processes using prepreg constitute the greatest part with approximately $43 \%$ of the market share [11]. Witten et al. [11] conclude that the main driving force behind the market growth is the increasing share of CFRPs used in automotive and aerospace applications. According to these authors [11], the growth of composites in the automotive sector is highly dependent on the success of reducing material and manufacturing costs for composite components so that the material becomes affordable to use in family cars. In the aerospace industry, the increased use of automation as a way to reduce the manufacturing costs of composite components is seen as an important factor to further increase the use of composite materials [12-14].

\subsection{INDUSTRIAL CONTEXT}

The research presented in this thesis has been conducted in collaboration with an industrial partner within the Swedish aerospace industry, and mainly focused on the manufacturing of CFRP products for commercial aircraft. This has provided good insight into the current challenges and needs for the future development of automation technology for the manufacturing of products for aerospace applications made from carbon fiber-reinforced polymers. The solutions presented in the coming chapters are aimed toward solving challenges for the aerospace sector, which is characterized by high quality standards and very extensive requirements for validation of new products and manufacturing processes. The high quality standards and the procedures for process and product validation are set in place to satisfy customer and legislative requirements [4]. The aerospace sector was an early adopter of composite materials, and carbon fiberreinforced polymers in particular, as the materials' possibility to improve performance and reduce weight could justify the high costs. Today, the aerospace and defense sector is the main user of carbon composites, with about $30 \%$ of the total demand based on weight, as can be seen in Figure 4 [11]. Figure 5 shows that the same sector accounts for approximately $61 \%$ of the total revenues from carbon composites [11]. According to Witten et al. [11], the big difference between the amount of carbon composites and the revenue in aerospace can be explained by the manufacturing methods and quality requirements that are used within the sector, and the authors particularly highlight high costs due to approval processes and material control as an important reason. 


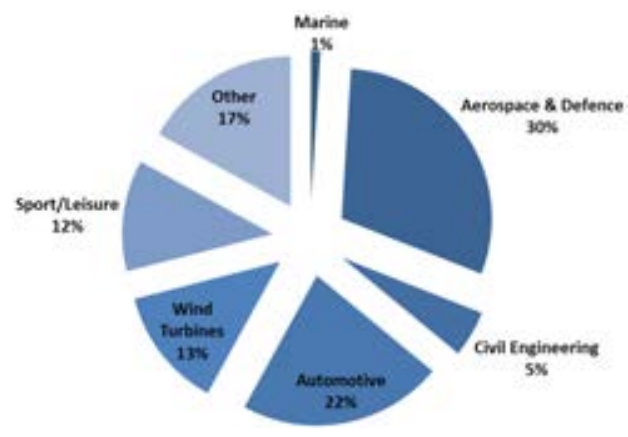

Figure 4: The global demand for carbon composites by application, based on weight [11].

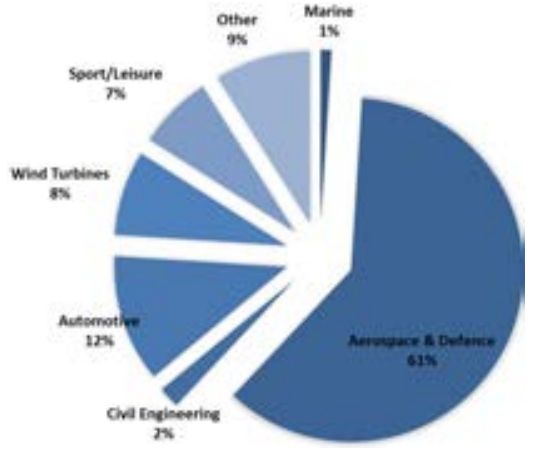

Figure 5: The revenue from carbon composites divided by application [11].

\subsection{AUtOMATION OF COMPOSITE MANUFACTURING}

The largest portion of CFRPs in primary aircraft structures is manufactured using different methods for layup of unidirectional materials [13]. For prepreg materials, manual layup methods, where sheets of prepreg are stacked on a mold to build up the shape of the final part, are highly labor intensive and much labor is spent on material handling and mold layup $[3,15]$. Automated alternatives have been developed to reduce the need for manual labor. There are automated layup techniques that are suitable for large structures with simple geometries, but the current automation alternatives struggle with problems related to affordability, process reliability and overall productivity $[12,13]$. These automated alternatives are limited in terms of part complexity and size $[16,17]$, and there are a number of products that cannot be efficiently manufactured using the current methods for automated layup [18]. Developing automated solutions for the manufacturing of composite products made from prepreg requires a thorough understanding of the raw material, as well as an in-depth understanding of the manufacturing processes. Chatzimichali and Potter [12] point out that robotic application companies lack material expertise and do not consider the unique material properties enough when developing automated solutions, and that this might be one reason for the lack of automation alternatives for manufacturing using prepreg materials. The difficulty to automate manufacturing processes is seen as an important factor that might hamper the continued growth of composite materials [12,14]. The lack of automated manufacturing solutions leads to frequent use of manual operations for the manufacturing of many CFRP products. The industrial partner that has been involved in much of the presented research has expressed a need to develop automated manufacturing solutions that can help bridge the gap between manual and automated manufacturing and lower the thresholds for introducing automation. One reason for this is the competition from low wage-countries for the highly labor-intensive manual layup processes. 


\subsection{RESEARCH AIM}

The increased use of composite materials within the aerospace industry drives the need for more rational manufacturing alternatives. Much work in composite manufacturing is done by hand, and the automation solutions that have been developed are limited in application and associated with high investment costs. For complex products, there are no real alternatives to manual manufacturing, which drive cost in high-wage countries like Sweden. As stated above, the limited variety of automated processes and the difficulty to automate this type of manufacturing are factors that can limit the continued increase use of carbon fiber-reinforced polymers. Therefore, the aim of the research presented in this thesis to explore automated solutions for the manufacturing of advanced prepreg-based aerospace products in low and medium manufacturing volumes. The goal for the automated solutions is to provide cost-effective alternatives to the current, wellestablished manufacturing practices.

\subsection{RESEARCH QUESTIONS}

In order to meet the research aim stated above and help guide the research process, four research questions (RQs) have been formulated.

RQ1: How can automated manufacturing systems for the manufacturing of complex CFRP products made from prepreg be designed so that they meet the needs and requirements of the aerospace industry and are suitable for low and medium production volumes?

RQ2: What key methods and technologies are required to enable the design of the manufacturing system outlined in RQ1?

RQ3: How can key enabling methods and technologies be designed in the manufacturing system outlined in RQ1?

RQ4: What challenges affect the development of the key enabling methods and technologies?

The four research questions should be viewed in the context of low to medium volume manufacturing of advanced composite products based on prepreg materials for the aerospace industry. The first research question is of a more comprehensive nature, and is clearly linked to the subsequent three questions that aim to explore parts of the more general RQ1 in greater detail. To explore the research questions, physical demonstrators have been designed, built and tested according to a demonstrator-centered research approach, as presented in Chapter 2. In this thesis, the developed demonstrators are manufacturing cells for automated manufacturing of composite products, or in one case a concept for such a manufacturing cell. The demonstrators have been used as platforms, or concepts, to identify, develop and test methods and technologies required to enable automated manufacturing. The methods and technologies that are categorized as key enabling methods and technologies require substantial research and development work 
before they can be implemented in an automated manufacturing cell in an industrial context.

\subsection{RESEARCH DELIMITATIONS}

In Section 4.3, the manufacturing process for transforming prepreg material on a roll of raw material to a completed product, ready to be assembled in an aircraft, is described in detail. This manufacturing process requires a great number of process steps, and the automated manufacturing solutions presented in this thesis only consider the first steps in the process. In Chapter 5, the detailed scope of each demonstrator is presented, however none of the demonstrators include the steps taken after the prepreg has been formed to the desired shape and is ready for the step called cure assembly. Cure assembly is not included in the demonstrators, because this process step is highly complex and involves draping and fixing a wide array of auxiliary materials on three-dimensional molds. This process step is generally performed manually, even for products that employ well-established automated manufacturing practices for the preceding process steps.

In the development of the demonstrators, the focus has been on identifying key enabling methods and technologies and on designing and testing such methods and technologies. For the demonstrators that have been realized as physical manufacturing cells, testing of the enabling methods and technologies has been the highest priority. The integration of the control systems for the manufacturing has been given less importance in the development, and therefore the manufacturing cells as a whole are not completely automated. Some manual intervention is required to run the demonstrators. For example, in demonstrators using two robots, the control of the robots is not coordinated. Some support tasks, like material handling between the processes for which enabling methods and technologies have been developed, are also manual to save resources in the development of the demonstrators.

The goal for the automated solutions is to provide cost-effective alternatives to the current, well-established manufacturing practices, and a focus on low-cost solutions has been a common theme for the development of all the demonstrators. The enabling methods and technologies have been developed based on standard off-the-shelf solutions to keep costs down and to provide general solutions that can be used to manufacture a number of different products. However, detailed cost analyses are not included in this thesis.

\subsection{PUBLICATIONS}

The thesis follows the format of an article thesis, and the papers with a connection to the four research questions formulated earlier are appended to the dissertation. The connection between each paper and the respective research questions is illustrated in Table 1. The papers cover more than one research question each, and the papers cover the RQs with different levels of detail, but all the research questions have been addressed in multiple papers. The different colors indicate the strength of the connection between the paper and research question, ranging from a weak connection (white) to an intermediate connection (light blue) to a strong connection (dark blue). 
Table 1: Connection between papers and research questions. (Strong links are indicating by dark blue, intermediate with light blue and weak connections with white.)

\begin{tabular}{|l|l|l|l|l|l|l|l|}
\hline & Paper I & Paper II & Paper III & Paper IV & Paper V & Paper VI & Paper VII \\
\hline RQ1 & & & & & & & \\
\hline RQ2 & & & & & & & \\
\hline RQ3 & & & & & & & \\
\hline RQ4 & & & & & & & \\
\hline
\end{tabular}

\subsubsection{APPENDED PAPERS}

The appended papers are listed below, along with a description of the authors' contributions to each paper.

\section{Paper I}

Björnsson A. \& Johansen K. (2012) "Composite Manufacturing: How Improvement Work Might Lead to Renewed Product Validation" in Proceedings of the Swedish Production Symposium 2012 (SPS12), 6th-8th November 2012, Linköping, Sweden, peer-reviewed.

Andreas Björnsson collected the data through interviews and a literature review and wrote the paper. Kerstin Johansen supported the data collection and analysis as well as the writing of the paper.

\section{Paper II}

Björnsson A. Lindbäck J. E. \& Johansen K. (2013). “Automated Removal of Prepreg Backing Paper - A Sticky Problem" in Proceedings of the SAE 2013 Aero Tech Congress and Exhibition, 24th-26th September 2013, Montreal, Canada, peer-reviewed.

Andreas Björnsson initiated and wrote the paper based on data collected in close collaboration with Jan Erik Lindbäck, who also contributed with hardware development for the tests and provided an industrial perspective on the process development. Kerstin Johansen supported and guided the writing process.

\section{Paper III}

Björnsson A. Jonsson M. \& Johansen K. (2015). "Automation of composite manufacturing using off-the-shelf solutions; three cases from the aerospace industry" in Proceedings of the $20^{\text {th }}$ International Conference on Composite Materials (ICCM20), 19th-24th July 2015, Copenhagen, Denmark.

Andreas Björnsson initiated and wrote the paper, which is a summary of the licentiate thesis entitled "Enabling Automation of Composite Manufacturing through the Use of Off-The-Shelf Solutions" written by Andreas Björnsson. Marie Jonsson assisted in the data selection and analysis and supported the writing process. Kerstin Johansen helped to improve the readability of the paper. 
Paper IV

Björnsson A. Lindbäck J.E. Eklund D. \& Jonsson M. (2016) "Low-cost Automation for Prepreg Handling - Two Cases from the Aerospace Industry” SAE International Journal of Materials and Manufacturing 9(1), peer-reviewed.

Andreas Björnsson initiated and wrote the paper and was responsible for developing the dual-arm solution together with a group of three master's students. Daniel Eklund and Marie Jonsson were mainly responsible for the development of the single-arm demonstrator and all the data from that case. Jan Erik Lindbäck was involved in developing the general process for prepreg pick and place as well as detailed developments in both cases. Marie Jonsson also supported the writing of the paper.

\section{Paper V}

Björnsson A. Jonsson M. Lindbäck J.E. Åkermo M. \& Johansen K. (2016) "Robotforming of prepreg stacks - development of equipment and methods" in Proceedings of the 17th European Conference on Composite Materials (ECCM17), 26th-30th June 2016, Munich, Germany.

Andreas Björnsson initiated and wrote the paper and was responsible for the development and testing of technology and methods that, to a large degree, were developed in a series of student projects. Jan Erik Lindbäck contributed with industrial knowledge, was responsible for establishing the systems requirements and helped to evaluate the tests. Marie Jonsson helped to improve the readability and structure of the paper. Malin Åkermo contributed with background knowledge on robot forming and general forming theory, and Kerstin Johansen supported the writing process.

\section{Paper VI}

Björnsson A. Jonsson M. Eklund D. Lindbäck J. E. \& Björkman M. (?). “Getting to grips with automated prepreg handling" submitted for review to Production Engineering Research and Development.

Andreas Björnsson initiated and wrote the paper and was responsible for the manufacturing cell where two of the end effectors (Cases $3 \& 4$ ) were tested, and was responsible for the development of the dual-arm solution (Case 4) together with a group of three master's students. Marie Jonsson and Daniel Eklund contributed with all the data from Case 2, and Daniel Eklund developed the end effector for Case 3. Jan Erik Lindbäck was responsible for developing the end effector in Case 1, in collaboration with two students in a master's thesis project. Jan Erik Lindbäck was involved in the development of all four cases, and contributed with an industrial perspective to the development of the cases. Mats Björkman helped to improve the readability and structure of the paper.

\section{Paper VII}

Björnsson A. Jonsson M. \& Johansen K. (?) “Automated material handling in composite manufacturing using pick-and-place systems - a review" submitted for review to Robotics and Computer-Integrated Manufacturing. 
Andreas Björnsson initiated the paper, collected and analyzed the data and wrote the paper. Marie Jonsson contributed by refining the data analysis as well as the text. Kerstin Johansen helped to improve the text.

\subsubsection{OTHER PUBLICATIONS}

Lindbäck J. E. Björnsson A. \& Johansen K. (2012) "New Automated Composite Manufacturing Process: Is it possible to find a cost effective manufacturing method with the use of robotic equipment?" in Proceedings of the Swedish Production Symposium 2012 (SPS12), 6th-8th November 2012, Linköping.

Björnsson A. Johansen K. \& Alexandersson D. (2013) "Three-Dimensional Ultrasonic Cutting of RTM Preforms - A Part of a High Volume Production System" in Proceedings of the 19th International Conference on Composite Materials (ICCM19), 28th July - 2nd August 2013, Montreal, Canada.

Björnsson A. Thuswaldner M. \& Johansen K. (2014) "Automated Composite Manufacturing Using Off-The-Shelf Automation Equipment - A Case from the Space Industry" in Proceedings of the 16th European Conference on Composite Materials (ECCM16), 22nd-26th June 2014, Seville, Spain.

Björnsson A. (2014) "Enabling Automation of Composite Manufacturing through the Use of Off-The-Shelf Solutions" Licentiate Thesis, Linköping University. 


\section{RESEARCH METHOD}

This chapter starts with some general views on and definitions of the terms research, research approach, design, method and tool. Next follows a brief description of a few suitable research designs and methods, a discussion on research reliability and validity, and data analysis. The chapter concludes by presenting the utilized research approach and the research context. 


\subsection{A GENERAL OUTLOOK ON RESEARCH}

According to Williamson et al. [19], curiosity and a need to understand and interpret the world around us is a basic human behavior, but this day-to-day activity is differentiated from formal research activities by the thoroughness and precision that characterize research. Furthermore, Williamson et al. [19] point out that research needs to be a highly self-conscious act. As there are many different fields of research, each with their own traditions, there seems to be a multitude of different definitions of the term research. In an effort to present a broad view on research, Williamson et al. [19] cite five different definitions of the term research, and among these five they present Hernon's [20] general definition:

- "Research is an inquiry process that has clearly defined parameters and has as its aim, the:

- Discovery or creation of knowledge, or theory building;

- Testing, confirmation, revision, refutation of knowledge and theory; and/or

- Investigation of a problem for local decision making." (Williamson et al. [19] pp.6)

Another general definition provided by Leedy and Ormrod [21] states:

"Research is a systematic process of collecting, analyzing, and interpreting information (data) in order to increase our understanding of a phenomenon about which we are interested or concerned." (Leedy and Ormrod [21] pp.2)

In addition to the general definition above, Leedy and Ormrod [21] point out two important cornerstones for formal research: first, that it sets out to enhance the understanding of a phenomenon, and second, that the discoveries made are communicated to the scientific community. Leedy and Ormrod [21] also present two main characteristics of research: research originates from a question or a problem, and a problem is usually divided into more manageable subproblems. Research problems, questions or hypotheses guide the research process towards a clearly articulated goal, following a specific plan of procedure. In the attempt to resolve the problem that initiated the research, data collection and interpretation are required, and certain critical assumptions must be made. A clear characteristic is that research by nature is cyclical or more exactly helical, where new knowledge and identified problems from one study serve as a basis for future studies. [21] To summarize, research starts with a question and follows a structured plan or procedure to a defined goal. This indicates that research can be considered a fairly linear and organized process. However, Williamson et al. [19] remark that the research process rarely is as well organized as might be perceived by the characteristics presented above, and that it requires flexibility from the researcher [19].

The research in this thesis fits well with both the definitions of research above. The creation of knowledge and a deeper understanding of observed phenomena have been the fundamental goals for carrying out the research. Many of the characteristics of research put forth above fit well with the research presented in this thesis. The research has been guided by general research questions, which in turn have been broken down 
into smaller subproblems. It has to a large degree followed a helical structure, where knowledge and experiences from one demonstrator have formed the basis for future investigations. Research results have been communicated to the larger scientific community through publications in journals and as contributions to academic conferences.

Williamson et al. [19] divide research into two major categories: basic research, which aims to derive new knowledge, and applied research, which is concerned with solving specific problems in real-life situations. The authors [19] point out that applied research is more pragmatic and emphasizes solutions for actual problems, while basic research is only indirectly involved in the application of created knowledge on specific, practical problems. The division between these two categories is however not always clear. Applied research might generate new theories and contribute to building fundamental knowledge and findings in basic research can have practical applications. [19] The research in this thesis clearly belongs to the applied research category, as it aims to explore how solutions for automated manufacturing of prepreg-based products in low and medium manufacturing volumes can be developed for the aerospace industry.

In the research methodology literature, the definitions and use of terms such as research design, research approach, research methodology, research method, research tool and research technique differ slightly between different publications, and some of the terms have overlapping definitions. A specific definition of the terms and how they are used within this thesis is therefore in order. The term research methodology is herein used to describe the most fundamental outlook, or way of viewing, the field of research and encompasses the major philosophies of research like the positivistic and interpretivistic outlooks. Research approach is used to describe, in a practical sense, how the research was conducted, i.e. how the planned research design was executed. The research design includes a brief description of the research including the guiding questions, the presumed goals and what methods, tools and techniques will be used. The term research method is similar to Williamson's [22] definition of the term. The research method provides a roadmap for undertaking research, as well as describes techniques and tools used to gather and analyze data that is suitable for that particular method. A research method is supported by a theoretical explanation of its value and use, and is usually an established way of doing research within a specific research field. Examples of research methods are the survey, case study, experimental design, system development design and action research. Research tools and techniques, such as interviews, questionnaires or observations, are for example used to describe how data can be collected. The connection between all these terms can be clarified by viewing tools and methods as parts of the research method, which in turn have an important part in describing the research design, which in turn dictate how the research should be conducted, i.e. the research approach. A fundamental outlook on research, the research methodology, governs all of the others. 


\subsection{ESTABLISHED RESEARCH DESIGNS AND METHODS}

The research described in this thesis belongs, as previously concluded, to the wide field of applied research. It is conducted in an industrial environment, and to further narrow down the field of research, it can be described as manufacturing engineering research. The field is multidisciplinary and employs knowledge from a variety of engineering disciplines, for example automation, robotics and material science. Below follows a selection of established research designs and methods that refer to the same type of environments, problems and challenges that have been encountered when conducting the research presented in this thesis. The presented research designs and methods have influenced the utilized research approach, as is described later in the chapter.

\subsubsection{INDUSTRY AS A LABORATORY}

As the research described in this thesis is conducted in close collaboration with industrial partners, it is interesting to look at the advantages and challenges in close collaboration with industry. The industry as a laboratory research design stems from the area of software engineering research. It is, to a large extent, based on an observation presented by Potts [23], which states that a traditional research-then-transfer approach leads to laboratory research that often fails to address significant problems. In order to improve the ability to transfer new research results from the research domain to industrial applications, the author [23] proposes an approach in which the research is conducted in close collaboration with industry, and where the researcher identifies research problems in close collaboration with industrial partners. The researcher continuously evaluates solutions in an iterative manner, as illustrated in Figure 6, always in close collaboration with industrial projects. Interim results can be applied to practical problems, and feedback can help improve subsequent investigations [23].

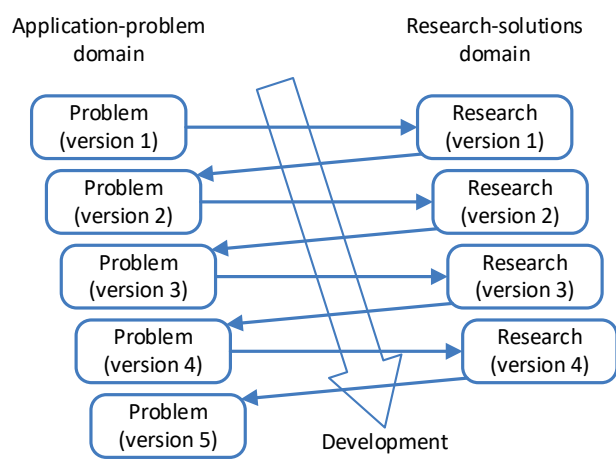

Figure 6: The industry as a laboratory research design. Illustration based on Potts [23].

Furthermore, Potts [23] notes that the collaboration with industry, in the form of continual and incremental case studies, can help to refine research ideas and help to prevent the research and the application domain from diverging. The industry as a lab research design puts emphasis on case studies as a way of conducting research, and not only as a way to affirm the value of existing research results. Results generated when working as described above can sometimes be generalized from a system to a domain, 
but it is unrealistic to expect that the results should be generalized to all projects or systems. However, Potts [23] highlights that gaining a deeper understanding of a good practical solution can offer valuable insights to more general principles. [23]

\subsubsection{ACTION RESEARCH}

Action research is a method for applied research that focuses on finding a solution to a local problem in a local context [21]. It is often intended to bring about a change of practice, while at the same time generating new knowledge [24]. Action research is used in a wide array of disciplines, for example organizational behavior, environmental planning and community development, but also for research in a psychology practitioner environment [24,25]. The most fundamental characteristic of action research is its cyclical nature. Four similar steps, as illustrated in Figure 7, occur in a similar sequence. It is an emergent process where knowledge from one cycle is used to shape the next, and much emphasis is put on the reflection required before starting a new cycle [26].

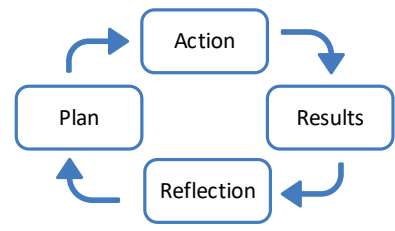

Figure 7: A typical research cycle in action research as presented by Oosthuizen [24].

When applying action research, the initial research question as well as the research design are often fuzzy, and the questions and the design are gradually refined one research cycle at the time [25]. One of the key principles in action research is to let the data from one step determine the next step [25]. There is no reason to use the same approach or the same tools and techniques as used in previous cycles [24]. Due to its cyclical nature, action research can be used to both propose and test theories, and stable knowledge can be built when the same theories appear to hold true from cycle to cycle and from one group, situation or time to another [24]. Dick [26] argues that good action research should contain multiple research cycles with extensive planning before an action and thorough analysis afterwards. The researcher should continuously try to disapprove the interpretations arising from earlier cycles, and the cyclical nature should be used to critique and refine the tools and techniques employed [27]. Divergent data should be thoroughly analyzed, and the literature should be consulted as to try to disconfirm emerging interpretations [27]. Action research is usually concerned with single situations, e.g. a single group within a company, and therefore the method is seldom suitable to test the general applicability of theories [24].

\subsubsection{SYSTEMS DEVELOPMENT RESEARCH}

Systems development research is a type of engineering research that falls under the applied science category. The method stems from information systems research, where it is used to study the effective design, delivery use and impact of information technology in organizations [28]. Systems development research is a way to perform research through exploration and integration of available technologies to produce a 
system or a system prototype, and the research focuses more on theory testing than theory building [28]. Nunamaker et al. [29] describe system development research as consisting of four research strategies, as illustrated in Figure 8 and explained in the following section.

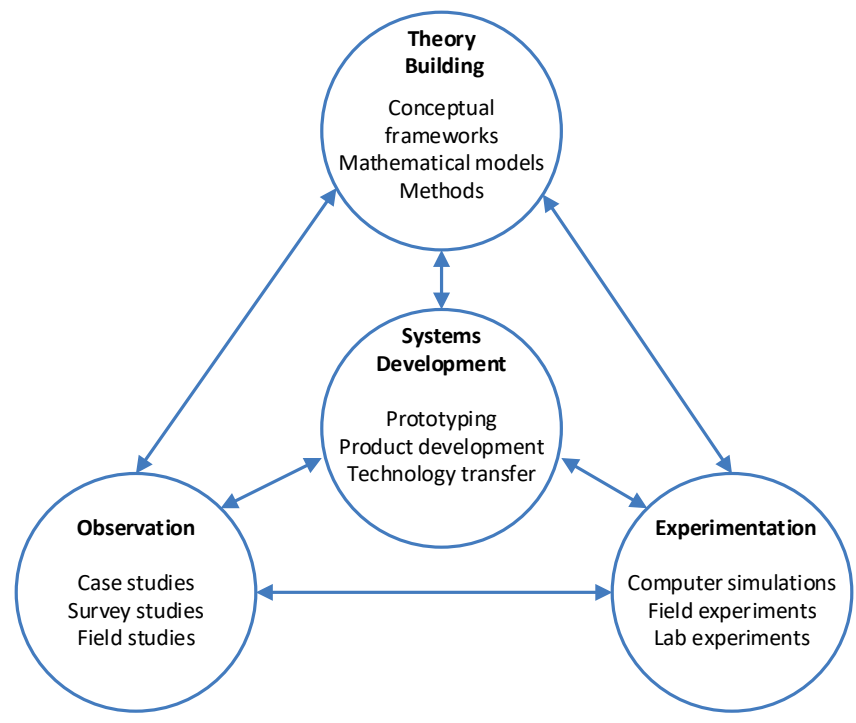

Figure 8: The four research strategies in systems development research, as presented by Nunamaker et al. [29].

In the description provided by Nunamaker et al. [29], the theory-building strategy includes the development of new ideas and concepts and the construction of conceptual frameworks, methods and models. Theories usually emphasize generality, and therefore the outcome from the theory building is of limited practical value to the target domain. Experimentation aims to validate underlying theories, or might aim to explore issues of acceptance and technology transfer. This research strategy includes different types of lab and field experiments as well as simulations. The experimental designs are guided by theories from the theory building and are facilitated by the systems development. Observation strategies (for example case studies, field studies and surveys) help generate knowledge to build a hypothesis that will be tested by experimentation. Observations can also be used to develop generalizations that can help set up future investigations. The fourth research strategy, systems development, is in turn comprised of five separate stages that are illustrated in Figure 9 [29].

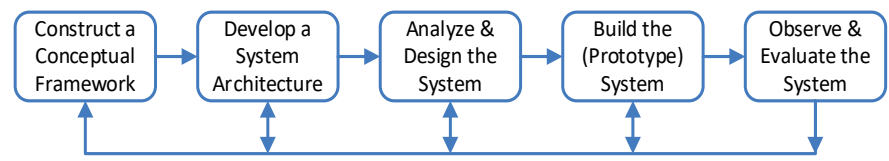

Figure 9: The five stages of systems development, as presented by Nunamaker et al. [29]. 
According to Nunamaker et al. [29], in the first stage the researcher formulates a conceptual framework that justifies the significance of the pursued research question. In the second stage, the system architecture is developed. It acts as a roadmap for the build process and puts the system components into perspective, specifies the required functions and defines the relationship and interface between different components in the system. The analyze and design stage entails the most important part in systems development research, the design of the system. Based on an understanding of the studied domain and through the application of technical and scientific knowledge, various alternatives are created and evaluated. This stage generates design specifications that support the fourth research stage, where prototypes and the final system are built. The implementation of a working system can provide researchers with insights to the selected concept and frameworks and the considered design alternatives, as well as the selected alternative. In the fifth and final stage, the researcher performs a number of experiments and observations to evaluate the system built. The system's performance and usability can be evaluated, as well as its impact on individuals and organizations. The evaluations should be based on criteria developed in the preceding stages. Experiences gained from developing the systems can lead to ideas for further developments and theories to explain newly-observed phenomena. [29] Burstein [28] concludes that the systems development research method differs from conventional systems development because it has a major focus on the concept that the system illustrates, rather than the quality of the implementation. Furthermore, the evaluation step is very different using the research method compared to testing a commercial system, as the evaluation is based on research questions set up in the concept building stage, and the functionality of the system is very much a secondary issue. [28] Nunamaker et al. [29] regard the ultimate success of the theories and systems to be transfer of technology, i.e. that the developed system is implemented by an organization.

\subsubsection{DEMONSTRATOR-CENTERED RESEARCH}

Demonstrator-centered research was developed for research within the field of manufacturing engineering with a high degree of collaboration with industrial partners, as is often the case for research within this field. Jonsson [30] describes the research to be based on an industrial challenge that is constantly changing, and it is important to note that there can be a number of working solutions to meet a challenge. A research objective is formulated based on the industrial challenge and the knowledge base, the latter consisting of both academic and industrial knowledge. The research objective guides the research process, and together with the industrial challenge and the knowledge base form a base layer that supports the four research stages outlined in Figure 10. [30] 


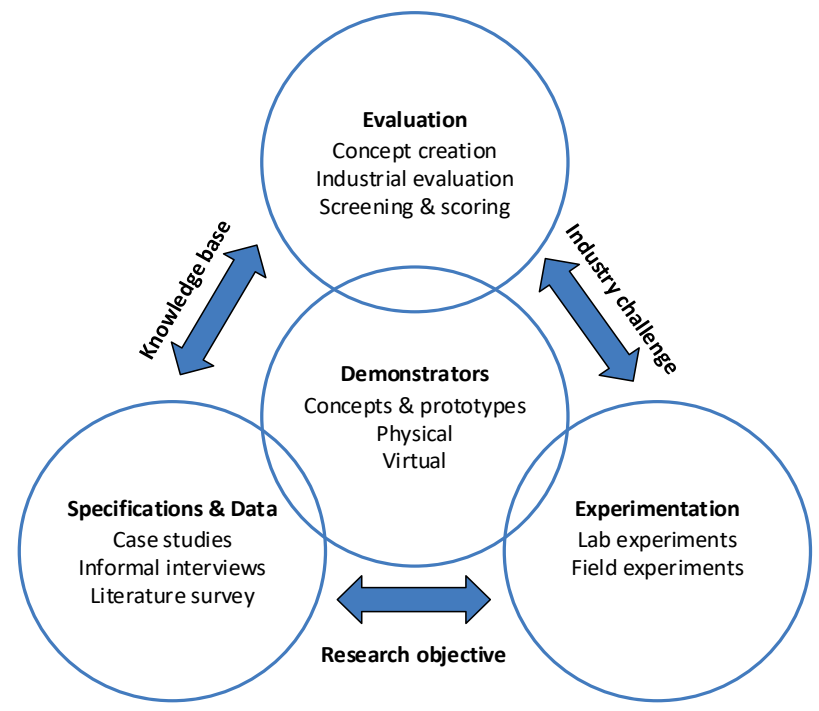

Figure 10: The four research stages and the base layer in demonstrator-centered research, as presented by Jonsson [30].

The most central of the four stages is the demonstrator stage. Jonsson [30] highlights that a demonstrator serves two purposes. First, it acts as a platform for experimentation and evaluation to build new theory and gain insights on issues related to the research objective. Second, the demonstrator acts as an important communication tool between the researcher and the industry. Furthermore, Jonsson [30] uses a broad definition of the term demonstrator that can include physical equipment ranging from components to fullscale manufacturing cells in an industrial environment. It also includes non-physical objects such as virtual models, simulations and executable software programs. [30]

According to Jonsson [30], the practical approach when working with a demonstrator is generally iterative and depending on the problem at hand, many different tools and techniques can be used in the different research stages. A common workflow is to develop specifications for the demonstrator based on the industrial challenge. The specifications are communicated to industrial partners and refined based on their input. Based on the specifications and the information learned while formulating them, technical concepts are developed virtually and evaluated. Selected concepts are realized as prototypes and presented to industrial partners. The development process might also include lab experiments to evaluate technical solutions. [30]

\subsubsection{CASE STUDiES}

Both systems development research and demonstrator-centered research show examples of using case studies as a means to understand the problem at hand and its context. In defining what a case study is Darke and Shanks [31] cite Yin [32], who highlights that a case study is an empirical investigation of a contemporary phenomenon in its original setting. To complement this description of the method, Darke and Shanks [31] point out that in a case study, multiple sources of evidence are used, and that a wide range of tools 
and techniques are used to collect data. Leedy and Ormrod [21] describe a case study as an in-depth study of an individual event over a period of time, and emphasize that it is a suitable method for learning more where little is known. Gall et al. [33] present three purposes of a case study: to produce a detailed description of a phenomenon, to develop a possible explanation of it, or to evaluate the phenomenon. According to Leedy and Ormrod [21], extensive amounts of data, in many forms, are collected by the researcher, who spends time on-site interacting with people during the data collection. During the data collection it is important to record contextual details. [21] The data collection in case studies can be emergent, i.e. knowledge from early data collection helps to determine subsequent data collection [33]. Case studies can either be a single-case design, where one case is studied in-depth, or a multiple-case design, where several cases are examined to allow for cross-case analysis and comparison [31]. The data from a case study is analyzed to identify patterns and themes, and to be able to formulate constructs that can explain observed phenomena [33]. A case study is unique in that it is not until the researcher starts writing the report that the case is completely specified, as researchers must sort through all the data collected and only report the cases, or aspects of the case, that have a bearing on the research question at hand [33]. A case study report should contain a rationale for the case study and detailed descriptions of the context and the collected data, as well as a discussion of patterns found and how the case and the results from the case study can be connected to a larger context [21].

\subsection{ANALYZING THE DATA}

In general, there are two major types of research data: qualitative and quantitative. Williamson [22] describes quantitative data as data in the form of numbers, and qualitative data as data in the form of text. The data from the research methods and research designs described above can be both qualitative and quantitative, and in many cases, a combination of both types of data is generated. For analyzing quantitative data, statistical tools and methods are commonly employed [21]. For qualitative data, there are no strict rules on how to interpret and analyze collected data [34]. Data that is qualitatively analyzed is compared across other data sources, across other methods and across time [21]. Gall et al. [33] present three major approaches to analyzing qualitative data: interpretational, structural and reflective analysis. Maxwell [35] proposes that the first thing a researcher should do before starting a formal analysis is to go through the collected data to get a sense of how to analyze it, and to form tentative ideas about categories and relationships within the data. After that, analysis can be made according to one of three strategies: reflective analysis (memos), categorizing strategies (for example coding and thematic analysis) or connecting strategies (for example narrative analysis). [35]

\subsection{VALIDITY AND RELIABILITY}

In research, validity and reliability are commonly used terms that are of great importance when determining suitable research approaches, tools and techniques for data collection and approaches to data analysis in order to draw correct conclusions. Leedy and Ormrod [21] define the two terms by referring to a research instrument, stating that the validity of an instrument is the extent to which it measures what it is intended to measure, while 
reliability describes the consistency with which it yields a certain result with unchanged conditions. These definitions also apply to more qualitative research approaches, as Maxwell [35] notes that in these approaches, the researcher acts as the research instrument, whose eyes and ears are gathering the information. Tanner [36] divides validity into three groups. Construct validity refers to the extent that a measurement actually measures the construct that it was designed to measure. Internal validity describes how an observed result is attributable to a deliberate action, and not caused by an unknown factor. External validity refers to the generalizability of findings in a wider context.

Maxwell [35] calls attention to the fact that validity should be viewed as a relative property that must be assessed in relationship to the research context. Maxwell's [35] view on validity is that it refers to the correctness or credibility of a description, conclusion, explanation, interpretation or any other sort of account. Furthermore, Maxwell [35] introduces the term validity threat, which should be interpreted as a way that a researcher might be wrong. In experimental research, experiment settings are controlled to deal with both anticipated and unanticipated threats to validity, for example using control groups, random sampling and control and test of statistical significance. In qualitative research, this control is rarely possible and validity threats usually must be managed along the way. From Maxell's [35] standpoint, validity threats can be referred to as one of two major categories: researcher bias or reactivity. Researcher bias implies subjectivity of the researcher, i.e. a selection of data and interpretations that fits with the researcher's existing theory, goals or preconceptions. Reactivity describes the influence that the researcher might have on the setting that is studied. Bias and reactivity are hard to eliminate, and therefore it is important to understand possible biases and how a researcher might influence a study, and clearly explain how it will be managed. [35] A fundamental approach is to always look for evidence that can challenge emerging conclusions and that might hold potential validity threats. There are a number of suggested strategies to achieve research results with good validity. A list of such strategies, which is presented below, is based on information from Leedy and Ormrod [21], Gall et al. [33], Merriam [37] and Maxwell [35].

- Intensive, long-term involvement. Collect data over an extended period of time.

- Rich data. Collect data that is detailed and varied enough to provide a good picture of a phenomenon.

- Member checking, respondent validation. Present recorded data and emerging interpretations to the participants in a study and ask for their feedback.

- Peer examination. Ask for collegial examination of data and emerging interpretations.

- Triangulation. Comparing data that has been collected using multiple data sources, methods and tools.

- Negative cases. Search actively for discrepant data that does not support the emerging interpretation.

- Numbers, quasi-statistics. Sort out quantitative data in qualitative studies and use statistics to be able to for example, show if an event is common or rare. 
- Comparison. Compare data from different studies, for example multiple-case research design.

- Chain of evidence, audit trail. Build clear and meaningful links through the whole process from research question, data collection and interpretation to the conclusions.

- Truthfulness in reporting. Make sure that the report is a good reflection of the study.

- Contextual completeness, thick description. Provide extensive accounts of the context in which the study takes place.

- Researcher reflection. Continuous reflection and, if necessary, reorientation during the study on behalf of the researcher.

- Statement of researcher's experiences, assumptions and biases.

\subsection{UTILIZED RESEARCH APPROACH}

The research approach used in this thesis is, to a great extent, based on the demonstratorcentered research design developed by Jonsson [30]. The demonstrator-centered research design has been selected as it provides a structured way of exploring a research objective in an industrial context. The research design fits very well with the research questions presented in the introductory chapter. It provides a natural workflow for both identifying enabling methods and technologies as well as developing methods and technologies and testing them in the form of a manufacturing cell built for experimentation and evaluation purposes. Challenges that affect the development of methods and technologies have been identified by reviewing published information (both academic and industrial publications). They have also been identified while working with the demonstrators and when establishing the background and the prerequisites for the demonstrators. The applied research design has been used for testing hypotheses or theories, and as a part of this, explorative technology development has been an important element. The development of the demonstrators has been a collaborative effort together with an industrial partner and several research organizations.

According to Jonsson [30], a demonstrator is an artifact that is used as a tool by a researcher to explore a research objective. A demonstrator can be either physical, such as in the case of technical equipment, or virtual, as in the case of simulation models. [30] In this thesis, the term demonstrator is used for a narrower context. All the demonstrators that will be presented in the coming chapters are either concepts for manufacturing cells or actual manufacturing cells. Therefore, the term demonstrator is used to denominate a manufacturing cell that is developed to be a tool for experimentation in order to explore research objectives or research questions. An important property, shared by all the demonstrators in this thesis, is that they are decoupled from their original context to facilitate greater control over experiments.

Working with the demonstrator-centered research design, the scope of the demonstrator must be clearly defined and the system borders for the demonstrator should be set at an early stage. A simple way of defining the system borders of a demonstrator is to define the input to and output from the demonstrator, as illustrated in Figure 11. At this stage, 
the demonstrator can be considered as a black box, and it is not necessary to take into account all the activities required to transform the input into the output. In the demonstrators presented in the following chapters the output is often referred to as a demonstrator product, since it is the product that the manufacturing cell, i.e. the demonstrator, is designed to manufacture.

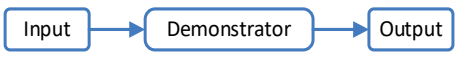

Figure 11: Specifying the system borders for the demonstrator by defining the input and output from the demonstrator.

After defining the system borders, the scope of the demonstrator can be defined as well as all the activities and hardware that are required to transform the input into the output. In the terminology used in this thesis, the scope of a demonstrator can be divided into enabling methods and enabling technologies and their respective subgroups, as illustrated in Figure 12. Enabling methods can be broken down into two subgroups, procedures and processes, where a process is considered to be a set of procedures. An enabling method is a well-defined way of performing a number of procedures and processes. For example, an enabling method can describe how to act when removing a piece of protective backing paper from a prepreg ply. In order to realize this method in an automated solution, hardware is required. An enabling technology includes hardware from the lowest component or part level, through assemblies of components, to the more complex system level.

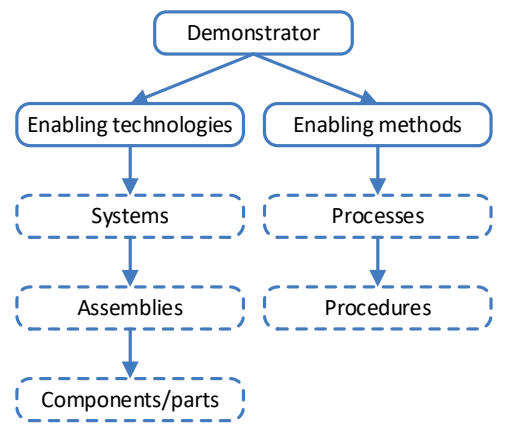

Figure 12: A demonstrator can be broken down into enabling technologies and enabling methods and their respective subgroups.

Some of the enabling technologies and enabling methods required to transform the demonstrator input into the demonstrator product can be off-the-shelf solutions that require little development or research work to be used in the demonstrator. Other enabling technologies or methods are novel, and require an extensive amount of research and development to be able to realize the demonstrator. These are categorized as key enabling methods and technologies. 
The procedures used when working with a demonstrator-centered research approach varies slightly from one demonstrator to another, but a generic workflow can be identified. The workflow is illustrated in Figure 13, and the six separate stages in the figure are explained in more detail below. It should be noted that the process to develop and test a demonstrator is highly iterative, and that it is common to return to a previous phase to alter decisions based on experiences gained in later phases. For example, experiences from the development of enabling technologies or methods might influence the entire demonstrator, and therefore requiring the researcher to return to the concept phase.

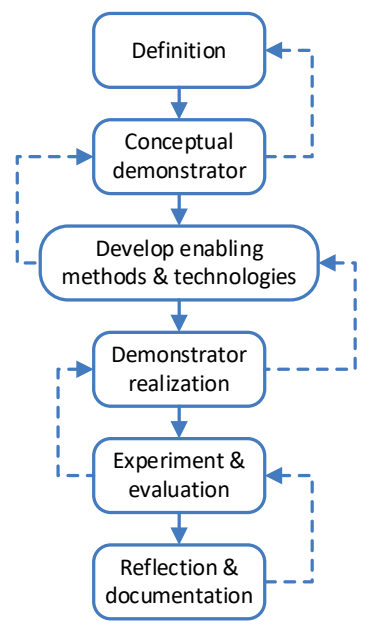

Figure 13: An illustration of a typical workflow when developing a demonstrator using a demonstrator-centered research approach.

\subsubsection{DEFINITION}

In the first phase, the definition phase, the industrial challenge is identified and the industrial context as well as the existing knowledge base are explored. Based on the identified industrial challenge and the research aim and research questions presented in Chapter 1, a local research objective for the demonstrator is formulated. The system borders and the scope of the demonstrator are clearly defined, and research and industrial partners are engaged. In the definition phase it is also important to develop preliminary specifications for the demonstrator. Based on these specifications, preliminary evaluation criteria are developed. The demonstrator specifications are requirements on the performance of the demonstrator, and can be for example manufacturing speed, ability to handle variations, and quality requirements of the manufactured product. The specifications are the basis for developing evaluation criteria. The evaluation criteria are more detailed descriptions of how the concepts, prototypes and complete demonstrator should be evaluated in order to make sure that they comply with the specifications. Specifications and evaluation criteria are agreed to by the demonstrator stakeholders, i.e. the research and industry partners. In the definition phase, the specifications that are formulated are preliminary and will be refined in further stages. The evaluation criteria set during the preliminary phase are used to evaluate the concepts in the following phase. 
A very important part of the definition phase, in addition to identifying the industrial challenge and developing a clear understanding of the industrial context, is to map and evaluate the current state of the art within the research field connected to the demonstrator.

\subsubsection{CONCEPTUAL DEMONSTRATOR}

In the second phase, a number of concepts describing how the demonstrator could be designed are generated and evaluated based on the preliminary specifications and evaluation criteria from the first phase. In some cases, concept screening and concept scoring tools, as presented by Ulrich and Eppinger [38], have been used to evaluate concepts. In other cases, the different concepts have been evaluated at review meetings with all the partners involved in realization of the demonstrator. The most important part of this phase is to break down the selected demonstrator concept into enabling technologies and enabling methods, and to identify key enabling methods and technologies that require further research and development efforts to be used in the demonstrator. The research and development work is divided among the partners involved in the demonstrator, and one partner is usually assigned the responsibility of realizing the demonstrator. In order to be able to divide work between the partners, it is highly important to agree on interfaces between the enabling technologies and methods. The preliminary specifications and evaluation criteria from the earlier phases are refined and agreed to by all the partners. The specifications and evaluation criteria, in combination with the chosen interfaces, set the specifications for the enabling technologies and methods.

In the concept phase, it is also decided what enabling technologies and enabling methods should be included in the demonstrator realization phase. Due to time and budget limitations it might not be possible to include all the technologies and methods required to transform the input into the demonstrator product, and some steps might be excluded from an automated solution and instead realized by manual intervention. Generally, the excluded steps require methods and technologies that are off-the-shelf solutions. They are excluded to enable more resources to be dedicated to the development of key enabling methods and technologies. In some cases, referred to as conceptual demonstrators, no physical demonstrator is realized. Instead, a selection of the enabling technologies and methods required to manufacture the demonstrator product are realized and tested separately, but never brought together as a physical demonstrator. A conceptual demonstrator serves as a description of how these technologies and methods relate to each other and how they could be integrated into a manufacturing cell. The key contribution of a conceptual demonstrator is that it enables the identification of key enabling methods and technologies. Some of the enabling methods and technologies in a conceptual demonstrator are developed and tested and can contribute with detailed knowledge on methods and technologies. A conceptual demonstrator can be a suitable alternative in research projects with a low budget or tight schedule.

\subsubsection{DeVELOP ENABLING METHODS AND TECHNOLOGIES}

In this phase, a lot of work is taking place in parallel. Enabling methods and technologies are developed and refined by different partners involved in the development of the 
demonstrator. In many cases, an enabling method and an enabling technology are developed conjointly, as they often are highly dependent on each other. The development of enabling methods is often based on in-depth studies of how similar operations are performed manually. The studies of manual operations are often complemented by broad reviews of automated solutions to find examples of similar methods that have been automated. Methods are tested and evaluated in different forms of experiments, often in combination with an enabling technology. Technology reviews are a frequently used approach to investigate components, assemblies or systems that might be used as enabling technologies in the demonstrator. A technology review often contains a thorough review of published materials from academia, e.g. books and scholarly journals as well as commercial information in the form of product manuals and handbooks published by equipment manufacturers. Patents can also serve as a source of information. The literary review is complemented by interviews with experts and users. Hands-on testing of components, assemblies or systems is also an important part of a technology review. Based on the experiences gained during technology reviews, concepts for enabling technologies can be developed and evaluated in order to select a promising solution that can be prototyped and tested in a laboratory environment. This is a highly iterative process, with many loops back and forth before an enabling method or technique is ready to be implemented in the demonstrator. For conceptual demonstrators, where the developed technologies and methods are not integrated into a physical manufacturing cell, the two following phases are bypassed and the development of enabling technologies and methods is followed by the reflection and documentation phase.

\subsubsection{DEMONSTRATOR REALIZATION}

In this phase, the enabling methods and technologies developed in the previous phase are brought together and integrated into one demonstrator. Simple tests are run to test the integration between different components and systems. Once the integration is complete, the experimentation and evaluation phase starts. Usually, one of the research partners is responsible for the overall integration, but each partner contributes in installing and testing their enabling technologies and methods. The integration of all the developed methods and technologies into one manufacturing cell exposes the interconnection between them, and helps to identify connections between them that are difficult to predict in earlier phases. Conflicting requirements between different methods and technologies in the demonstrator can be discovered, forcing a return to the previous phase. This opportunity to identify indistinct connections between different methods and technologies is unfortunately lost in the case of conceptual demonstrators.

\subsubsection{EXPERIMENTATION AND EVALUATION}

In this phase, all the functionalities of the demonstrator are tested as a whole. The demonstrator is tested based on the evaluation criteria to determine if it meets the specifications. The test and experiment phase generally also includes continuous improvement of the demonstrator, where the outcome of a set of tests determines improvement actions. The process is highly iterative, and in some cases it is necessary to return to earlier phases. The phase also includes a demonstration, where the 
demonstrator is run to show its function to all the research partners involved in the development of the demonstrator and to representatives from industry. The demonstration aids dissemination of the results from the demonstrator, especially to industrial partners.

\subsubsection{REFLECTION AND DOCUMENTATION}

In the last phase, the results from the experimentation and evaluation phase, along with the experiences from developing the demonstrator, are documented and communicated, for example in the form of contributions to academic conferences and as papers submitted to scholarly journals. The results from one demonstrator are compared to earlier demonstrators and published results from other research groups to achieve triangulation. Reflections on the demonstrator and the process used to develop it generally result in a number of suggestions for future research. These often include ideas for further development of the demonstrator to improve its performance, to include omitted methods or technologies, to make the demonstrator more general, or to be able to apply it in another context.

\subsection{DATA FROM THE DEMONSTRATORS}

The research presented in this thesis has mostly generated qualitative data that has been evaluated using reflective analysis. Qualitative data has, for example, been collected through semi-structured interviews, literature reviews, on-site observations, and review of technical documentation and manufacturing documentation. Much qualitative data has also been generated during the development, experiments and evaluation of enabling methods and technologies as well as the complete demonstrators. Series of quantitative data have also been generated during experiments. For example, tests to explore the precision of automated layup of prepreg plies generated numerical results. However, the data series of quantitative data have been small, and no statistical evaluation of the data has been conducted. To improve the validity of the research results presented in this thesis, a number of the strategies presented in Section 2.4 have been used. Data has been collected from multiple sources and using different methods and tools, where possible. The data from the different sources has been compared and triangulated to look for similarities and divergences. Data collected through interviews have in many cases been validated by member checking. For the development and evaluation of the conceptual demonstrators as well as the evaluation and tests using the demonstrators, peer examination has been a frequently applied strategy to improve the validity of the research. Data that might challenge emerging conclusions or that diverge have been particularly examined. The demonstrators have been built in labs isolated from their intended industrial setting to allow greater control over experiments, and thereby strengthen their internal validity.

\subsection{RESEARCH CONTEXT}

The research presented in this thesis has been conducted in an industrial setting and in collaboration with a number of research partners. The development of the demonstrators has been a collective undertaking. The responsibility for development of enabling methods and technologies and the realization of the complete demonstrator has been 
divided differently among the research partners in the different demonstrators. Chapter 5 provides descriptions of the developed demonstrators, along with an account of the researcher partners' contributions to each demonstrator. The development of some methods and technologies has been brought forward through student projects. These projects have been specified and actively supervised by the researchers involved in the development of the demonstrators. Student projects have also, in some cases, been used to generate concepts in the early stages of developing a demonstrator. The research is based on an industrial challenge, and the development of a demonstrator includes elements of traditional product development and employs tools and methods used in more generic engineering disciplines. However, the main aim when developing a demonstrator is to generate and spread knowledge based on research questions. A demonstrator is developed with a particular demonstrator product in mind, but during the development the generalizability of developed methods and technologies is given a high priority. It is important to stress that the demonstrators are used as tools to explore a wide research objective, and not just to manufacture the demonstrator product. 


\section{MANUFACTURING SYSTEMS, AUTOMATION AND FLEXIBILITY}

This chapter provides a general theoretical foundation for the two research domains, automated manufacturing systems and flexibility. The chapter covers basic definitions of manufacturing systems, automation and flexibility. Different ways of classifying automated solutions are presented, along with advantages associated with the implementation of automated solutions. Brief outlooks on automation costs and suitable approaches for developing automated solutions are also provided. Finally, different types of flexibilities and their connection to each other are presented, along with a general framework that explain different aspects of flexibility. 


\subsection{AUTOMATION OF MANUFACTURING SYSTEMS}

In the introductory chapter, it was clearly disclosed that the research presented in this thesis aims to explore automated manufacturing systems for the manufacturing of CFRP products for aerospace applications. However, both manufacturing systems and automation are wide and ambiguous terms, and narrower definitions of the terms are therefore in order. The term manufacturing systems is commonly used, but it seems that different authors have different interpretations of the boundaries of such systems. To clarify, this thesis uses the definition provided by Groover [39], which states that a manufacturing system is:

"a collection of integrated equipment designed for some special mission, such as machining a defined part family or assembling a certain product." (Groover [39] pp. 102)

Groover [39] points out that manufacturing systems, apart from the physical hardware, also include people, and that a manufacturing system is a part of a larger production system which includes all the people, equipment and procedures that comprise a company's entire manufacturing operation.

Also, for automation there are a number of definitions provided by different authors, where some put more focus on the reduction of human labor, such as Wilson [40], who defines automation as "automatically controlled operation of an apparatus, process, or system by mechanical or electronic devices that take the place of human labour". Lamb [41] further highlights the importance for an automation system to remove the human from the control task in this definition: "Automation is the use of logical programming commands and mechanized equipment to replace the decision making and manual command-response activities of human beings. " Kandray [42] considers definitions that focus on eliminating the human from the manufacturing system to be too narrow, as automation does not always replace the worker but rather reduces human participation and changes the nature of the human work. Instead, Kandray [42] proposes a wider definition: "Automation is the application of mechanical, electrical, and/or computer technology to reduce the level of human participation in task performance." As reduction rather than elimination of human labor fits well with the demonstrators presented in the later chapters of this thesis, this wider definition proposed by Kandray [42] is used to describe automation in this thesis. Nof [43] points out that automation is comprised of four major elements: power source, process (the operations or functions), autonomy (the organization and control of the hardware) and platform (includes hardware such as machines, tools, devices and systems). In this thesis, attention is primarily given to the process and platform elements of the automated systems.

Robots are often associated with automation in a manufacturing context, and the term robotization sometimes appears in the literature. There are a multitude robot types, but in this thesis the term robot is used to describe industrial robots as they are described by the ISO 8373:2012 standard [44]. It states that a robot is an automatically controlled, reprogrammable, and multipurpose manipulator. It is programmable in three or more axes, which can be either fixed in place or mobile for use, and is developed for industrial 
automation applications. [44] In accordance with the Springer Handbook of Automation [43], the use of robots is considered an important subset of automation, not a specific research domain. Hence, the term robotization is not used. According to Wilson [40], robots provide two major types of benefits when used in automation solutions: first, they provide flexibility as changing their movement patterns is made by simple reprogramming; and second, they are standard machines with well-known capabilities, and robot vendors generally offer a wide range of different robots to choose from. However, it should be noted that the robot is only one part of an automated solution, and that it must be integrated with other types of equipment to provide the required tasks. The integration of the equipment is very important to the success of an automation project.

\subsubsection{ClassificATION OF AUTOMATION}

Automation can be considered from many different aspects. For example, it can be classified based on which hierarchal level of a company's manufacturing operations it is implemented. Table 2 presents five different levels where automation can be considered, as presented by Groover [39].

Table 2: The five possible levels of automation in a production plant, as presented by Groover [39].

\begin{tabular}{|l|l|l|}
\hline 5 & Enterprise level & Corporate information system \\
\hline 4 & Plant level & Production system \\
\hline 3 & Cell or system level & Manufacturing system - groups of machines \\
\hline 2 & Machine level & Individual machines \\
\hline 1 & Device level & Sensors, actuators, other hardware elements \\
\hline
\end{tabular}

Another aspect of automation is the ability of an automated system to react to changes. A very basic division can be made between hard automation, where changes to the system often require mechanical alterations, and soft automation, where an automation system can be changed by means of reprogramming [45]. A slightly more diversified division of automation in a manufacturing system is presented by Kandray [42], who argues that three standard types can be identified:

- Fixed automation (Special purpose automation where the process sequence is fixed by the organization of the processing stations and which is inflexible in allowing new products.)

- Programmable automation (The performed processes and their respective order can be changed. Multipurpose equipment is used and the system requires reprogramming and changing of fixtures to allow different products.)

- Flexible automation (A further development of programmable automation with virtually no time lost for changeover of parts.)

Another way of categorizing or classifying automation is by looking at the level of control and self-government that an automation system has. Not all systems are fully automated, which means that there are systems that require more or less human intervention. These systems are sometimes broadly defined as semiautomatic systems 
or referred to as partial automation [43]. In the book Automation and management from 1958, Bright [46] presents a table with seventeen levels of mechanization (reproduced as Table 3). This table has been used by later authors [43] to describe levels of automation on the basis that mechanization is defined as the application of machines to perform work, and when mechanization is designed with cognitive and decision-making functions such as process control and automatic control, the modern term automation becomes more appropriate. Bright [46] reflects on the use of the term automation instead of mechanization, but uses the well-established word from 1958, as it is more suitable when comparing different manufacturing plants with each other, as is the case in Automation of management. Bright [46] points out that the classifications in the table should not be interpreted too strictly, and notes that examples can be found that do not match the classification. The seventeen levels of mechanization aim to bring order and understanding, and to provide a basis to be able to compare different systems. 
Table 3: The levels of mechanization (or automation) as presented by Bright [46].

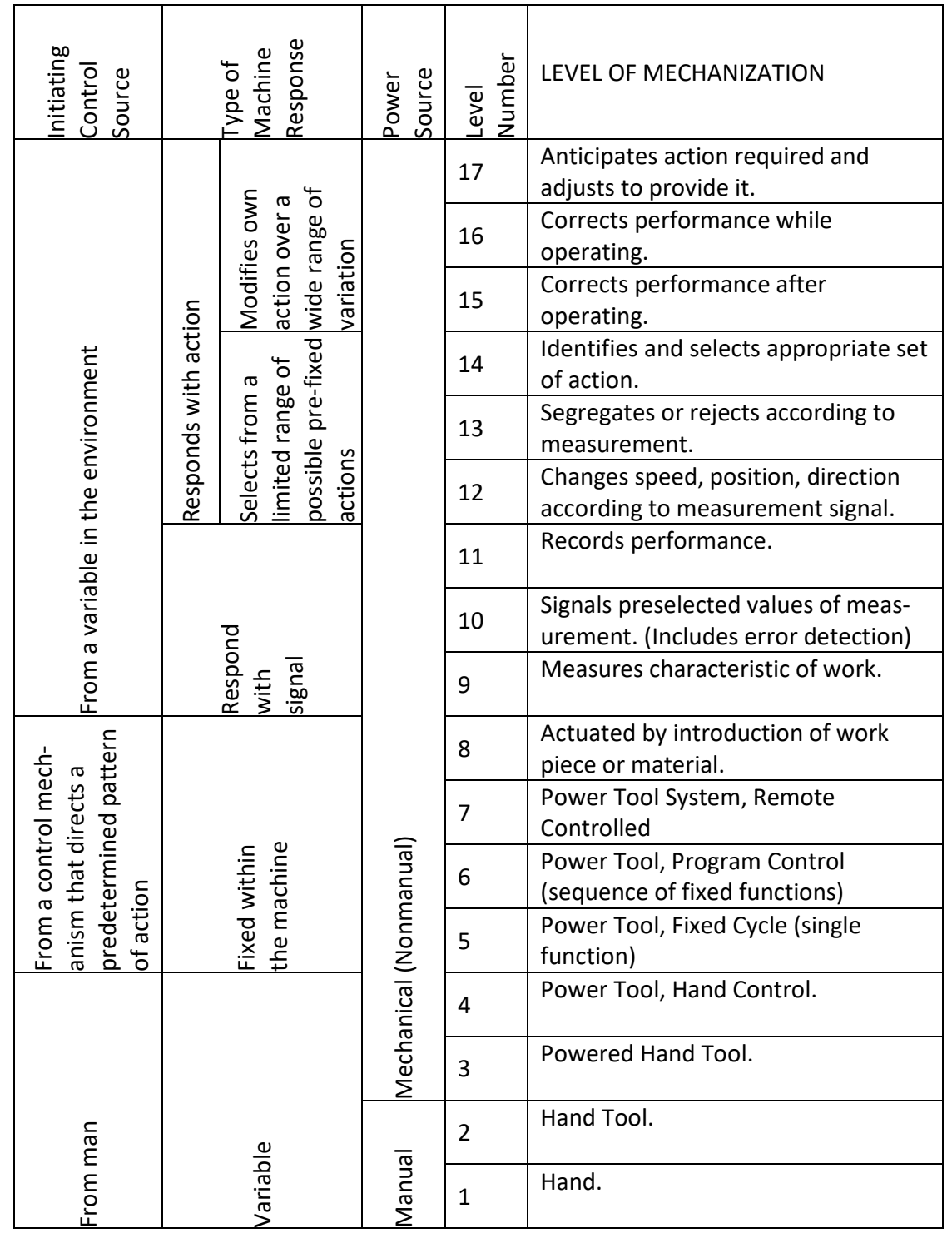




\subsubsection{REASONS FOR IMPLEMENTING AUTOMATION}

Looking at the general automation literature, a number of advantages with automated manufacturing are listed. Sometimes the authors refer to them directly as benefits or advantages; in other cases, they are presented as goals of or reasons for automation. A small selection is presented in Table 4 to show some of the major advantages or reasons presented for venturing into automated manufacturing.

Table 4: A compilation of benefits and advantages as well as goals and reasons for implementing automation in manufacturing operations.

(Based on Ceroni [47], Kalpakjian \& Schmid [45], Groover [39] and Lamb [41].)

\begin{tabular}{|c|c|c|}
\hline Ceroni [47] & Benefits & $\begin{array}{l}\text { Increased productivity } \\
\text { Reduced operating costs } \\
\text { Increased product quality } \\
\text { Increased flexibility } \\
\text { Elimination of health and safety hazards } \\
\text { Higher precision } \\
\text { Ability to run longer shifts } \\
\text { Reduced floor space }\end{array}$ \\
\hline $\begin{array}{l}\text { Kalpakjian \& } \\
\text { Schmid [45] }\end{array}$ & Goals & $\begin{array}{l}\text { Integrate various aspects of manufacturing } \\
\text { Improve productivity } \\
\text { Improve quality } \\
\text { Reduce human involvement } \\
\text { Reduce work piece damage } \\
\text { Raise the level of safety } \\
\text { Economize on floor space }\end{array}$ \\
\hline Groover [39] & Reasons & $\begin{array}{l}\text { Increase labor productivity } \\
\text { Reduce labor cost } \\
\text { Mitigate effects of labor shortage } \\
\text { Reduce or eliminate routine manual tasks } \\
\text { Improve worker safety } \\
\text { Improve product quality } \\
\text { Reduce manufacturing lead time } \\
\text { Accomplish processes that cannot be done manually } \\
\text { Avoid the high cost of not automating }\end{array}$ \\
\hline Lamb [41] & Advantages & $\begin{array}{l}\text { Relieve human operators from hard and monotonous } \\
\text { work or hazardous environments } \\
\text { Facilitate tasks beyond human capabilities (for } \\
\text { example tasks that require high strength or speed) } \\
\text { Faster manufacturing } \\
\text { Lower manufacturing costs } \\
\text { Systems can include quality verifications } \\
\text { Automation can serve as a catalyst for improvement in } \\
\text { general }\end{array}$ \\
\hline
\end{tabular}

Despite all the benefits of automation, there are situations where manual labor is preferred over automation. This can for example be tasks that require manual dexterity, demand eye-hand coordination, require continuous adjustments in the task, or where physical access to the work location is limited or is complex to automate [39]. 
Automation is not necessarily a way to lower manufacturing costs; certain tasks can cost more to automate than to perform manually [41]. Automation is typically best suited for processes that are repeatable and consistent and for high manufacturing volumes [41]. The expected production quantity is crucial to determine what type/level of automation is suitable to produce parts economically [45]. Investing in the automation of new processes can be a risk-filled business, as the cost for research and development required to automate and process are difficult to accurately predict [41]. According to Ceroni [47], the cost of operator wages generally decreases while capital, maintenance, design and power costs tend to increase when implementing automation. However, it is difficult to quantify and capture the benefits of automation using traditional financial analysis. Such tools are short term in nature, and automation might hold long-term strategic effects and benefits that are overlooked in traditional financial analysis [47]. It is, therefore, important to try to consider not only the pure financial aspects of an automation project, but also its strategic implications.

Compared to case-specific equipment, robots have a number of benefits. According to Ceroni [47], robots are multipurpose and can be reprogrammed for a great variety of tasks; they can also be reused in new projects once an automation cell is decommissioned. Because of this, robotic systems' service life can often be three or more times longer than that of fixed automation. In general, tooling costs for robotic systems tend to be lower, and production startup occurs sooner because of fewer construction and tooling constraints compared to fixed automation. [47]

In working with automation projects, the common sense approach described by Groover [39] is good to have in mind. The process emphasizes the need to first understand the process at hand in great detail, to break it down into basic steps and to analyze it in relation to preceding and subsequent processes. When a detailed understanding has been achieved, the process should be simplified to as great an extent as possible and unnecessary steps should be removed. Once the process has been reduced to its simplest form, automation solutions should be conceived. [39] Development of automation solutions forces the users to rethink and systematically define and integrate the functions of their operations, and this reengineering process can create major economic benefits [47].

\subsection{FLEXIBILITY}

An area which has been briefly touched upon in earlier sections of this chapter is flexibility. Flexibility is in itself a major research area, with a diverse selection of definitions and models used to define and describe it. A few basic concepts are presented below to provide a background for discussing in later chapters the need for flexibility in the demonstrators. There are numerous definitions of the term flexibility and closely related terms like agility, reconfigurability and changeability, and the definitions might overlap each other depending on the view. A commonly cited definition for flexibility is provided by Upton [48]:

"Flexibility is the ability to change or adapt with little penalty in time, cost, effort or performance." (Upton [48] pp.73) 
Upton's definition is general in nature and captures what many of the flexibility definitions within the manufacturing flexibility field try to capture: the ability to change or react with as little impact to the manufacturing system performance as possible.

Flexibility is generally conceived as a highly desirable property but it comes at a cost, and thus should only be pursued when it can enhance a company's competitiveness [49]. Much work has been invested in identifying costs associated with the introduction of flexibility, but the more complex issue of flexibility's impact on profitability has received far less attention [50]. Since flexibility comes at a cost, the level of flexibility must be balanced to the need. Situations where the potential flexibility is greater than that required means that savings can be made by reducing the flexibility [51]. However, flexibility seems to be a notoriously difficult property to measure. A number of theoretical frameworks and methods have been developed to identify different types of flexibilities and to analyze different aspects of flexibility [48,49,52-54]. There are also attempts to develop models to be able to measure the level of flexibility in a system [55]. However, implementation of such models seems to be scarce. The term flexibility is often used to describe possible flexibility, rather than flexibility that has been demonstrated in actual cases [48].

Sethi and Sethi [54] define eleven different types of flexibilities and group them into three groups (as shown in Figure 14) based on how the flexibilities relate to each other. Machine, material handling and operational flexibility are viewed as three fundamental types that are the basis for the five system flexibilities, which in turn are the basis for the three aggregate flexibilities. For example, program flexibility is based on process and routing flexibilities, which in turn are based on the three basic flexibilities. Similar classifications of flexibility types have also been proposed by Browne et al. $[52,56]$ and Koste and Malhotra [55].

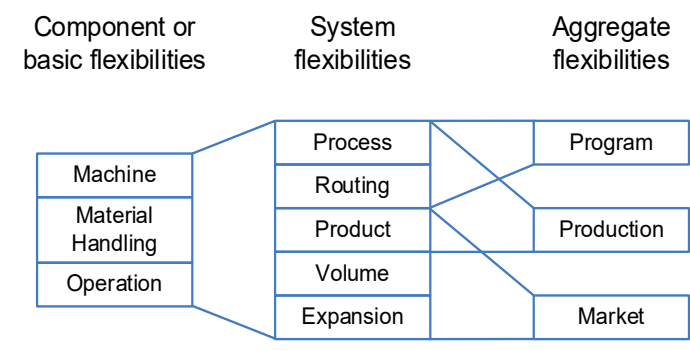

Figure 14: The eleven flexibility types and their mutual relationships as presented by Sethi and Sethi [54]. 
Sethi and Sethi [54] provide the following explanations of the eleven flexibility types:

- Machine flexibility refers to the various types of operations that a machine can perform without requiring a substantial effort in switching from one operation to another.

- Flexibility of a material handling system is its ability to move different part types efficiently for proper positioning and processing through the manufacturing facility it serves.

- Operational flexibility of a part refers to its ability to be produced in different ways.

- Process flexibility relates to the set of part types that a system can manufacture without major setups.

- Product flexibility describes the ease with which new products can be added or substituted.

- Routing flexibility describes the ability of a manufacturing system to manufacture parts through alternate routes through the system.

- Volume flexibility is the ability of a manufacturing system to operate profitably over different output levels.

- Expansion flexibility captures the ease of which a system's capacity and capability can be increased.

- Program flexibility describes the ability of a system to run unattended for long periods.

- Production flexibility describes the range of part types that a manufacturing system can produce without requiring major capital investments.

- Market flexibility is the ease with which a manufacturing system can adapt to changes in the market.

Upton [48] presents a model that is illustrated in Figure 15. It highlights several different aspects that can be considered when discussing flexibility. Upton does not present formal flexibility types, as the 11 types presented by Sethi and Sethi [54]. Instead, Upton's [48] dimension level describes what type of change must be managed. A dimension can for example be fluctuations in incoming material, the ability to manufacture different versions of a type of product, or a need for a different product mix. Each dimension can be viewed in three different time frames. Operational flexibility concerns changes with a day-to-day perspective, tactical flexibility is about adapting to occasional changes that occur in a month-to-month time frame, and strategic flexibility covers the long time frame of several years. Furthermore, Upton [48] identifies three different ways of considering flexibility within each time frame, called elements. Range describes the ability to adapt to a large range of changes within a specific change dimension. For example, it can define the extent of possible product sizes or production volumes. The mobility element describes the penalty cost of moving within the range, and it can be measured by the time or cost that a change results in. The uniformity element captures the ability to maintain a certain performance, for example in terms of quality yield, despite changes within a range. When addressing a system's flexibility, the boundaries of the system must be clearly defined, as moving the boundaries slightly can greatly affect the system's flexibility. [48] 
Dimension Time frame Element

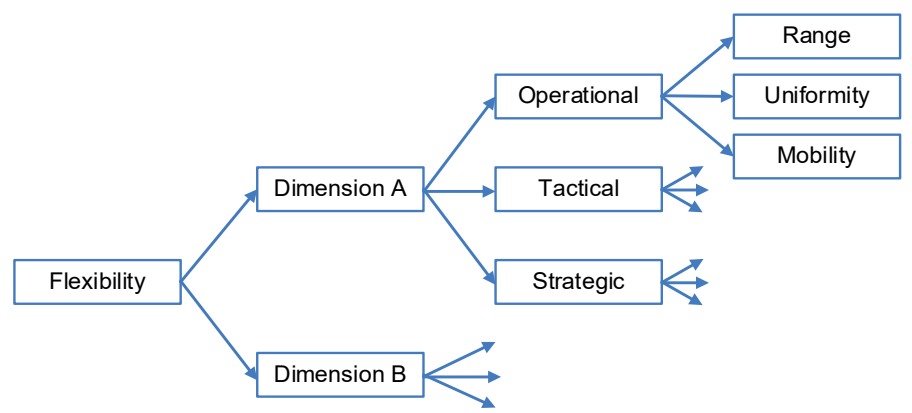

Figure 15: Upton's framework for identifying and analyzing different types of flexibility, redrawn from [48].

As mentioned earlier, there are a number of other models and frameworks for defining flexibility. Some consider flexibility at the higher hierarchical levels of a company and take a more strategic perspective (for example Gerwin [51], Buzacott and Mandelbaum [57] and Slack [49]), while others are more oriented towards flexibility at a machine or manufacturing cell-level (for example Brown et al. [52]). In the context of an automated manufacturing system, Nof [43] proposes a view on flexibility with two major aspects:

- The number of different states that can be assumed automatically.

- The length of time and the amount of effort (setup process) necessary to respond and execute a change of state.

The presented definitions, views and aspects of manufacturing systems, automation and flexibility aim to provide a background for the coming chapters, where different approaches to the automated manufacturing of CFRP products will be presented. 


\section{MANUFACTURING OF COMPOSITE PRODUCTS}

This chapter provides a broad introduction to fiber-reinforced polymer composites in general and prepreg material in particular, as well as gives a comprehensive theoretical basis for the automated manufacturing of CFRP products made from prepreg. It starts with a short historical review of the implementation of composite materials, followed by an in-depth description of fiber-reinforced polymers and prepreg materials. Thereafter follow examples of manual manufacturing methods using prepreg. Then, different methods for forming prepreg laminates are presented. The manual methods provide a basic understanding that is helpful for understanding the automated manufacturing methods that follow the presentation of the manual methods. Automated manufacturing methods for forming and layup of prepreg are presented, and to broaden the area, a review of solutions for automated handling of other types of materials is also provided. The last part of the chapter covers requirements and challenges that affect the design of automated solutions, as well as gives a brief presentation of two innovative alternatives to automated manufacturing of composite products made from prepreg. 


\subsection{HISTORICAL USE OF COMPOSITE MATERIALS}

The use of composite materials like clay reinforced with straw and laminated wood has a long history, while the history of fiber-reinforced polymers is much shorter. One of the earliest reports of high-performance FRPs is from the late 1930s, where experiments with flax fibers impregnated with phenolic resin were carried out to evaluate the material as an alternative to metallic materials in aircraft construction [7]. During the Second World War, cellulose fibers impregnated with phenolic resin were used to manufacture aircraft drop tanks and seats for the Spitfire fighter [7]. Early experiments with glass fibers and phenolic resins gave few positive results, due to poor adhesion between fibers and the matrix; it was not until the early 1950s, with the introduction of polyester and epoxy resins, that glass fiber-reinforced polymers really took off [7]. One of the first major applications of advanced composites in aircraft was fiberglass rotors for helicopters [8].

In the mid-1960s an improved manufacturing technique for manufacturing highperformance carbon fibers marked the start of carbon fiber-reinforced polymers [9]. Carbon fibers were expensive and reserved for high-tech and high-cost applications, and the first offset for large volumes of carbon fibers was for sporting goods, in particular golf clubs [9]. In the aerospace sector, the use of carbon fibers started in military aircraft and spread rapidly from flight control surfaces such as rudders and flaps to primary structures like stabilizers, wings and fuselages [8]. Today, agile fighter aircraft contain in the region of $40 \%$ composites in their structural mass, and about $70 \%$ of the surface of the aircraft are covered with composite materials [13].

According to Roeseler et al. [8], the introduction of composites in the commercial aircraft industry has occurred gradually over time due to high safety standards. Composites have been introduced in three phases. First, composite materials were introduced in tertiary components like interior parts such as sidewalls and bag racks. Second, once the materials had proven successful in the early implementations, they were introduced in secondary structures such as rudders, ailerons and flaps. Third, composites were introduced in primary structures such as stabilizers, wings and fuselage barrels. [8]

Teixeira-Lage [10] provides a short exposé on the introduction of composite materials in Airbus aircraft and notes that in the 1970s, aircraft like the Airbus A300 contained less than 5\% composite materials in their structural weight, including GFRP fairings and radome and CFRP airbrakes and rudders. In the 1980s the A320 contained about $10 \%$ composite materials, with the vertical and horizontal tailplanes made from CFRPs. When the A380 was introduced, the composite percentage was increased to just over $20 \%$. A giant leap forward was then taken with the introduction of the A350, with a structural weight made up of approximately $53 \%$ composite materials including CFRP wing covers, spars and fuselage panels [10]. The same development can be seen at Boeing, which first introduced CFRPs for primary structures in the horizontal stabilizer of the 737 in 1984, and which today manufactures the 787, where composite materials represent half of the aircraft's structural weight, with the wings, stabilizers and fuselage 
made from CFRPs [8]. The use of composite materials has been shown to cut down on the number of parts and reduce weight in aerospace applications [13]. As noted in the introduction, the use of FRPs has increased, and the two newest commercial aircraft from Boeing and Airbus, the 787 and the A350, both contain more than 50\% composite materials. The 787 aircraft is currently being produced at a rate of 12 per month, and the rate is planned to increase to 14 units per month by the end of the decade [58]. The A350 was launched a few years after the 787 and has not yet reached the same manufacturing rate, but it is scheduled to reach a build rate of 10 aircraft per month in 2018 [59]. At the same time as the manufacturing of civil aircraft with a high composite content was ramped up, BMW launched the i3 car on the market in the end of 2013. The car, which relies heavily on CFRPs to reduce weight, has as of 2016 been delivered in about 60,000 units, and the i8, which also contains a substantial amount of carbon fiber-reinforced polymers, has thus far seen delivery of more than 10,000 units [60]. The increased use of composite materials, in particular carbon fiber-reinforced polymers, in both aerospace and automotive applications, has led to a strong growth of the composite market, where the annual growth rate of CFRPs between 2010 and 2015 was $12.3 \%$ [11].

\subsection{COMPOSITE MATERIALS AND THEIR CONSTITUENTS}

In the introduction, the broad term composite materials was narrowed down to carbon fiber-reinforced polymers (CFRPs), and it was highlighted that composite materials consist of two major constituents: reinforcement and matrix. The reinforcement's major role is to provide strength to the composite, while the matrix protects the reinforcing fibers from the surroundings and helps to transfer loads to the fibers. The matrix has a major influence over the processing characteristics of a composite material, and thus has an important influence on the prerequisites for the manufacturing of composites [61]. For fiber-reinforced polymers, there are two main types of matrixes, thermoset and thermoplastic polymers. Thermoset polymers are comprised of two or more substances that are mixed prior to use. Mixing the substances triggers a curing process, which means that there is a limited material lifetime after mixing. Even though curing starts after mixing, many matrix materials require curing at elevated temperatures and pressures to achieve the desired material properties, especially materials used for high-performance applications. The focus in this dissertation is on CFRP with thermoset matrixes, and in particular epoxy, which requires highly-controlled curing in an autoclave with elevated temperatures and pressures.

The other major constituent in a composite material, the reinforcement, also has an impact on the manufacturing prerequisites for the manufacturing of composites. There are two major aspects to consider for the reinforcement of a fiber reinforced polymer, the fiber material and the arrangement. Among the common fiber materials are glass, aramid, boron and carbon. Carbon fibers are the type of reinforcement material considered in this research. The fibers can be chopped to short lengths or used in the form of long, continuous fibers. Furthermore, they can be arranged in random patterns or with controlled fiber orientation. Continuous fibers can either be straight or crimped, as is the case in woven reinforcements. Reinforcements, where continuous fibers are aligned in the same direction, are usually referred to as uni-directional (UD) materials. 
The form of the reinforcement has an impact on the behavior of the reinforcement during manufacturing, as well as on the properties of the final component. In manufacturing methods like resin transfer molding (RTM) where injection processes are applied, the fiber reinforcement and the polymer matrix are handled as two separate materials until the injection process step, in which the composite material is created at the same time as the shape of the final part. Other manufacturing methods begin with raw material containing a mixture of fibers and matrix.

\subsubsection{PREPREG}

For advanced applications, it is common to use prepreg materials, where the fibers have been pre-impregnated with the polymer matrix. Prepreg materials are prepared by material suppliers under highly controlled conditions which yield high quality in general and very good control over the important fiber volume fraction, i.e. the amount of fibers in relation to the matrix. The fiber volume fraction has a significant effect on the material properties of a manufactured product, and since the fibers provide the strength in a composite material, a high fraction of fibers is often desired. After the impregnation stage, the material is semi-cured to what is referred to as a B-stage, and then frozen to prevent complete curing. The material is stored in freezers to prevent material degradation through curing. The prepreg can be protected by stiff backing paper or plastic film on one or both sides. Figure 16 shows a prepreg ply of unidirectional carbon fibers impregnated with epoxy resin that is protected with a stiff backing paper on one side and a blue plastic film on the other. Prepreg materials provide high quality and uniform material properties, but they are expensive. They are therefore mainly used for high-performance applications and are the common material type for the aerospace industry.

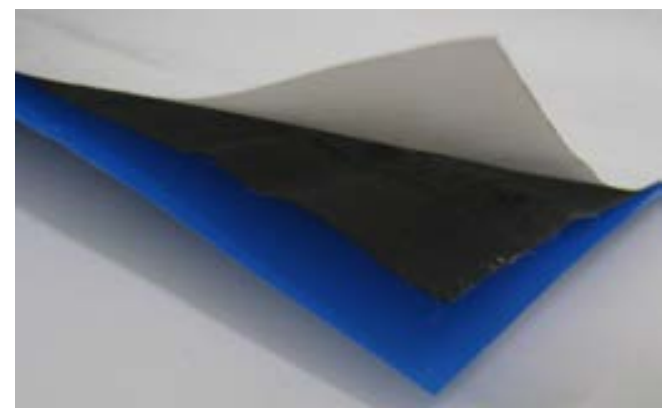

Figure 16: Prepreg made from unidirectional carbon fibers enclosed by a white backing paper and a blue plastic film. Figure from [6].

Prepreg materials have some key characteristics that are important to the quality of the final product, but that also have a distinct effect on the manufacturing method. Prepreg tack, shear and bending behavior have an effect on prepreg layup [62]. Prepreg tack is usually defined as the ability of two prepreg plies to adhere to each other, and this ability is necessary for easy layup and autoclave curing [63]. The tack is dependent on the resin used as a matrix, the fibers as well as ambient conditions [63]. Depending on the manufacturing method and the use of backing paper, the tack level can differ between 
the two sides of a prepreg ply [64]. The level of tack is dependent on temperature and the age of the material, as well as on relative humidity in the air during aging [64]. The dependencies between tack and other parameters is complex. It has been shown that the material age can affect the tack response to heating [65], and that different prepreg materials exhibit very different responses to temperature changes, where low-tack prepreg shows an increased tack and high tack prepreg shows a decreased tack with increased temperatures [66]. The bond between two pieces of prepreg or a piece of prepreg and another surface is also affected by the contact time and force used during attachment [64].

\subsection{MANUAL MANUFACTURING METHODS}

Manufacturing composite products from prepreg materials requires a number of process steps, and there are all-manual manufacturing as well as automated solutions that can be employed. Many of the process steps are the same for both automated and manual manufacturing methods. Therefore, this chapter presents short descriptions of different manual alternatives for manufacturing composite products based on prepreg material.

\subsubsection{MANUAL LAYUP OF PREPREG}

In manual prepreg layup, a product is commonly built by manually placing pieces of prepreg, called plies, directly onto a mold. This manufacturing method, outlined in Figure 17, contains a number of process steps explained below. This example considers a prepreg with unidirectional (UD) carbon fibers impregnated with an epoxy resin that is a common prepreg material for aircraft components.

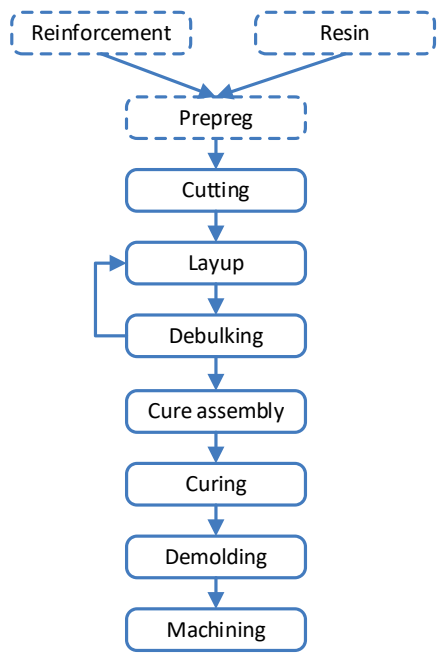

Figure 17: Manufacturing process for manufacturing a CFRP part from prepreg using layup. Figure previously published in [6].

Before the first step, ply cutting, can begin the prepreg, often in the form of a roll of up to two meters width, is taken out of the freezer and defrosted. The protective wrapping around the prepreg roll must not be removed before the prepreg has reached room 
temperature as to prevent condensation. Moisture on the material is unacceptable, as it negatively affects the properties of the material. In the next step, the broad roll is cut into a number of different plies with various shapes and fiber directions. Cutting can be done manually using a knife and templates, but for serial production, automated cutting machines that both cut and label the plies are most common. A set of all the plies required to manufacture a specific product is often referred to as a ply book. In the following layup step, an operator removes the protective backing paper and plastic film and places the plies onto a mold, as shown in Figure 18.

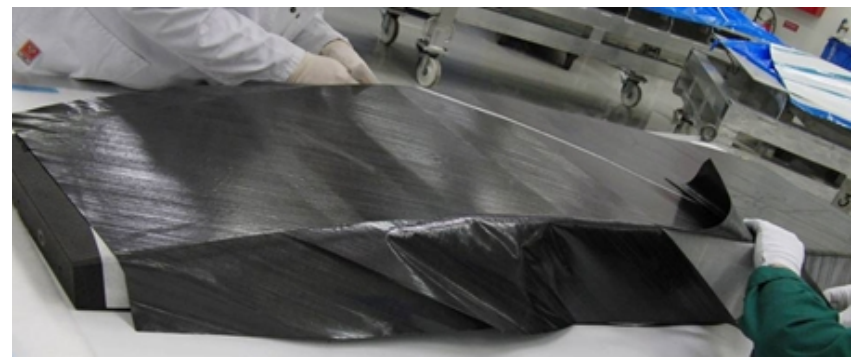

Figure 18: Manual layup of prepreg plies on a mold. Picture previously published in [6].

As a product can consist of a great number of differently shaped plies, drawings and work instructions help to guide the operator during layup so that the plies are placed at the correct location, in the correct layer and with the right fiber direction. The prepreg plies are tacked into place and consolidated by the operator pressing or rolling with simple tools. During all types of prepreg layup it is important to avoid sticking down several different areas of the prepreg at the same time as this might cause a double constraint, which can cause wrinkles if too much material is left between two areas where the ply has tacked to the surface. To assist correct ply placement in manual layup, guide pins and laser projectors can be used. The operator stacks a few layers of plies on top of each other and then follows a debulking process to compact the layup and remove air. In this process, the mold is covered with a vacuum bag and the vacuum is drawn and held for about ten minutes. After the wait time, the vacuum bag is removed and the layup of the following layers continues. The layup and debulking steps are repeated until all the plies have been placed on the mold. The mold is then prepared for the curing process by covering the prepreg with a number of different plastic films and breathers. The assembly is enclosed in a vacuum bag and a vacuum is drawn. The curing of highperformance composite products is usually done in an autoclave, where temperature and pressure can be controlled. The process follows a predefined curing cycle adapted to the prepreg material at hand and to the desired quality. After curing, the product is removed from the mold and in some cases secondary processing, like machining of edges and drilling of holes, is performed. In the aerospace industry, almost all products are subjected to non-destructive testing (NDT), and ultrasonic inspection is a commonlyemployed method to detect flaws in the product [67].

Aerospace manufacturing operations are subject to rigorous quality standards. Because the manufacturing steps taken before a composite product has cured have a particular 
impact on the quality of the final product, prepreg layup follows a highly controlled process. For the layup process, the plies must be stacked in the correct sequence and according to specifications on allowable gaps and overlaps between prepreg plies, and the position and orientation of the plies must also be to specification [3,67-71]. There are also requirements on fiber orientation: the industrial norm generally allows $a \pm 2^{\circ}$ or $\pm 3^{\circ}$ fiber orientation deviation compared to the drawing nominal $[16,67]$. However, controlling the fiber direction is difficult and many complex parts only have a single control rosette showing the four main directions to compare with [16,67]. The layup must be made so that no air is trapped between the plies, as this causes porosity and poor material properties in the cured product [72]. Bubbles and wrinkles are not allowed, however the requirements for these defects are usually not well defined and are therefore open for interpretation [67,71]. Bridging is a defect where the prepreg does not fully reach the bottom of an internal radii or cavity but hangs across like a bridge, as illustrated in Figure 19; this is not allowed in a prepreg layup. Contamination must be avoided and no foreign objects, for example pieces of backing paper or plastic film, are allowed to be included in the layup $[67,68,71,73]$. Defects caused by foreign objects in a prepreg laminate or part are usually referred to as FOD, or foreign object damage. There are also requirements governing the environment in which the layup should take place, for example specifying temperature, humidity and particles in the air [67,73]. There are time requirements for how long the prepreg is allowed to be stored and handled in room temperature before it must be discarded; this is usually measured in days [67].
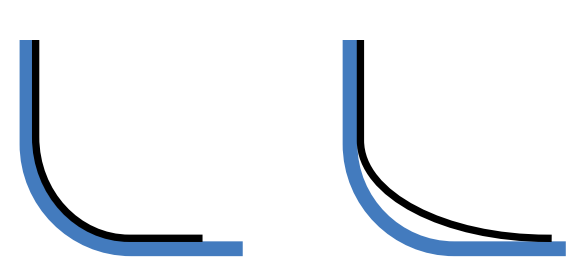

Figure 19: Left: The black prepreg laminate follows the mold shape tightly.

Right: The prepreg laminate does not adhere to the internal radii, leading to bridging.

Manual layup of prepreg is a highly labor-intensive manufacturing method, and the cost for the handling of prepreg and the layup can account for a significant part of the manufacturing cost of a composite product $[3,15,74]$. The cost for cutting and layup can account for $40-60 \%$ of the total manufacturing cost, but the cost distribution is highly dependent on the complexity and size of the final part [3]. Manual layup tests using woven prepreg have shown that changing the material used during layup or the shape of the final product can result in substantial time savings [62]. However, changing the material or shape of the final product can be a time-consuming and costly endeavor, as these types of changes usually require a comprehensive validation process before the changes can be implemented.

Manual prepreg layup on a mold is a complicated process, especially on molds with complex shapes such as double curvatures, tight corners or steep ramps or gradients $[75,76]$. Despite being a common manufacturing method, it is interesting to note that the manual layup step is a sparsely documented process that requires a high degree of 
craftsmanship among operators preforming the process [75,77]. However, in recent years in-depth studies to increase the understanding of manual layup have been performed, and the results from the studies have been used as a basis for both improving the manual layup and developing automated methods [75,77].

\subsubsection{A TWO-STEP APPROACH}

Layup of prepreg directly onto a mold, as described above, is a complex manufacturing method to automate, especially when considering smaller parts and products with complex shapes. However, there is an alternative to directly laying the prepreg plies onto a mold: the layup process can be divided into two steps, as illustrated in Figure 20.

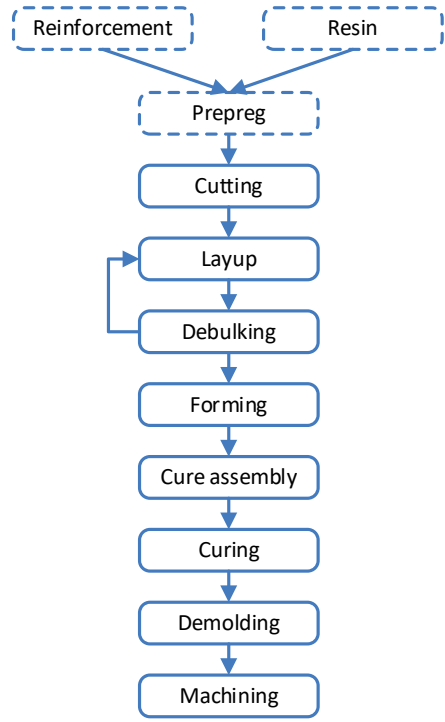

Figure 20: A two-step approach to prepreg layup. Figure previously published in [6].

A two-step approach, where flat laminates, often referred to as stacks, are laid up and then formed to the final geometry in a separate forming process, is common practice for a number of products with suitable geometries. Laminates laid up for forming are typically 1-5 mm thick [18]. The layup is greatly simplified, as it is transformed from a three-dimensional case that requires advanced draping capabilities to a much simpler two-dimensional case. The flat prepreg laminates can be prepared manually or using automated alternatives for layup. In the two-step approach outlined above, the forming step is highly important and there are several forming methods that can be used for forming a laminate to the desired product shape. The following section presents a short background on prepreg forming in general. It also presents a few well-established forming methods along with some novel, automated methods. 


\subsection{FORMING OF PREPREG LAMINATES}

Forming prepreg laminates is not as widely known or well developed as the forming of dry fiber reinforcements, so-called preforming, or the forming of pre-consolidated thermoplastic composite laminates, called thermoforming [18]. One of the most important deformation mechanisms required for forming flat laminates containing sheets of UD prepreg to three dimensional shapes is the ability of the prepreg plies in the laminate to move relative to each other during the forming [18]. This phenomenon is referred to as interply slip, or sometimes interply shear. The resistance to interply slip can be quite high and is dependent on the resin viscosity, the amount of resin at the sliding interface and the normal compacting pressure on the prepreg stack during forming [18]. As the viscosity in turn is dependent on temperature, humidity and material age, these factors also affect prepreg forming [18]. Non-cured prepreg has a clear viscoelastic behavior, which means that the material gradually relaxes under a constant pressure [78]. Tests show that prepreg relaxation behavior is temperaturedependent but also depends on the stacking sequence, i.e. the order of the plies in the laminate [78]. The deformation rate affects the shear stiffness in the laminate, and slowing down the forming process reduces the shear stiffness and improves the interply slip [76].

Heating the laminate can enable interply slip, but prolonged heating of the laminate risks affecting the resin by accelerating curing, and since large stacks require a much longer heat-up time than used during the layup of single layers of prepreg, the heating must be a controlled process [76]. Another important deformation mechanism for threedimensional forming is intraply shear. It is the major deformation mechanism that allows an individual prepreg ply to conform to a curvature with a varying radius [18]. To some extent, intraply shear allows for a change in area by stretching the material in the bias directing, i.e. at a 45 degree angle, to a cross-plied prepreg pair [79]. Carbon fibers are stiff, and therefore fiber stretching during forming is minimal and has little influence on the forming behavior, but UD prepreg has an ability for transverse stretching, and this mechanism can lead to unsuitable local deformations such as splitting of the surface plies [18].

During the forming of carbon-epoxy prepreg laminates, the most common defects that occur are different types of wrinkles [18]. The formation of wrinkles is a complex process that is affected by a number of parameters. For example, lowering the forming speed can reduce wrinkling for certain laminates (for example cross-plied prepreg pairs), but shows very little effect on other laminates with another combinations of fiber directions (e.g. a laminate with 0/90/45/135) [76]. The friction between layers and the fiber direction is important for the formation of wrinkles during forming [80]. Costacking of critical layers in a stack can reduce wrinkling tendencies; in severe cases, changing the entire stacking sequence to avoid difficult fiber angles can eliminate wrinkling [80].However, there are severe limitations to changing the stacking sequence for products in the aerospace industry. Design guidelines discourage grouping of plies with the same orientation together, and it is normal that the stack layup is symmetrical about its center ply to avoid warping of the laminate during curing [18]. 


\subsubsection{VACUUM FORMING AND HOT DRAPE FORMING}

A common forming method is vacuum forming. In this method, a prepreg laminate is placed onto a mold and covered with protective films and a rubber membrane, as illustrated in Figure 21. A vacuum is drawn under the membrane, forcing the prepreg laminate to conform to the shape of the mold. As heat lowers resin viscosity, the prepreg can be heated to facilitate the forming process [3]. Heat-assisted vacuum forming is known as hot drape forming (HDF). Both vacuum forming and HDF provide little ability to control the forming course, and the applicability of the methods is highly dependent on the prepreg material, the stacking sequence in the laminate (the order in which plies with varying fiber orientation are stacked) and the geometry of the final product. Doublecurved shapes are complicated to form due to wrinkling, and $\Omega$-shaped beams are not possible to form in a single step forming process, as it is difficult to avoid bridging between the web and the flange. The double-diaphragm method, where the laminate is sandwiched between two rubber membranes and formed in the same way as vacuum forming or HDF, allows for some added complexity, but this method is also limited in terms of geometrical features.
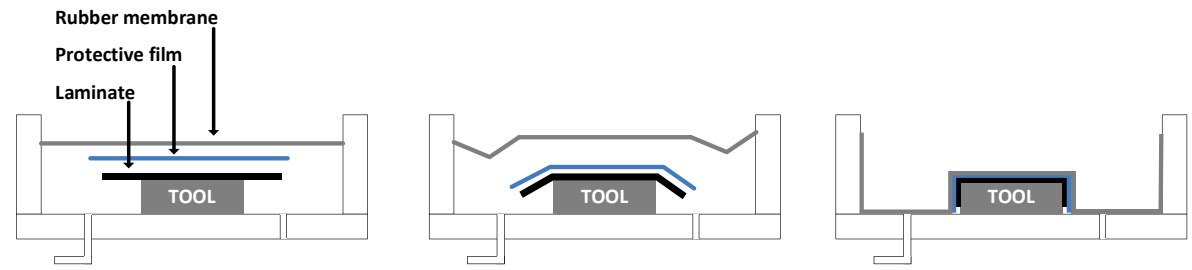

Figure 21: An illustration of the vacuum forming method based on Campbell [3].

\subsubsection{SEQUENTIAL FORMING}

A forming method that offers higher control of the forming process and thereby the ability to form more complex geometries is sequential forming. In this method, a prepreg laminate is placed on a mold with the desired geometry and successively, step by step, formed to the mold shape using simple tools like scrapers and rollers, as shown in Figure 22. The sequential forming method is mostly used for manual forming of thin laminates. Hair dryers can be used to gently heat the prepreg laminate in order to facilitate the forming.

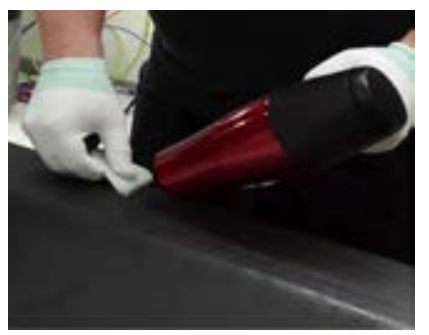

Figure 22: Manual forming of a prepreg laminate using a scraper to form the laminate and a hairdryer to gently heat the prepreg, facilitating the forming. 
In cases where manual sequential forming is used to form thin laminates, the manufacturing process might look similar to manual layup. In this thesis, the difference between a forming operation and layup directly onto a mold is defined by two things:

- The number of plies. For layup, only one ply at a time is placed on the mold, whereas in the forming case, a laminate containing several plies is formed.

- A forming operation is always preceded by a layup process that generates the flat laminates.

Sequential forming of prepreg laminates can be automated by using an industrial robot equipped with a scraper to gradually deform the laminate to the desired geometry. This method, called robot-forming, has been developed and tested by Sjölander and Åkermo [81] within a research project. The authors [81] report successful forming of a U-shaped spar with a recess area. The same team has also been responsible for developing and testing robot-forming of thick laminates on a U-beam as part of one of the demonstrators; more detail on this is presented in Section 6.5. Robot-forming has been developed in research projects, and there seems to be no industrial implementation of this type of robot-forming today. The robot-forming process has been shown to be capable of forming complex shapes, but so far with low forming speed.

\subsubsection{GLIDE FORMING}

Another method for automated forming of flat laminates is a continuous forming method called glide forming, presented by Redondo [82]. In this method, a flat laminate is placed between two heating blankets on a mold and heated before the forming process begins. The forming is done by pressing a large inflatable roller (looking like a wheelbarrow wheel) against the mold. The heating blankets and the roller slide along the mold continuously, forming the laminate to the shape of the mold in one pass. A second set of inflatable rollers follows the major roller to press down the prepreg during cool-down to avoid springback. An automated version of the system requires three robots, where one robot moves the heating blankets forward during the forming and the second robot follows with the forming roller. The third robot continuously adjusts the position of the unformed laminate so that curved shapes can be manufactured. The system can form long $\Omega$-shaped stringers up to $4 \mathrm{~mm}$ thick, and L-shaped profiles with a thickness of $7 \mathrm{~mm}$ and forming speeds of $300 \mathrm{~mm} / \mathrm{min}$ have been reported. The system is limited in terms of geometrical complexity, and for example only mild curvatures and no joggles have been considered. [82]

\subsection{Automated TAPE LAying AND Fiber Placement}

In an effort to reduce the high level of manual work in the manufacturing of composite components based on prepreg materials, automation alternatives have been developed. The first thrust to automate prepreg manufacturing was to automate the cutting of prepreg plies [83]. The next step was to develop automated alternatives for the layup of prepreg. Today, there are two dominant technologies for the automated layup of prepreg: automated tape laying (ATL) and automated fiber placement (AFP). Both types of systems deposit prepreg tape layer by layer on a mold; the major difference between the two is the width of the deposited tape. The first developments of ATL technologies came 
in the late 1960s, and the oldest patent in the area is from 1967 [16]. Research machines were developed in the 1970s. The first generations of ATL and AFP machines evolved from technology developed by traditional CNC machine manufacturers that were already heavily involved in automated aircraft manufacturing [84]. The aerospace sector was an early adopter of the automated layup technologies. At Airbus, ATL was first implemented in connection with the introduction of CFRPs in large primary structures like the vertical and horizontal tailplane on the A320 in the 1980s [10]. AFP was introduced in the A380 program in the beginning of the $21^{\text {st }}$ century, and Airbus further developed the technology to handle more geometrically complex parts such as wing spars a few years later in the A350 program.

In an ATL machine, a large head deposits prepreg tape, typically with a width of 75,150 or $300 \mathrm{~mm}$ [17], onto a mold by pressing the prepreg into place with a compaction roller. The protective backing paper is removed from the prepreg as part of the layup process, and heating elements are used to control the tack during layup [4]. Tapes are deposited one by one with a gap of $0.5-1 \mathrm{~mm}$ between them, and when one course is complete the prepreg is cut. The distance between the knife and the compaction roller, in many systems around $100 \mathrm{~mm}$, is called the minimal course length and it is the shortest distance that can be laid up [17]. As most ATL machines store the prepreg material in the layup head, the heavy head (shown in Figure 23) needs a strong and stiff structure; therefore, ATL machines are usually built on large horizontal gantries or vertical columns [17].

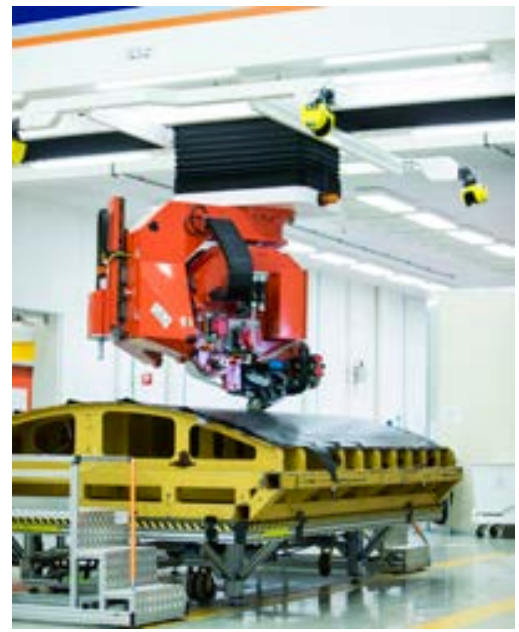

Figure 23: Prepreg layup onto mold using ATL.

(Photographer Per Kustvik, copyright Saab AB.)

AFP machines lay up several narrow strips of prepreg called tows at the same time, typically with a width of $3.2 \mathrm{~mm}, 6.4 \mathrm{~mm}$, or $12.7 \mathrm{~mm}$, and they can place as many as 32 tows in parallel [17]. Each tow can be cut individually, and the speed of each tow is individually controlled, which allows layup of more complex geometries than ATL [17]. AFP systems generally have a lower minimal course length, typically around $50 \mathrm{~mm}$ 
[17]. The deposition heads are smaller, and there are a number of solutions where the material is stored in a separate unit and fed to the deposition head. The smaller and lighter heads allow for AFP systems to be robot mounted, but there are also gantry and column (Figure 24) types of machines. Robotic systems tend to have a lower investment cost, but the gantry type of AFP machines provides higher productivity by handling more tows in the head [17].

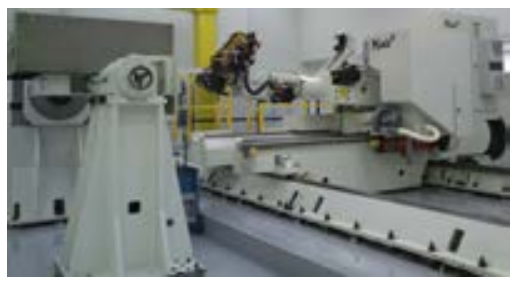

Figure 24: A column-type AFP machine.

Traditionally, AFP and ATL machines have been designed to be able to lay up a wide variety of part shapes and sizes, making the machines large, sophisticated and expensive, but some machine suppliers also develop part-purpose systems that are simpler yet only address a specific range of parts [84]. There are also machine concepts where the same machine can switch between multiple heads, and thereby act as both an ATL and an AFP machine [84]. In both ATL and AFP systems, rollers press the prepreg to the mold during layup, which eliminates the debulking step that is necessary in manual layup [3]. After the layup is completed, the component follows the same processing steps as in manual layup, starting with cure assembly.

\subsubsection{ATL AND AFP CAPABILITIES}

When comparing the material scrap rates, it can be noted that they tend to be higher using ATL than AFP, due to the wider tape used in ATL [85]. AFP offers much lower scrap rates than manual layup, where prepreg plies are cut from broad rolls of prepreg, although the additional cost for slitting the narrow tapes from wide rolls of prepreg can in some cases offset the savings of lower material waste [16].

Part geometry has a big impact on the possible productivity of ATL and AFP. The span for the actual productivity (commonly measured as $\mathrm{kg}$ of prepreg laid up per hour) is very wide, and can range from 2-150 kg/hour for AFP applications and 10-150 kg/hour for ATL [86]. A highly contoured part requires narrower tape or a smaller tow and will take a longer time to manufacture [85]. The smaller the part gets the shorter the layup courses are, and that means that the machine spends more time on activities such as accelerating, deaccelerating, turning around and cutting compared to the actual layup of fibers, which clearly affects productivity [85]. ATL is generally used for larger, less contoured components, which opt for higher productivity in terms of the amount of prepreg deposited per hour.

Another issue that limits productivity in automated layup is the rigorous quality standards in aerospace applications. Today's industry standard requires manual inspection of each prepreg layer to detect defects before the next layer is deposited, since 
the new layer hides the defects from visual detection [87]. During inspection the ATL or AFP machine must be stopped to allow an operator access to the layup. The inspection can account for a significant portion of the layup time [88]. One example from the AFP layup of large aircraft fuselage sections shows that approximately $32 \%$ of the total time in the machine is spent at inspection and repair, while only $27 \%$ of the time is spent on the actual layup operations [89]. Automated systems for in-line inspection, aiming to remove the need for manual inspection, are being developed but have yet to be implemented in manufacturing operations [87].

ATL and AFP are high-cost investments. It is difficult to find published data showing the cost of the machines, but some examples have be identified. For example, the National Composite Center in Bristol invested \$4 million in a robotic AFP [90]. Other reports on costs place AFP machines in the range of \$5-25 million, depending on size and sophistication [91]. For products that are possible to layup using ATL or AFP but that end up in the lower area of the productivity spectrum, the combination of high cost and low productivity can render automated layup using these established methods a less than cost-effective solution.

The geometry of the part not only affects productivity; complex shapes might be very difficult or impossible to manufacture using ATL or AFP layup directly onto a mold as well. Both technologies are limited in terms of the geometric complexity of the manufactured part. Geometrical features like double curvatures, tight corners and steep ramps are challenging [92]. There are examples of products, with small internal radii, where it is impossible to use ATL or AFP [93]. Even though more capable to manage complex geometries than ATL, the geometrical capability of AFP machines is in fact really very limited [16]. The limitations stated above consider automated layup directly onto a contoured mold, but as presented in section 4.3.2, it is sometimes possible to take a two-step approach where a flat laminate is laid up and then formed in a separate forming operation. The layup is greatly simplified, as it is transformed from a threedimensional case that requires advanced draping capabilities to a much simpler twodimensional case. This can make it possible to use ATL or AFP for the layup of flat laminates. An example of an early application, suitable to manufacture products like stringers, spar caps and longerons, was a combination of an ATL machine that laid up flat laminates with all the required build-ups with a vacuum forming process that transformed the flat laminate to the required profile shape [83]. For laminates with simple shapes and uniform thickness, an efficient approach is to use an ATL machine to layup a large laminate that, after the layup is completed, is cut into several smaller laminates with the desired outline. However, small laminates or laminates with areas with small additional plies for extra reinforcement can be impossible to realize due to the minimal course length [17]. Laminates with a tapered edge, where each ply is slightly wider than the previous as illustrated in Figure 25, opt for very low productivity. To layup the laminate in Figure 25, it has to be laid up starting with the most narrow layer facing down. This is because the prepreg tape has to be extended outside the outer edge of each ply and the outer edges of each layer have to be cut clean and the scrap removed before the next, wider layer of prepreg is laid up. 


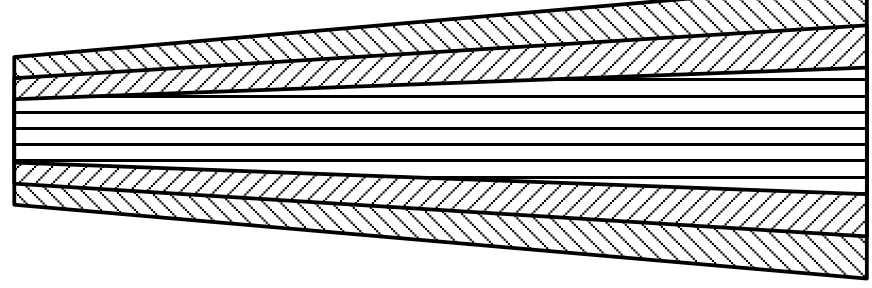

Figure 25: A laminate with a tapered edge that is unsuitable for automated layup using ATL or AFP.

It can be concluded that ATL and AFP present an appealing alternative for the automated manufacturing of certain types of products. Large products with mild contours are suitable for ATL, but for more challenging geometries, AFP can be an alternative. In a general sense it can be noted that the more complex the shape and the smaller the size of the part, the lower productivity the two technologies provide. Small parts and parts with complex shapes might be impossible to layup using ATL and AFP. There are also flat laminates that cannot be laid up using the same technologies. There are examples of many types of components used within the aerospace industry, such as ribs, spars and brackets, that are too small to be efficiently manufactured using ATL and AFP [18]. The focus on technical developments in automated composite manufacturing has therefore recently shifted to how to automate the manufacturing of components that cannot be efficiently manufactured using AFP [16].

\subsection{PICK-AND-PLACE SOLUTIONS FOR PREPREG LAYUP}

As ATL and AFP are not applicable for all types of products, alternatives to the automated layup of tapes or tows have been explored. An alternative approach to using tape or tows is to automate the layup of prepreg plies cut from the same type of rolls with prepreg that are used for manual layup. Just as in manual layup, this requires the automated solution to pick up a multitude of cut plies of varying size and geometry and place them onto a mold or a flat layup surface. These concepts are often referred to as pick-and-place concepts, and this approach to material handling is common in many other industries, for example in the automated handling of thin sheets of steel for pressing operations. This type of concept usually uses industrial robots equipped with end effectors designed to handle and manipulate a particular material. Pick-and-place systems aim to be low-cost alternatives compared to ATL and AFP.

On the use of pick-and-place systems for prepreg layup, Elkington [75] notes that many of the attempts have led to systems with very limited capability to handle complex shapes. The sequential approach used for manual layup, where the operator continuously evaluates the outcome of one action during the layup in order to determine the next step in the layup, makes the layup of complex shapes a complicated endeavor to automate [75,77]. Chatzimichali and Potter [12] highlight the importance of understanding the unique material properties of prepreg materials when developing automated solutions, as they suggest that the lack of automation alternatives for prepreg layup might be caused by a lack of material knowledge among robot application companies. Ward et al. [94] 
suggest that many attempts to automate prepreg layup using pick-and-place concepts have also failed due to a combination of high capital requirements and low output volumes, as well as technological barriers like the lack of efficient and reliable end effectors for handling prepreg. Furthermore, Ward et al. [94] conclude that, realistically, the only available alternatives for automated manufacturing based on prepreg materials are ATL and AFP. Automating direct layup of prepreg on a mold with small size and with complex geometries is a complicated task, and no real off-the-shelf solutions that facilitate cost-effective manufacturing of small and complex components can be found $[12,75]$. Manual layup is often applied in these cases, in lack of other options. As described in section 4.3.2, it is in some cases possible to use a two-step approach, where a flat laminate is laid up and formed in a subsequent process. This deconstruction greatly simplifies the layup, as it transforms it from a three-dimensional layup that requires draping capabilities to a two-dimensional layup. Thereby, it can simplify the automation of prepreg layup using a pick-and-place approach.

When reviewing the field of pick-and-place layup of prepreg it is clear that so far, few systems have been developed and implemented, and there is not much published material on automated prepreg layup using a pick-and-place approach. To provide a wider perspective, the scope in the next section is therefore broadened to include automated handling of different types of materials used in different forms of manufacturing of composite products. The common denominator between all the reviewed solutions is that they are designed to handle materials that have low structural rigidity. The section is followed by a few descriptions of specific solutions for prepreg layup. It can be noted that only a few such systems have been found, and that almost all of them are products of research projects. After that follows a presentation of challenges that have been identified when it comes to automated layup of prepreg using a pick-andplace approach, particularly to manufacture products for the aerospace sector. The chapter is concluded by providing some examples of automated manufacturing using prepreg that are not using a traditional pick-and-place approach.

\subsection{A REVIEW OF AUTOMATED MATERIAL HANDLING}

Paper VII presents a wide review of automated solutions for pick and place used in various manufacturing methods to manufacture composite products. It shows that these types of solutions are applied to handle four different materials: dry fiber reinforcements, prepreg, thermoplastic tape and auxiliary materials such as plastic films used in cure assembly. Among these four categories, the automated handling of dry fiber reinforcements for injection methods has received the most attention, and the handling of auxiliary materials used in composite manufacturing processes seems to be the most novel field. The solutions employ industrial robots (in most cases articulated 6-axis systems, but in a few cases gantry robot designs) equipped with end effectors that are designed for picking up, fixing and releasing the handled materials. The material can be picked from a flat surface and placed on a flat layup area $(2 \mathrm{D} \rightarrow 2 \mathrm{D})$ or placed directly onto a contoured mold $(2 \mathrm{D} \rightarrow 3 \mathrm{D})$. The more complex handling required to place material onto a contoured mold seems to have received the most attention, as shown in Table 5. 
Table 5: Sources presenting work related to 2D or 3D material handling. Some sources present work dealing with both types of material handling, and hence are represented in both categories. Table from paper VII.

\begin{tabular}{|c|c|}
\hline $2 \mathrm{D} \rightarrow 2 \mathrm{D}$ & 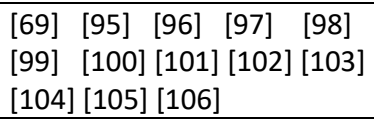 \\
\hline $2 D \rightarrow 3 D$ & $\begin{array}{l}{[70][96][98]} \\
{[108][109][110][111][107]} \\
{[113][114][115][116][117]} \\
{[118][119][120][121][122]} \\
{[123][124][125][126][127]}\end{array}$ \\
\hline
\end{tabular}

\subsubsection{GRIPPING TECHNOLOGIES}

In order to pick up and hold the material in place during the handling operations a number of different gripping technologies, illustrated in Figure 26, can be used. The review of solutions for automated handling in Paper VII shows examples of how these technologies are used, and in Paper II technical details on of the technologies are explored. The review presented in Paper VII shows that the most commonly used grippers are the three technologies grouped together in the pneumatic generated suction category. Standard vacuum systems designed to work with significant pressure difference in combination with low airflows are very common, and there is a multitude of different shapes and materials to choose from, but standard vacuum grippers are unsuitable for use with porous material [128]. For porous materials such as dry fiber reinforcements, systems with high airflows such as low-vacuum grippers and coanda grippers are more suitable $[128,129]$. The cryo gripper lifts material by rapidly freezing a contact liquid (often water) onto the surface of the material, forming a bond between the material and the gripper [130,131]. Adhesive grippers use a sticky surface to grip materials and are unsuitable as they risk contaminating the material [131]. The water used for the cryo grippers also poses a risk for contamination. Electroadhesive grippers are based on electrostatic adhesion between the gripper surface and the material to be handled. Mechanical clamping grippers is a technology that is commonly employed for handling rigid materials. The problem with clamping grippers is that they generally require access to two sides of the material to grip. If both sides are accessible they provide a stabile grip and a simple release [131]. Needle grippers work on the principle of inserting several small needles into the material which provide a steady grip. Noncontact grippers based on the Bernoulli principle offer a desirable possibility for handling sticky materials, as the material floats underneath the gripper. However, this creates problems with the positional accuracy of the material during handling, and for the handling of limp materials there is a risk that the gripper causes small deformations to the material during handling [132]. 


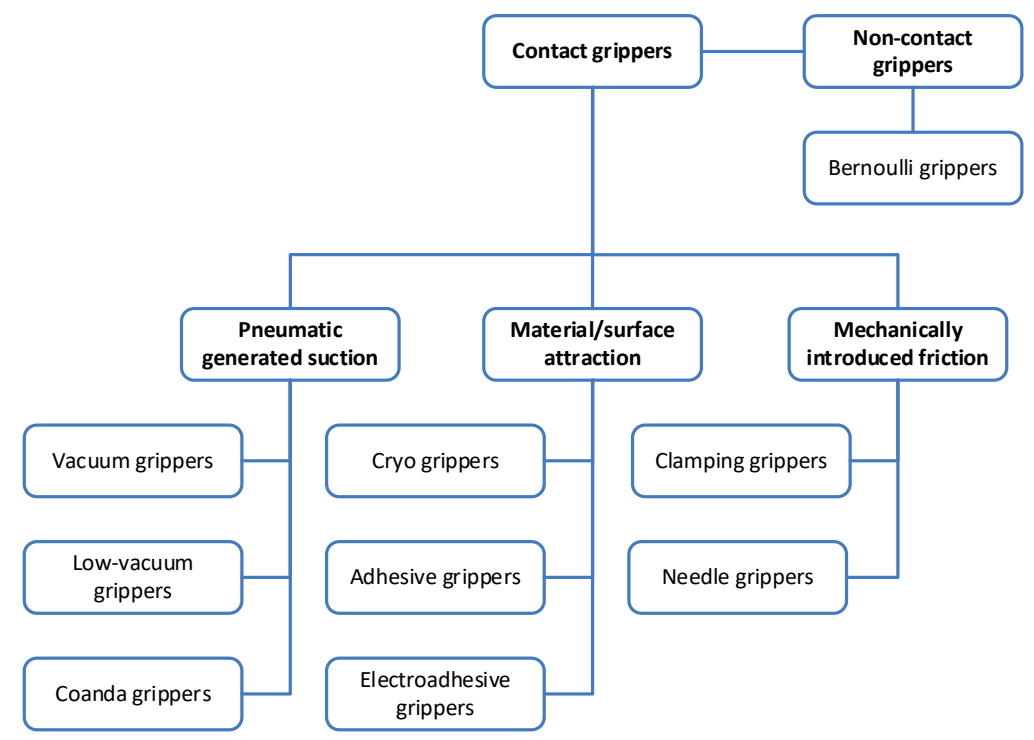

Figure 26: Overview of gripping technologies. Figure from Paper II.

The review of solutions for the automated handling of composite materials shows that the most commonly employed gripping technologies are vacuum grippers, low-vacuum grippers and coanda grippers. There are also several solutions that employ needle grippers, and a few that rely on mechanical clamping and cryo grippers. No solutions using adhesive, electroadhesive or Bernoulli grippers are found in the review. Most of the systems found in the review use several grip points (i.e. several vacuum suction cups, needle grippers, clamps or cryo gripper units) in the end effector. The distribution of the grip points is either spread out over the entire surface of the plies that the end effectors should be able to handle, or located along the edges or at the corners of the plies. The review indicates that a distribution over the surface is a more common approach, and it can be noted that many of the solutions that grip at the corners or edges of the plies use two or more robotic arms for the handling operation [70,112,113,122,123].

\subsubsection{FROM 2D PICKUP TO 3D PLACEMENT}

Automated layup of composite materials onto a three-dimensional geometry requires the ability to transform the material from a two-dimensional arrangement at the pick-up location to a three-dimensional shape, and this requires the end effector to conform to the new geometry. The transformation from 2D to 3D might convey a need to change the distance between the grip points, as illustrated in Figure 27. For grippers that have a firm grip and where the material cannot slide along the gripper surface, the distance between the grip points must be changed during draping onto a 3D mold. Of course, the end effector must also be able to adapt to the mold geometry; this transformation to the new geometry can be achieved either actively or passively. 


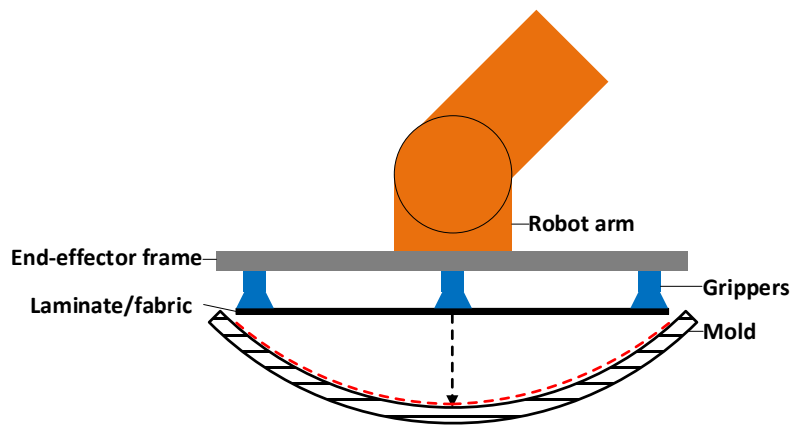

Figure 27: Going from 2D pick up to 3D placement requires the end effector to change form and might also require the distance between the grippers to change. Picture from Paper VII.

The review shows that systems designed to drape material onto a three-dimensional mold can be divided into four groups based on their grip point distribution (over the full ply surface or at the edges/corners) and if they adjust to the required mold shape actively or passively. As can be seen in Table 6, active draping seems to be the most common approach for systems that grip at the edges or the corners, while passive draping is more common if the grip points are distributed on the surface. Passive draping can for example be realized by pressing a flexible surface against a mold. Active draping requires repositioning of the grip points, which can be realized either by using multiple robot arms or using actuators built in the end effector. A high number of actuators tends to drive end effector complexity, and in general the need for three-dimensional layup drives the complexity of the layup method as well the required hardware.

Table 6: Sources describing systems for automated composite handling that are able to lay up material in a three-dimensional mold can be divided into four groups based on how they grip the material and how they can conform to the 3D surface.

\begin{tabular}{|l|l|l|l|}
\hline \multicolumn{2}{|l|}{ Grip points at edges or corners } & \multicolumn{3}{|l|}{ Grip points spread over surface } \\
\hline Active draping & Passive draping & Active draping & Passive draping \\
\hline$[70][108][112]$ & {$[118][126]$} & [111] [120] [127] & {$[96][98][107]$} \\
{$[113][115][117]$} & & & {$[109][110][111]$} \\
[118] [122] [123] & & & {$[114][116][121]$} \\
& & & {$[124][125]$} \\
\hline
\end{tabular}

The review concludes that most research efforts seem to be directed towards threedimensional layup, and that no real examples of industrial implementation can be found. Furthermore, the review highlights that it is hard to find generic solutions that can handle a great multitude of ply shapes, ply materials and mold geometries. 


\subsection{EXAMPLES OF PICK-AND-PLACE SOLUTIONS FOR PREPREG LAYUP}

The review of systems for the automated handling of materials presented above includes a few examples developed for the automated handling of prepreg, and these are described in this section. The earliest publication on automated prepreg layup, in the review, is Curran et al. [69], who in 1987 presented a system for the layup of prepreg plies onto a flat mold. The system uses a six-axis industrial robot equipped with a squareshaped end effector measuring $500 \mathrm{~mm}$. The end effector is divided into 100 individually controlled cells that each contain a number of holes through which vacuum can be drawn or air can be exerted. The cellular design makes it possible to pick up different ply shapes by activating the cells corresponding to the current ply shape. The gripping points are distributed across the surface of the ply and the gripper has no ability to conform, actively or passively, to a contoured surface. The plies are picked from a cutting table where they are surrounded by other plies. For the pick-up operation, open-loop control is employed as the locations of the plies are well known. For the laydown operation, a closed-loop system using a vision system to detect the exact position and orientation of the ply on the end effector as well as the correct position and orientation of the mold is used. The prepreg is released onto the mold by reversing the vacuum flow so that air is ejected from the holes in the gripper. The authors observe that the prepreg tacks to the surface of the gripper, and that the blow-off pressure used for releasing the material must be carefully controlled to secure a release without damaging or distorting the ply. Furthermore, the authors note that a release of the ply, where one side is released followed by a successive release of the rest of the ply that is made possible by the individual control of the cells, is an advantageous feature that can help prevent air being trapped during prepreg layup [69].

The next example of an automated layup system for prepreg was developed by Newell, Buckingham and Khodabandehloo, who from 1995 to 1996 published three papers $[70,122,133]$ describing a system for automated layup of prepreg on a three-dimensional mold. The system, outlined in Figure 28, is designed for automated layup of prepreg onto double-curved molds and is tested using three different mold shapes as well as three different prepreg materials. Both woven carbon fiber and glass fiber prepreg as well as UD carbon fiber prepreg are used to test the system. 


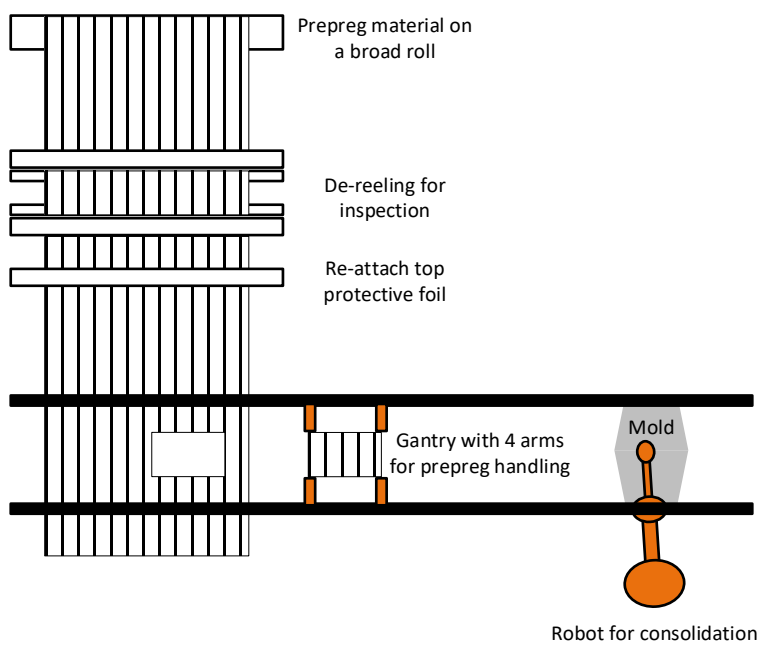

Figure 28: The layout of the cell developed by

Newell, Buckingham and Khodabandehloo. Figure redrawn from [122].

An operator places broad rolls of prepreg onto a de-reeling unit and threads the prepreg and the paper to the correct paths. For the woven prepreg materials, the backing paper is removed and both sides of the prepreg are visually inspected to detect defects before the plies are cut. As unidirectional prepreg is more fragile than woven material the upper backing paper is reattached after inspection, as illustrated in Figure 29. For UD prepreg, the backing paper is kept on the material until the ply has been placed and consolidated onto the mold.

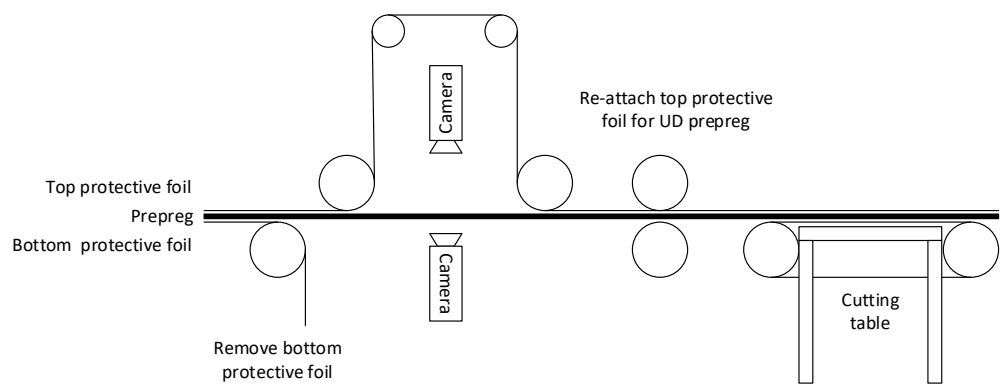

Figure 29: The removal and reattachment process of the backing paper used for the UD prepreg. Figure redrawn from [122].

The prepreg is cut using a static knife cutter and the material is held in place on a rubber belt using vacuum force during the cutting operation. The cut plies are removed from the cutting table using a four-armed gantry robot that grips the plies at the corners or at the outer edges using vacuum grippers. The ply is transferred to the mold and then gradually placed by the four-arm gantry and consolidated using a six-degree-of-freedom industrial robot equipped with a consolidation tool. The layup and consolidation are performed successively, where a part of the ply is lowered into the mold and consolidated before the next section of the ply is placed. This gradual layup and 
consolidation process helps to prevent wrinkles and bridging. The trajectories used when the material is laid up and consolidated are based on simulations. The tests show that the layup and consolidation step is the most time consuming in the manufacturing cell. For the layup of UD prepreg, the backing paper must be removed after the consolidation is completed. The robot that is used for the consolidation changes tools from the consolidation tool to a needle gripper and peels off the backing paper. The robot changes tool again to a camera that is used to inspect the ply after the backing paper has been removed. Extensive tests show that the system works for all the products and for all materials, however the fragile nature of UD prepreg causes severe problems. The authors note that the system will not be entirely autonomous, and foresee that such a system will require operator involvement in error recovery and to perform regular maintenance to prevent resin build-up on the areas in contact with the prepreg. The system also relies on manual operators to load prepreg rolls and to remove the part from the mold once layup is completed.

Lowflip was a three-year research project that ended in late 2016. The project explored different areas of automated manufacturing of composite products. One of the project aims was: "To develop low cost and flexible multifunctional handling, placement and draping solutions for both small complex parts (pick \& place solutions) and big structures (automatic fabric placement solutions)" [134]. So far, no final results from the project have been published, but two interesting concepts for automated prepreg layup have been presented in the form of computer simulations complemented with descriptions of each concept [123,134-136]. The first concept is a pick-and-place system for laying up precut prepreg plies on a small to medium-sized mold with a light curvature. A standard 6-axis industrial robot equipped with an end effector is used to perform the layup. The end effector consists of a framework holding vacuum gripper units. Each gripper is mounted on adjustable axes so that its position within the framework can be altered to fit the ply geometry. The gripper units can also be moved in the direction normal to the ply, which allows for some 3D draping capability. This function is intended to be used to pre-shape the plies during the transfer from the flat pickup location to the contoured mold.

The second concept developed within the Lowflip project aims to automate the prepreg layup of large-sized structures. This uses unidirectional ATL tape with a width of $300 \mathrm{~mm}$ as raw material, but can be adapted to narrower tape as well. A cutting machine cuts the tape to the desired length and two standard 6-axis industrial robots grip the tape at each short side using clamping grippers. The two robots are positioned on linear axes for extended reach. They move in a synchronized motion from the cutting machine to the large layup mold that is positioned on a rotating table. A third robot, of the same type, is equipped with a compaction roller. The two robots holding the prepreg successively lower the tape onto the mold, while the third robot consolidates the prepreg so it sticks to the mold. The prepreg is handled without any backing paper. The mold that is positioned between the holding robots can be rotated to allow layup of different fiber angles. 
Accudyne Systems have developed an automated solution for the layup of prepreg plies as part of a research project reported by [124]. The solution is intended to manufacture a beam that is approximately $1.6 \mathrm{~m}$ long, $0.3 \mathrm{~m}$ wide and $76 \mathrm{~mm}$ thick and consists of 737 prepreg plies. Most of the plies are UD carbon fiber prepreg, but the product also includes plies with UD and woven glass fiber prepreg. The company has developed a prototype which consists of a conformable structure with a huge number of vacuum suction cups spread over a large surface. The prototype can pick up plies from a flat surface and deposit them on the mold with a curved and slightly twisted shape. In a real application the prototype is intended to be mounted on a 6-axis industrial robot, but for the tests a simpler mechanism has been used. The layup tests show that the position of the suction cups is key to eliminate drooping of the prepreg plies.

The material supplier Hexcel has developed an automated system for the layup of flat prepreg stacks for compression molding [95]. The system uses standard industrial robots equipped with flat end effectors equipped with vacuum grippers to handle the prepreg plies. Square-shaped plies are picked from a cutting machine and placed on a flat layup area with a positional tolerance of less than one millimeter. Each ply is inspected to detect defects like gaps and foreign object damage (FOD) during the layup sequence. After placing the desired number of plies in the stack it is consolidated using vacuum consolidation with controlled temperature. After consolidation the square-shaped laminate is moved to a cutting station where it is cut into four preforms and the scrap inbetween is removed. The preforms are automatically labeled and fitted with an adhesive film before they are packed.

The system developed by Accudyne Systems is dedicated to the manufacturing of a single product, as the vacuum cups are mounted in fixed positions adapted to the mild curvature of the final product. Hexcel's system is also dedicated to a specific part geometry. However, the system is based on the stacking of a square-shaped laminate from which the four preforms are cut out of at the end of the manufacturing process. This makes most of the steps in the process independent of the shape of the preform. As long as the preforms can be cut out from the square-shaped laminate, the system requires relatively small changes to accommodate new preform shapes. To stack a square-shaped laminate and then cut out the preforms from the laminate simplifies the design of the manufacturing cell, as many of the systems only need to handle one ply or laminate geometry. It also improves the layup rate, as one layer in the stack only consists of one ply. However, it can come at a cost of higher scrap rates. Since all plies in the squareshaped laminate have the same size and the size is not matched to the outline of the preform, it removes the possibility to cut plies that exactly fit the preform shape and that can be nested to reduce the scrap rate during cutting.

The system presented by Newell, Buckingham and Khodabandehloo is the most comprehensive and versatile of the systems, as it includes all process steps starting from prepreg on a broad roll all the way to a complete layup on a contoured mold. The system is designed to handle several different prepreg materials and can manufacture products of different forms. The layup concept for large products developed within the Lowflip project also holds the possibility for high versatility. The use of large industrial robots 
mounted on linear axes and that grip the prepreg tape at the outer edges provides good ability to adapt to different mold shapes as well as different ply shapes and sizes. However, layup of small plies might be difficult to realize while gripping at the outer edges. The Lowflip system for large parts, just as the system presented by Newell, Buckingham and Khodabandehloo, has separated the tasks of layup and consolidation between different robots, making it possible to gradually attach the prepreg plies to the mold. The gradual approach, used for layup on a contoured mold in these two cases, can simplify the design of the end effectors used for the layup. The end effectors do not have to transform the prepreg ply into the exact shape of the mold at once, as is required in the Lowflip system for small products. The system for 2D layup presented by Curran et al. acknowledges the need to be able to handle a multitude of ply shapes, and has a simple solution to achieve this by dividing the end effector surface into different zones that can be turned on and off to correspond with the required ply shape. The system is designed to handle prepreg without protective foils and backing paper, and therefore exhibits the problem that the prepreg can tack to the end effector surface. Forcing the prepreg to release from the end effector involves the risk of distorting the prepreg. The system presented by Newell, Buckingham and Khodabandehloo removes this issue by handling the UD prepreg with backing paper attached. However, it conveys a need for a removal process after layup.

\subsection{REQUIREMENTS AND CHALLENGES}

Layup of prepreg must follow a range of quality requirements. The plies must be stacked in the correct sequence, and there are specifications on gaps and overlaps between prepreg plies as well as the position and the orientation of the plies [3,67-71]. There are also requirements on fiber orientation; $\pm 2^{\circ}$ or $\pm 3^{\circ}$ fiber orientation deviation compared to the drawing nominal $[16,67]$ are accepted. Wrinkles and bridging are not allowed, however the requirements for wrinkles are usually not well defined and are therefore open for interpretation [67,71]. Contamination must be avoided and no foreign objects, for example pieces of backing paper or plastic film, are allowed to be included in the layup $[68,67,71,73]$. There are also requirements governing the environment in which the layup should take place, for example specifying temperature, humidity and particles in the air $[67,73]$. There are time requirements for how long the prepreg is allowed to be stored and handled at room temperature before it must be discarded, usually measured in days [67]. The quality requirements listed above influence the design of pick-andplace solutions. There are also other challenges that have been highlighted in the literature to affect the design of automated layup using a pick-and-place approach. The material properties of prepreg with low structural rigidity and a tacky surface are particularly challenging for automated layup systems [69,122]. The level of tack is dependent on temperature and the age of the material as well as on relative humidity in the air during aging, and the level can differ between the two sides of a prepreg ply [64]. The dependencies between tack and other parameters are complex. In addition to the tack, the shear and bending behavior of a prepreg also have an effect on prepreg layup [62]. Furthermore, a system for the automated layup of prepreg must cater to a wide range of ply shapes and sizes [69]. More details on the challenges that have been presented in the literature can be found in Paper VI and VII. 


\subsection{Alternative AUTOMATION APPROACHES}

Examples of automated solutions other than ATL, AFP and pick and place are scarce, but a few can be identified. One interesting solution is called bandaging. This process, described by Oberfranz [137] and Sarh et al. [83], was developed to manufacture stiffeners for large skins by using a robot to wrap prepreg on aluminum mandrels and fold them in a separate automated step to form a cuboid with one open side. This process was introduced at Airbus in the mid-1980s [83,137].

Another two-step approach to automated layup is presented by Elkington [75], who in his doctorial thesis describes a method developed for the automated layup of woven carbon fiber prepreg material. The process starts with pre-shearing the prepreg using a press. The pre-sheared prepreg is moved to the mold, where the pre-shearing process has generated a good fit to the mold geometry. In the following step, called final layup, a robot equipped with rollers and a wedge-shaped pressing tool successively tacks the prepreg in place following an established sequence that avoids double constraints and other deficiencies. The sequence, based on previous experience of manual layup as well as on simulations, was developed in an iterative way during a series of physical layup tests. In this process, with pre-shearing and final layup using a standard robot, prepreg plies are intended to be added one by one. The material handling required is excluded, however, as Elkington's dissertation focuses on the development of the pre-shearing and final layup processes. [75] 


\section{DEMONSTRATORS}

This chapter introduces the four demonstrators that have been used to explore the research aim presented in the introduction. The demonstrators' context, as well as enabling methods and enabling technologies for each demonstrator, are briefly presented. The research results stemming from the development and testing of the demonstrators are provided in Chapter 6 


\subsection{RESEARCH PROJECTS AND DEMONSTRATORS}

The four demonstrators presented in this chapter have all been developed as part of either a specific research project or a subsection, in this case work package, of a research project. The research projects and work packages have been united by the aim to explore different aspects of automated manufacturing of composite parts using prepreg material, and through the use of a demonstrator-centered research approach. The same industrial partner has been engaged in the development of all the demonstrators. Each research project has had several participating partners, for example research institutes, universities and companies that have cooperated in the development of the demonstrators. The workload has been divided among the partners, and different enabling technologies or methods have been developed and tested separately before being integrated into the complete manufacturing cell, the demonstrator, for final testing. One of the demonstrators is a conceptual demonstrator that has not been realized as a complete manufacturing cell. Instead, the enabling methods and technologies have been tested separately. The four demonstrators are summarized in Table 7 and presented in detail in the coming chapters.

Table 7: Summary of the four demonstrators presented in the thesis.

\begin{tabular}{|l|l|l|l|l|}
\cline { 2 - 5 } \multicolumn{1}{c|}{} & Demonstrator 1 & Demonstrator 2 & Demonstrator 3 & Demonstrator 4 \\
\hline $\begin{array}{l}\text { Manufacturing } \\
\text { process }\end{array}$ & Prepreg layup & $\begin{array}{l}\text { Complete } \\
\text { manufacturing of } \\
\text { assembled } \\
\text { prepreg structure }\end{array}$ & $\begin{array}{l}\text { Layup and } \\
\text { forming of } \\
\text { prepreg }\end{array}$ & Prepreg layup \\
\hline Material & Prepreg & Prepreg & Prepreg & Prepreg \\
\hline Input & Cut prepreg plies & Prepreg on roll & Cut prepreg plies & Prepreg on roll \\
\hline Output & Flat laminate & $\begin{array}{l}\text { Assembled } \\
\text { structure for co- } \\
\text { curing }\end{array}$ & $\begin{array}{l}\text { Formed } \Omega \text { - } \\
\text { shaped beam }\end{array}$ & Flat laminate \\
\hline $\begin{array}{l}\text { Enabling } \\
\text { methods \& } \\
\text { technology }\end{array}$ & $\begin{array}{l}\text { Prepreg layup } \\
\text { Backing paper }\end{array}$ & $\begin{array}{l}\text { Ply cutting } \\
\text { Prepreg layup } \\
\text { Backing paper } \\
\text { removal } \\
\text { Robot forming } \\
\text { Automated } \\
\text { assembly }\end{array}$ & $\begin{array}{l}\text { Prepreg layup } \\
\text { Backing paper } \\
\text { removal } \\
\text { Robot forming }\end{array}$ & $\begin{array}{l}\text { Prepreg layup } \\
\text { Backing paper } \\
\text { removal }\end{array}$ \\
\hline Industry & Aerospace & Aerospace & Aerospace & Aerospace \\
\hline
\end{tabular}

The four demonstrators target manufacturing operations using prepreg materials, and they share the same industrial challenge. This challenge can be comprehensively described as a need to lower the costs for manufacturing operations where wellestablished automation solutions, such as ATL and AFP, are either not possible to use due to technical limitations, or where they do not provide a cost-effective solution for the manufacturing, and where a high degree of manual work is therefore required. The aim is to reduce manufacturing cost in order to retain manufacturing operations in highwage countries. Figure 30 illustrates when each demonstrator was developed. It can be noted that the demonstrators have been developed in sequential order and partly in 
parallel. Many of the experiences from the early demonstrators have been transferred to later ones, gradually refining and improving some of the enabling methods and technologies, and at the same time adding unique challenges, for example by having different demonstrator products in each demonstrator. In working with the first demonstrators, much effort has also been put into exploring the state of the art in the field of automated manufacturing of composite components using prepreg; automated prepreg layup and forming of prepreg laminates in particular have been studied. In connection with Demonstrator 1, a study was undertaken to explore the quality requirements and the need for validation and qualification of changes made in a manufacturing system for automated composite manufacturing within the aerospace industry. The study, presented in Paper I, involved companies in addition to the industrial partner to provide a wider perspective of the area. The result from this study serves as an important background for the development of all the demonstrators.

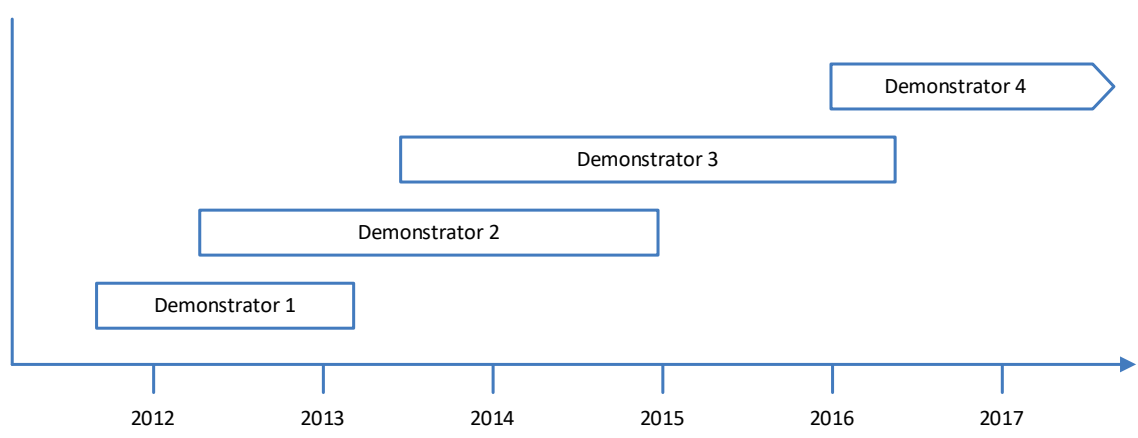

Figure 30: A timeline showing the four demonstrators presented in this thesis.

\subsection{DEMONSTRATOR 1: A CONCEPTUAL DEMONSTRATOR FOR THE LAYUP OF FLAT PREPREG LAMINATES}

This is a conceptual demonstrator that outlines a manufacturing cell for the automated layup of flat prepreg laminates. It includes the steps "automated pick and place of prepreg plies" and "separation and removal of prepreg backing paper." The input to the demonstrator is cut prepreg plies that can be placed on a cutting machine table or another flat surface. The desired output is flat laminates, consisting of several layers of prepreg plies, ready for forming to beams with rectangular cross-section in a subsequent process. The prepreg is an aerospace-grade material with unidirectional carbon fibers embedded in a thermoset polymer matrix. The demonstrator product, i.e. the flat laminate, is today laid up manually due to geometry that makes it impossible to lay up using ATL equipment. In a subsequent forming step, two flat laminates are formed into a rectangular beam. Studies have shown that layup of the rectangular-shaped beam directly on a mold using AFP is possible, but is not a cost-effective solution. Therefore, the automated layup of flat laminates using an industrial robot and the subsequent forming is considered an interesting alternative to explore. The scope of the 
demonstrator and an illustration of how the conceptual demonstrator might be realized are presented in Figures 31 and 32.

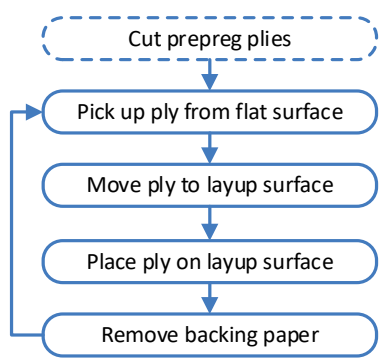

Figure 31: A flowchart showing the scope of Demonstrator 1.
Cutting machine

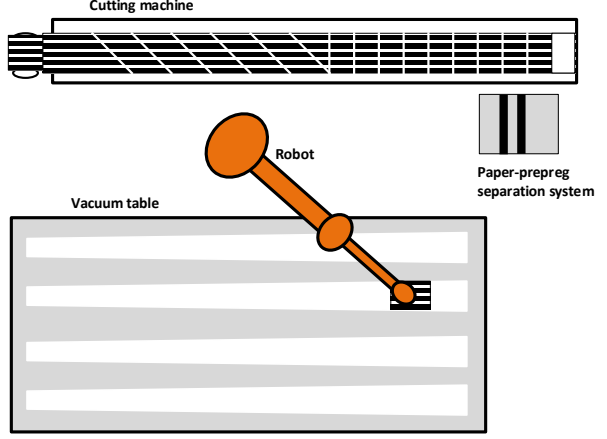

Figure 32: An illustration of how the conceptual demonstrator might be realized as a physical manufacturing cell. Originally published in [6].

The conceptual demonstrator is used to identify what enabling methods and technologies are required to automate the layup process, i.e. the key enabling methods and technologies. It is concluded that end effectors that can handle a limited ply book need to be developed, and because the automated handling of prepreg is simplified by keeping the backing paper attached to the prepreg during handling, methods and technologies for automated removal of backing paper need to be developed. An end effector for the layup of prepreg and hardware to remove the backing paper are developed and tested but the developed solutions are tested separately, not as a complete system, and therefore this demonstrator is considered a conceptual demonstrator. The author and the industrial partner defined the demonstrator concept, identified key enabling methods and technologies and developed them in close cooperation. A prototype end effector for the layup of prepreg plies with an integrated gripper used for removing the backing paper was designed and realized in a student project. The project was based on specifications developed by the author and the industrial partner, and was supervised by the industrial partner. The prototype is shown in Figure 33.

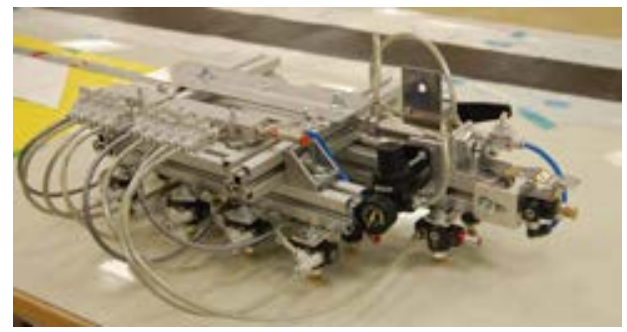

Figure 33: Prototype gripper for the handling of prepreg plies and the layup of a flat prepreg laminate, developed in Demonstrator 1. Picture reprinted from [138]. 


\subsection{DEMONSTRATOR 2: A MANUFACTURING CELL FOR LAYUP, FORMING AND AUTOMATED ASSEMBLY OF COMPONENTS}

The second demonstrator is an automated cell that is capable of manufacturing a Ushaped beam and assembling it with a number of other components made from uncured prepreg material. The input is prepreg on a roll and components for the assembly operation. The output is an assembled structure ready for the cure assembly followed by curing in an autoclave. The prepreg is an aerospace-grade prepreg with unidirectional carbon fibers embedded in a thermoset polymer matrix. The demonstrator includes automated cutting and layup of prepreg plies and removal of backing paper using a robot. The flat layup is formed to the U-shape using a second robot. The beam is then assembled with the other components. However, some manual intervention is required during the assembly. The scope of the demonstrator is illustrated in Figure 34.

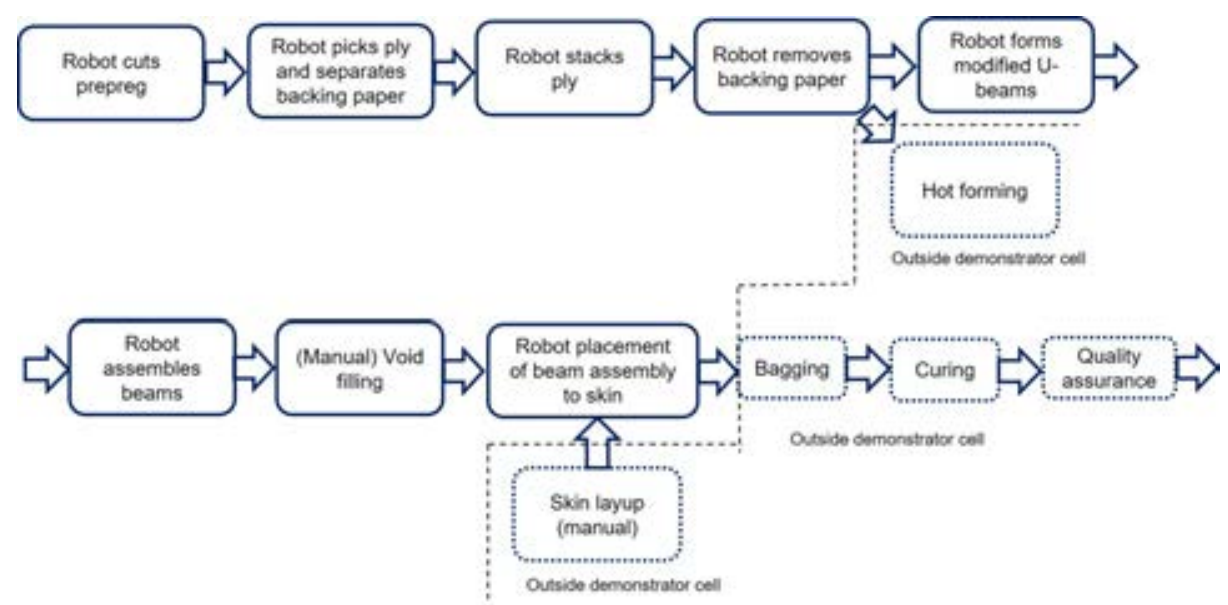

Figure 34: The scope of Demonstrator 2. Figure reprinted from Paper IV.

In order to realize the demonstrator (illustrated in Figure 35), enabling methods and technology for robot cutting were developed. The methods and technology for the automated layup of a flat laminate and removal of the backing paper used in Demonstrator 1 were further refined and implemented in the demonstrator. This included the development of a new end effector for handling the prepreg plies, shown in Figure 36. Also developed were methods and technology for forming the U-shaped beam and for the assembly process. 


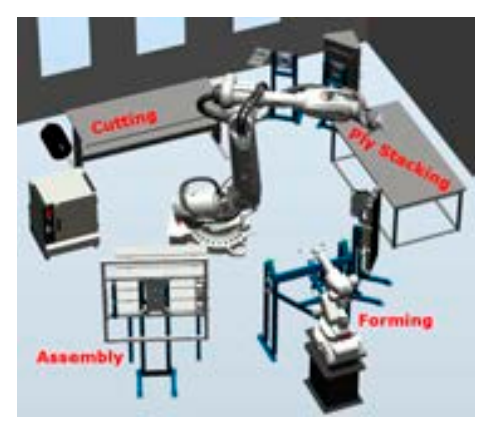

Figure 35: The layout of Demonstrator 2.

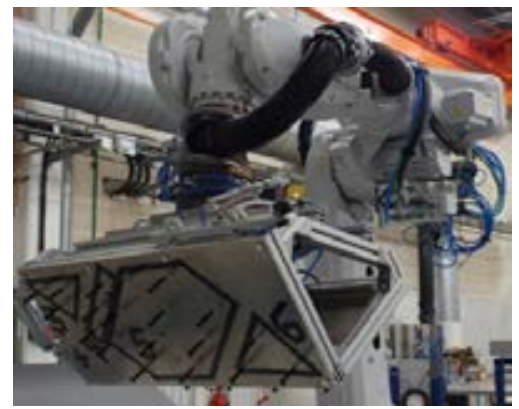

Figure 36: The end effector developed for automated layup of prepreg plies. Figure originally published in Paper IV.

One research partner was responsible for the demonstrator realization and for developing all the enabling technologies and methods apart from the method and technology used for the forming. They were developed by the same team that had previously developed robot forming of a U-shaped spar with a recess area that is described in [81]. The author was not actively involved in the development of the demonstrator, but followed the work and analyzed the outcome together with the research partners that developed the demonstrator.

\subsection{DEMONSTRATOR 3: A MANUFACTURING CELL FOR PREPREG LAYUP AND FORMING OF A $\Omega$-SHAPED BEAM}

The third demonstrator is a manufacturing cell that lays up a flat prepreg laminate using two robots equipped with different types of end effectors and forms the flat laminate to a $\Omega$-shaped beam using one of the robots. The input to the cell is cut prepreg plies, while the output is an uncured $\Omega$-shaped beam. The prepreg is an aerospace-grade prepreg material with UD carbon fibers embedded in a thermoset polymer matrix. The scope of the demonstrator along with an illustration of the beam are shown in Figures 37 and 38. A product, similar to the demonstrator product, is today manufactured using manual layup and forming. In the manual operation, thin laminates are laid up and sequentially formed on the mold in a repeating process until the desired thickness of the beam has been achieved. The reason to not lay up and form one laminate with the full thickness is that forming a thick laminate requires a higher force than is suitable for manual forming. It is not possible to lay up the prepreg directly on the mold using ATL or AFP solutions due to the internal radii at the flange of the beam. Automated layup of the flat laminates using ATL is technically possible, but it is not considered a cost-effective solution for the layup of the thin laminates. 


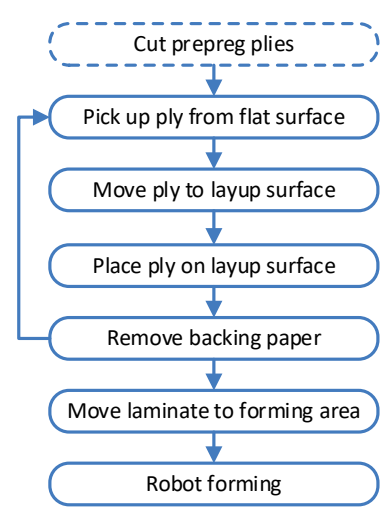

Figure 37: The scope of

Demonstrator 3. The layup task is divided between two robots.

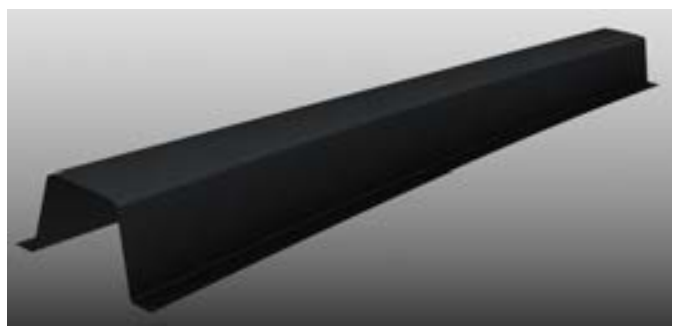

Figure 38: An illustration of the demonstrator product. Picture reprinted from Paper V.

Two different end effectors (shown in Figure 39) have been developed to explore two different concepts on how to design end effectors that can handle a multitude of ply shapes and sizes and that can easily incorporate new ply shapes. The development of the two end effectors has been based on experiences gained from earlier demonstrators, and the method and technology for removal of the backing paper are the same as in previous demonstrators. In addition to the end effectors and the equipment used for the removal of the backing paper, a vacuum table was developed to hold the prepreg plies in place during layup and backing paper removal. The method and technology required for forming the beam have been developed based on experiences from the second demonstrator, but using a slightly different approach. The transfer of the laminate from the vacuum table to the mold was performed manually.

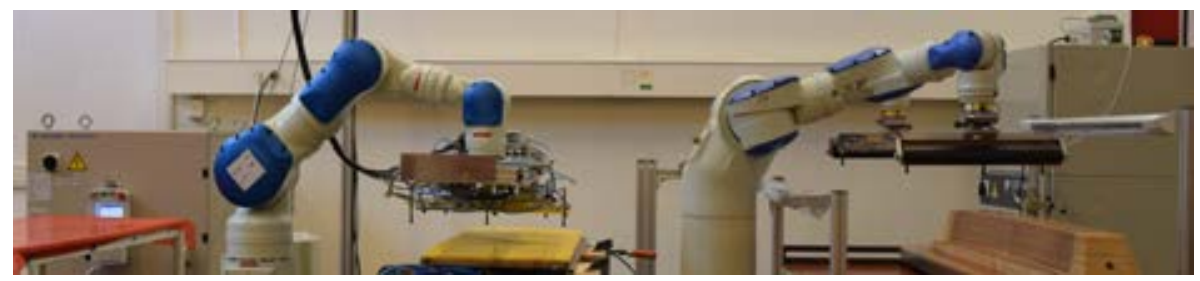

Figure 39: The layout of Demonstrator 3 showing the two types of end effectors used for the layup of prepreg plies.

The author acted as project manager for the demonstrator and was responsible for the development, realization and testing of the demonstrator. The development of the methods and technology for robot forming was made in very close collaboration with the industrial partner, and different concepts for robot forming were explored in student projects supervised by the author. One of the end effectors (that used a single-arm robot), along with the heating system used for forming, were developed by the research partner that was responsible for the realization of Demonstrator 2. The dual-arm solution for prepreg layup was the result of a student project specified and supervised by the author. 


\subsection{DEMONSTRATOR 4: A MANUFACTURING CELL FOR LAYUP OF FLAT LAMINATES}

This demonstrator is a manufacturing cell for the layup of flat prepreg laminates. The scope is similar to Demonstrator 1, and the two demonstrators target manufacturing of the same type of products. Demonstrator 4 is part of an ongoing research project, and the development of the demonstrator is in the early stages of the realization phase. The input to the demonstrator is aerospace-grade UD prepreg with carbon fibers embedded in a thermoset matrix. The output is a flat laminate that can be formed to a beam in a subsequent forming operation. Vacuum forming of this type of geometry is considered a well-known method, and is therefore not included in the demonstrator. Just as for Demonstrator 1, a similar flat laminate is today laid up manually due to the geometry that makes it impossible to lay up using ATL equipment, and studies have shown that layup directly on a mold using AFP is not a cost-effective solution. The scope of the demonstrator is illustrated in Figure 40.

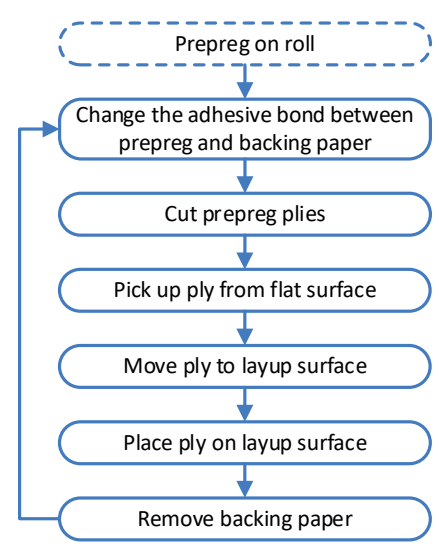

Figure 40: The scope of Demonstrator 4.

The main focus of this demonstrator is to develop alternative methods and technologies for automated removal of backing paper to the solution that has been tested in the previous three demonstrators. The method for handling the cut plies is similar to that used in previous demonstrators, but a new end effector that suits the plies required for this particular demonstrator product is developed. The demonstrator includes robot cutting, which was omitted in Demonstrator 1, and the cutting of plies is realized using the same methods and technologies used in Demonstrator 2. The author has been involved in the development of the demonstrator concept and the development of methods and technologies for removing the backing paper together with other research partners and the industrial partner. The author specified and supervised a bachelor's thesis that developed and tested a prototype for the removal of backing paper. 


\subsection{CONNECTION BETWEEN THE DEMONSTRATORS AND APPENDED PAPERS}

The research results presented in the coming chapters, as well as most of the appended papers, are based on experiences and results from the development of the demonstrators. The connections between the papers and the demonstrators are outlined in Table 8 . In the appended papers, as well as in this thesis, only a few aspects, e.g. enabling methods and technologies and demonstrator context, are reported. The descriptions above, however, aim to present the full scope of each demonstrator as it puts the developed methods and technologies in context and provides an understanding of the system aspects.

Table 8: The connection between the demonstrators and the appended papers.

\begin{tabular}{|l|l|l|l|l|l|l|l|}
\hline & Paper I & Paper II & Paper III & Paper IV & Paper V & Paper VI & $\begin{array}{l}\text { Paper } \\
\text { VII }\end{array}$ \\
\hline Demo. 1 & & & & & & & \\
\hline Demo. 2 & & & & & & & \\
\hline Demo. 3 & & & & & & & \\
\hline Demo. 4 & & & & & & & \\
\hline
\end{tabular}

Paper I explores the connection between changes to manufacturing systems for composite components and the need for product and process validation. It is based on the work done in the definition phase of Demonstrator 1 and provides an understanding of the context that the demonstrators are developed in, both in terms of validation and more general quality requirements within the aerospace industry. It also provides a background to the current manufacturing practices within the Swedish aerospace industry. Paper II presents Demonstrator 1 as well as details on the automated removal of backing paper. Paper III explores some aspects that affect the ability to use standard, off-the-shelf technology to automate composite manufacturing, and is based on the development of Demonstrator 1 and two other demonstrators that have been omitted from the thesis since they do not cover automated manufacturing processes using prepreg. (More information about the two omitted demonstrators can be found in $[6,139,140]$.) Papers IV and VI compare methods and technologies for automated prepreg layup that were developed in Demonstrators 2 and 3 (Paper IV) and Demonstrators 1-3 (Paper VI). The development of methods and technology for robot forming in Demonstrator 3 are presented in Paper V. The last publication, Paper VII, is not directly linked to results from any of the demonstrators. Instead, it provides a review of the area of automated handling of composite materials. As all of the demonstrators involve automated handling of prepreg, it provides an important understanding of potential challenges to automate this type of operation. It also contributes insight into how other researchers and companies have solved automated handling of different types of materials used for the manufacturing of composite products. Demonstrator 4 is still under development in an ongoing research project, and therefore no papers have been published based on the research connected to the demonstrator. However, the 
demonstrator provides some interesting data, which is presented and discussed within this thesis. 


\section{ENABLING METHODS AND TECHNOLOGIES}

In this chapter, the results from the development and testing of the four demonstrators are presented. The chapter starts with a resume and analysis of published information in the area of automated manufacturing using prepreg material and an account of the current manufacturing practices of the industrial partner. $\delta m$ e important commonalities between the information gathered from studies of the industrial partner's current manufacturing operations and published material in the area are highlighted. This is followed by an in-depth account of the quality requirements that apply to automated manufacturing systems such as the four demonstrators. The key enabling methods and technologies that have been identified by analyzing the four demonstrators are presented. Thereafter follows extensive in-depth presentations of the enabling methods and technologies developed for the four demonstrators. The chapter is concluded by presenting some important challenges that affect the development of automated manufacturing solutions for CFRP products made from prepreg, along with some general reflections on the developed methods and technologies. 


\subsection{THE CURRENT USE OF AUTOMATED SOLUTIONS}

Sections 4.4-4.10 provided a theoretical foundation on the use of automated solutions for the manufacturing of polymer fiber composite products made from prepreg based on broad literature reviews. It is, of course, highly interesting to compare the findings from published research papers, books and reports with the observations made while collaborating with the industrial partner involved in the development of the four demonstrators and through studying its current manufacturing practices. Below follows a short resume and analysis of the information presented in Sections 4.4-4.10. Thereafter follows a presentation of the industrial partner's current manufacturing operations, use of automated solutions and expressed views on the future development of automation. Additional descriptions of the industrial partner's manufacturing operations, prerequisites and interests in automated manufacturing can be found in Paper I and in $[6,141]$. The presentation of the current manufacturing operations also aims to provide a richer context to the environment that the demonstrators are targeted to be implemented in. The section is concluded by highlighting some important commonalities between the findings from the literature reviews and the empirical findings that originate from the collaboration with the industrial partner.

\subsubsection{SUMMARY AND ANALYSIS OF THE THEORETICAL FINDINGS}

The largest portion of CFRPs in primary aircraft structures is manufactured using layup methods for UD prepreg. Prepreg can either be laid up directly onto a contoured mold, or to a flat laminate that is formed in a subsequent forming operation. For forming flat laminates, vacuum forming and HDF are commonly used forming methods. Alternative methods such as robot forming and glide forming have been developed in research projects, but have yet to see industrial implementation. For automated layup there are two dominant methods, ATL and AFP, and they are frequently employed within the aerospace sector. However, ATL and AFP have limitations in terms of complexity and there is a group of products for which ATL and AFP cannot be used due to technical limitations. The possible productivity in terms of laydown rate for ATL and AFP is highly dependent on the geometry of a product. Large parts with uncomplicated shape provide an excellent case for ATL or AFP, whereas small, complex products yield a low output rate. The combination of high investment costs and low output can make these types of products unsuitable for ATL or AFP layup due to cost considerations, although technically possible to manufacture. A number of products where layup using ATL or AFP is unsuitable can be identified, for example spars, ribs and brackets. Much development work and research effort seem to be directed toward further developing the capabilities of ATL and AFP. However, as the two dominant methods for layup become more mature, it seems that the development of alternative solutions, for example pickand-place systems for prepreg layup, are attracting attention. So far, very few systems using the pick-and-place approach for prepreg layup have been developed and implemented. Almost all the systems that have been reviewed have been developed as part of research projects (with the exception of the Hexcel system presented in Section 4.8), and few systems have made the transition from a research project to implementation in a manufacturing environment. The developed pick-and-place systems have exhibited limited capabilities to handle complex geometries and suffered from low 
output and technical barriers, in some cases due to the lack of efficient end effectors for prepreg handling. Due to the limited automation alternatives, manual layup of prepreg is common.

\subsubsection{THE INDUSTRIAL PARTNER'S MANUFACTURING OPERATIONS}

An important part of developing a demonstrator is, as described in Section 2.5, to explore the industrial setting and to identify the industrial challenge. The same industrial partner has been engaged in all of the four demonstrators described in this thesis, and its current manufacturing practices have been explored to provide insight into the industrial context as well as to form an understanding of the industrial challenge. In particular, studies of different areas of the current composite manufacturing operations have been performed during the development of Demonstrators 1 and 3. The current manufacturing practices have been studied by means of interviews, on-site observations and studies of technical documentation such as drawings and manufacturing instructions. Below follows an account of the industrial partner's current manufacturing operations for manufacturing CFRP parts made from prepreg.

The industrial partner engaged in the development of the four demonstrators is a largesized Swedish enterprise in the aerospace and defense sector. The company's composite manufacturing operations manufacture the company's own products, but many of the composite products are manufactured for external customers. The company is a tier 1 partner that supplies parts directly to major manufacturers of civil aircraft. Some of the manufactured products are designed in collaboration with the final customer, while others are built directly to customer specifications. The company focuses on the manufacturing of integrated structures, for example wing structures and doors. For these products, the manufacturing rate can range from a few to around 25 products per week.

The composite workshop is equipped with an ATL that is used to lay up large parts with simple geometry directly on a mold or to lay up flat laminates. For many products that are laid up using the ATL machine, each layer must be manually inspected before the next layer can be laid up. This requires an operator to interrupt the layup process to be able to perform the inspection. Flat laminates that are laid up using ATL are formed using well-established forming methods, for example HDF. For products that do not utilize ALT layup, prepreg plies are cut in automated cutting machines and laid up manually. The automated cutting machines rely heavily on manual labor as all material handling, both before and after the cutting process, is manual. Table 9 lists all the operations required to cut plies using the cutting machines and shows if they are made manually or through automation. It is interesting to note that out of all the required operations, the only value-adding operation is the ply cutting. 
Table 9: The operations performed to cut plies using an automated cutting machine. Table from [6].

\begin{tabular}{|l|l|l|}
\hline Operation & $\begin{array}{l}\text { Manual } \\
\text { task }\end{array}$ & $\begin{array}{l}\text { Automated } \\
\text { task }\end{array}$ \\
\hline Cover cutting table with protective plastic film & & \\
\hline Put prepreg roll in cutting machine & & \\
\hline Pull out material on cutting surface & & \\
\hline Load program and find the start point & & \\
\hline Cut plies & & \\
\hline Label plies & & \\
\hline Remove cut plies, sort and place on material carrier & & \\
\hline Cut off and remove scrap material & & \\
\hline
\end{tabular}

The plies, cut in the automated cutting process, are either laid up one by one directly on contoured molds or laid up to form flat laminates that are formed using vacuum forming, HDF or sequential forming. An example of manual layup of flat laminates, in combination with vacuum forming, is the manufacturing of four beams with rectangular cross-section for which Demonstrator 1 targets to automate the layup. A time study of the current manufacturing practice reveals that much of the total time required to transform cut prepreg plies to the beams is used for manual layup. The total time for layup and vacuum forming found in Table 10 includes the time for all the manual operations performed to transform a sorted pile of prepreg plies to a beam with a rectangular cross-section. However, the times in Table 10 do not include the hold time, i.e. the wait time when a vacuum is maintained, which is a large part of the process time in a vacuum forming process. During the hold time, the operator performs other tasks related to the layup and forming.

Table 10: Fraction of manual layup in relation to total time for manufacturing beams. Table from [6].

\begin{tabular}{|l|l|l|l|}
\hline Beam & $\begin{array}{l}\text { Total time for layup and } \\
\text { vacuum forming [min] }\end{array}$ & $\begin{array}{l}\text { Time spent on } \\
\text { manual layup [min] }\end{array}$ & $\begin{array}{l}\text { Fraction of manual layup in } \\
\text { relation to total time [\%] }\end{array}$ \\
\hline A & 31 & 20,5 & 66 \\
\hline B & 32 & 21,5 & 67 \\
\hline C & 40,5 & 23 & 57 \\
\hline D & 52,5 & 34,5 & 66 \\
\hline
\end{tabular}

Vacuum forming is a process that requires little manual effort. The layup of flat laminates therefore represents a large part of the total manufacturing time in a process that combines manual layup and vacuum forming. For products that are manufactured using a combination of manual layup of flat laminates and manual sequential forming, the time spent on the layup represents a lower fraction of the total time. However, in these cases a lot of manual labor is also spent on manual ply handling in order to lay up flat laminates. 
Observations of the current manufacturing practices and interviews with manufacturing engineers have identified a number of products that cannot be laid up directly on the mold using ATL, due to a combination of complex product shape and the technical limitations of ATL machines presented in Section 4.5. Also, examples of products where the ATL layup of flat laminates is technically possible, but where it is not considered to be a cost-effective solution, have been identified.

As many of the manufactured products are integrated complex structures, they consist of several parts that can be manufactured using different manufacturing methods, as illustrated in Figure 41. The parts are assembled before the cure assembly and then cured together to generate an integrated, co-cured structure. The manufacturing volume of the final co-cured product might range from 3-25 per week. Each co-cured structure consists of a number of parts, and when it comes to beams and ribs that provide stiffness and strength, these parts are in many cases so similar that they are manufactured using the same manufacturing methods. For example, a co-cured structure might contain four very similar beams manufactured using the same manufacturing method, which means that the manufacturing volume of the beams is four times the output of the final product.

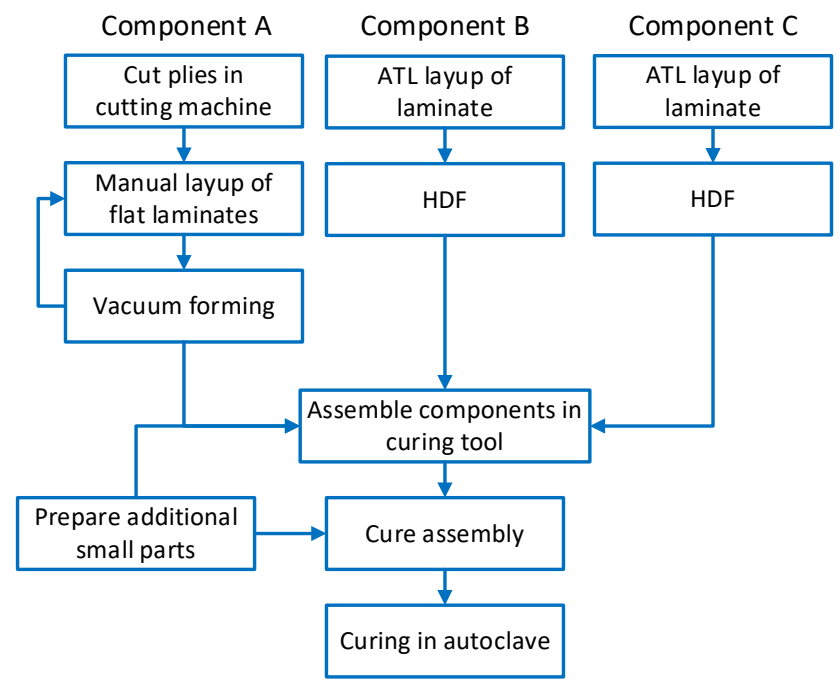

Figure 41: Flowchart showing the manufacturing of an integrated structure and the parts that it consists of.

The cure assembly process is completely manual and requires extensive handling of auxiliary materials. The curing takes place in large autoclaves, where it is possible to control the temperature and pressure. A number of products are cured together using the same cure cycle. Non-destructive testing (NDT), secondary processing such as machining, surface treatment and final assembly are not done in the composite workshop, but in other workshops within the company.

The industrial partner expresses a clear desire to develop automated solutions that can provide cost-effective alternatives to ATL and manual operations. The aim expressed by 
the industrial partner is to reduce the level of manual labor without having to invest in very expensive equipment. Improvement in cycle time and throughput time are considered secondary to the reduction of manual labor.

To conclude, an analysis of the current manufacturing operations discloses a high level of manual material handling, in particular handling of prepreg plies during ply cutting and layup directly on molds or layup of flat laminates that are formed in subsequent forming operations. Vacuum forming and HDF are used to form flat laminates, if possible, but some products have shapes that are too complex for these forming methods. For these products, sequential forming or layup directly on mold is applied. A high level of manual handling of auxiliary materials is also noted in the current manufacturing operations. Additional details on the industrial partner's manufacturing operations can be found in Paper I and in $[6,141]$.

\subsubsection{COMmunalities}

When comparing the data gathered from studies of the industrial partner's current manufacturing operations (presented in Section 6.1.2) to published material in the area, several important commonalities can be found. The use of manufacturing methods, in particular the use of automated manufacturing methods, as well as expressed interest for further development of automated manufacturing seem to, on a general level, correspond between the empirical data and data published in the literature. Some commonalities are presented below:

- ATL and AFP are viewed as well-established methods for prepreg layup directly on a mold and also to lay up flat laminates for forming, using either vacuum forming or HDF.

- Manual layup is used where automated technologies are not possible to use due to technical limitations, or where they do not provide a cost-effective solution due to low laydown rates in combination with high investment costs.

- It is possible to identify a set of products that are manufactured in low-to-medium volumes where today's automated solutions are not suitable, but are interesting to manufacture in an automated fashion.

- There is an expressed interest in finding automated solutions that can complement ATL and AFP, and which are suitable for manufacturing products with complex shapes that are manufactured in low and medium volumes.

\subsection{QUALITY REQUIREMENTS}

When using a demonstrator-centered research approach it is important to establish specifications and evaluation criteria to be able to evaluate the demonstrators. As presented in Section 4.9, the aerospace industry adheres to very strict quality requirements. The quality requirements naturally affect the specifications and evaluation criteria of a demonstrator, and therefore the quality requirements have been studied in detail. Below follows an account of quality requirements that apply to the manufacturing of CFRP aircraft parts made from prepreg, and that have been identified by means of interviews with industrial experts and observations of the industrial partner's current 
manufacturing operations. Many of the quality requirements that have been identified while working together with the industrial partner are the same type of requirements that were presented in the theoretical framework in Section 4.9. For manufacturing operations using prepreg materials, the requirements differ slightly depending on application and the final customer, but general requirements can be described as:

- Manufacturing processes are not allowed to contaminate the prepreg or to add any foreign objects, i.e. FOD must be avoided.

- The stacking sequence of the plies must be exactly the same as is specified on the drawing or in the working instructions.

- The positional accuracy is, in most cases, determined by the requirements on gap and overlap. For UD prepreg, no overlap is allowed between two adjacent plies and the largest allowable gap between two adjacent plies is approximately $2.5 \mathrm{~mm}$, as illustrated in Figure 42.

- In many cases, the position of the ply outline has a wide tolerance as many laminates and parts are laid up using plies that are slightly larger than the size of the final part. In these cases, the outline of the laminate or part is trimmed to the final form after layup. As long as all plies extend over the outline of the final part and conform to the requirements on gap/overlap and fiber angle they are acceptable. This is illustrated to the right in Figure 42.

- For plies that are laid up to a net-mold size, i.e. where no trimming of the outline is done after layup, the ply positions in relation to the outer edges are specified on the drawings and working instructions. They are generally comparable with the tolerance for gap.

- Fiber angle deviations are, as previously noted, difficult to measure but a common requirement on the deviation is less then $\pm 3^{\circ}$ measured on distances shorter than approximately $300 \mathrm{~mm}$, and $\pm 2^{\circ}$ measured on longer distances.

- Bridging and wrinkles are not allowed. However, there are different types of wrinkles as well as different interpretations on what constitutes a wrinkle. A common division is in-plane and out-of-plane wrinkles, and in-plane wrinkles are difficult to assess.

- For out-of-plane wrinkles, a crease that is less than a ply thick is in some cases not considered to be a wrinkle.
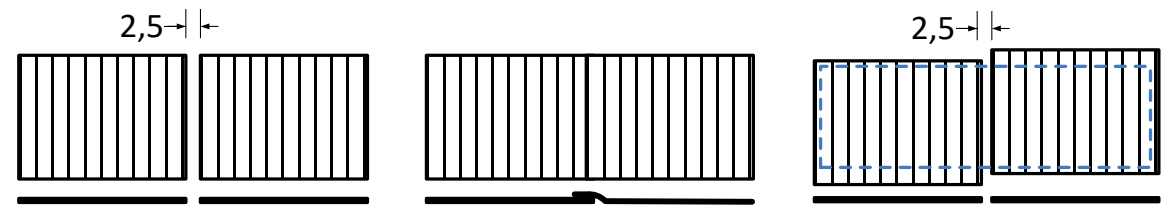

Figure 42: Acceptable gap, that is less than $2.5 \mathrm{~mm}$. Center: Overlap, not acceptable for UD prepreg. Right: Acceptable ply positions, as both plies cover the dashed blue outline of the final laminate and the gap is less than $2.5 \mathrm{~mm}$.

There are also requirements on the conditions in which the manufacturing takes place and the age of the prepreg. The general quality requirements are strict, and the level of 
inspections and quality controls during manufacturing and of the final products are set based on the risk of non-conformance as well as the type of product. Inspection levels are high, and in many cases $100 \%$ of the products are subject to inspection using for example nondestructive testing methods such as ultrasonic inspection.

For the manufacturing steps taken before a composite product has cured, the process parameters and the manufacturing methods have great impact on the quality of the final product. Processes and procedures are therefore described in detail in manufacturing specifications, along with the correct process parameters. The manufacturing specifications are generally developed in parallel with the development of a new product and are validated as part of the validation of a new product. Once a product has completed the validation process, the manufacturing specifications are fixed. After this, the manufacturing specifications are not allowed to be altered without a formal change procedure that often includes some sort of renewed validation. The extent of a validation process depends on the type of change and can range from a small theoretical study to a renewed product validation, which is a time and resource-consuming endeavor. For major changes, the final customer is involved. All change proposals for established manufacturing methods must be reviewed in great detail. Two seemingly similar change requests can imply very different effects on product quality, and therefore require very different levels of validation. The extent of a validation is determined by a number of factors, for example if the change affects the form or function of the final product, if it concerns a well-known material or manufacturing process, if it is temporary or permanent and to what extent the change affects the final product. The demand for validation and testing is generally high when it is hard to detect the undesired results of a change. In general, it is simpler to validate changes in areas where the company has a lot of experience than for new technologies or methods. The formal handling of change requests, as well as the requirements for validation of new products, are based on customer as well as legislative requirements. The strict requirements on validation makes the introduction of new manufacturing technology and manufacturing methods a complex and costly endeavor. More information on validation of changes to manufacturing methods or the introduction of new technologies or methods can be found in Paper I.

\subsection{KEY ENABLING METHODS AND TECHNOLOGIES IDENTIFIED}

The research questions, presented in Chapter 1, highlight how a very important part of the research presented in this thesis has been to identify key enabling methods and technologies required to enable the design of automated manufacturing systems for the manufacturing of complex CFRP products made from prepreg. In the presentation of the research approach in Section 2.5, enabling methods were presented as well-defined ways to perform a number of procedures and processes. An enabling method can, for example, describe how to remove protective backing paper from a ply. Enabling technologies were defined as the hardware that enables the method. It was also noted that some enabling methods and technologies can be considered off-the-shelf solutions that are readily available for implementation in an automated solution, while other methods and technologies require a substantial amount of research and development before they can 
be used in an automated manufacturing cell. These methods and technologies that require research and development work are referred to as key enabling methods and technologies. The use of demonstrators has provided an opportunity to analyze automated manufacturing systems for the manufacturing of complex products made from prepreg, and to identify and explore key enabling methods and technologies.

The demonstrators presented in Chapter 5 have somewhat different inputs and outputs, and therefore slightly different scopes. Demonstrators 1 and 3 have cut prepreg plies as their input, whereas Demonstrators 2 and 4 start from a roll of prepreg. For Demonstrators 1 and 4 the output from the demonstrator is a flat laminate, while in Demonstrator 3 it is a formed $\Omega$-shaped beam. In Demonstrator 2, a U-shaped beam is formed and assembled to a larger structure, which is the output from the demonstrator. However, the assembly of the large structure is described to provide the full scope of the demonstrator and is not a focus for the research presented in this thesis. The research presented herein considers all the steps that need to be taken to transform prepreg on a roll to a formed part using a two-step approach, where a flat laminate is laid up and then formed in a subsequent forming operation. The steps can be described as:

- ply cutting,

- layup of flat laminate, and

- forming of laminate

Ply cutting is a manufacturing step that today is commonly automated. Even in cases where layup and forming are done manually, ply cutting machines are common. As noted in Section 6.1.2, even though the actual cutting of prepreg plies is automated, the material handling associated with ply cutting is to a large extent manual. Clearing the cutting table from plies requires much manual labor. Based on access to off-the-shelf solutions for ply cutting, methods and technologies required to automate this step are not considered key enabling methods and technologies.

ATL and AFP machines can be used to lay up flat laminates, but as concluded in Section 6.1.1, low productivity for small laminates, in combination with high investment costs, can make them unsuitable for this operation. There are also technical limitations that can render them impossible to use for certain laminates. Automated layup of laminates using a pick-and-place approach have been explored as alternatives to ATL and AFP. Pick-and-place solutions have been developed in research projects, but there are few cases where they have seen industrial implementation, and there are no off-theshelf systems for layup using pick-and-place approaches that are suitable for the type of manufacturing that is the focus of this research. Methods and technologies for automated layup of flat laminates are therefore considered to be key enabling methods and technologies.

If automated solutions for the layup of flat laminates are designed so that they can pick prepreg plies from a cutting surface in a standard cutting machine, there is no need for extra methods or technologies for automated material handling of the plies in connection with the ply cutting process. The same goes for the automated handling of a finished 
laminate, specifically moving it from a layup area to the forming operation. It requires the same types of methods and technologies used for the layup of the laminate.

The development of methods and technologies required to lay up a flat laminate can, as indicated in Section 4.8 and shown in Section 6.4, be simplified by keeping the protective backing paper attached to the prepreg plies during the layup. In these cases, automated removal of the backing paper is necessary. Since this is a novel field were few examples can be found in the published literature, it requires the development of key enabling methods and technologies.

As concluded earlier in Section 6.1.1, vacuum forming and HDF are commonly employed methods for forming flat laminates, but they cannot be used for complex shapes, for example $\Omega$-shaped beams. Alternative forming methods for more complex shapes, e.g. robot-forming and glide forming, have been developed in research projects, but lack industrial implementations and cannot be considered off-the-shelf solutions. Although there are well-established alternatives, the forming of prepreg laminates is considered a key enabling method since the off-the-shelf alternatives are not applicable for complex-shaped products. It also requires key enabling technologies.

To conclude, the work with the four demonstrators has provided the opportunity to identify key enabling methods and technologies required to automate the manufacturing of complex CFRP products from prepreg. The key enabling methods and technologies are methods and technologies for:

- automated layup of prepreg plies to form a flat laminate,

- automated removal of backing paper, and

- automated forming of prepreg laminates.

Details on how these key enabling methods and technologies can be designed will be presented in the coming sections, starting with an in-depth description of methods and technologies for automated layup of prepreg plies.

\subsection{AUTOMATED PREPREG LAYUP}

All of the four demonstrators include automated layup of prepreg laminates. In order to achieve automated layup, methods and technologies for automated handling of prepreg plies using a pick-and-place approach have been developed. As part of the development of Demonstrators 1-3, four end effectors for prepreg handling have been built and tested. The end effector for prepreg layup developed for Demonstrator 4 has not yet been realized; therefore, the section below focuses on the four end effectors from Demonstrators 1-3. The four end effectors share some common characteristics:

- They are designed to handle UD prepreg where one side is covered with backing paper. The backing paper always faces upwards at the pickup location.

- The plies are picked up from a flat surface and deposited onto another flat surface.

- The end effectors are designed for a specific ply book, i.e. are limited to the set of plies required to lay up the laminate used for the demonstrator product. However, 
the two end effectors developed for Demonstrator 3 are specifically designed to allow for incorporation of new ply shapes and sizes.

- The solutions rely on vacuum grippers to pick up and fix the prepreg plies during the layup.

- All systems use standard industrial robots to provide the motions required to perform the layup.

The decision to keep the backing paper during the layup has a major effect on how the systems can be designed. The decision was based on published experiences (for example the systems described in Section 4.8), experiences from manual layup and preliminary trials. Keeping the backing paper was shown to provide increased structural rigidity to the prepreg plies. Without the backing paper the prepreg folds easily, in particular in the direction across the fibers, and thus requires good support, i.e. several grip points distributed over the ply surface to handle larger plies.

The decision to use vacuum grippers for the end effectors was made based on a broad technical review, where the most common gripping technologies were reviewed. The review also included manual tests, where several types of vacuum grippers were tested in combination with different prepreg materials, backing papers and protective polymer films. Based on the review and the manual tests it was concluded that vacuum grippers were suitable for the prepreg handling because:

- There is a large selection of sizes, shapes and materials to choose from. A few different vacuum suction cups are shown in Figure 43.

- They are off-the-shelf components that are readily available at reasonable cost.

- Vacuum grippers can be used when only one side of the material is accessible.

- They provide easy release.

- They can provide sufficient lifting force to pick up and fix a prepreg ply.

Keeping the backing paper during the automated handling of the prepreg plies has shown to facilitate the use of vacuum grippers as it provides a non-tacky contact surface. This eliminates the risk for resin buildup on the grippers and guarantees that the plies are released when the vacuum flow is turned off. The added stiffness provided by the backing paper reduces the risk for deforming the prepreg by drawing material into the vacuum suction cup, which permits a greater selection of vacuum cups to be used.

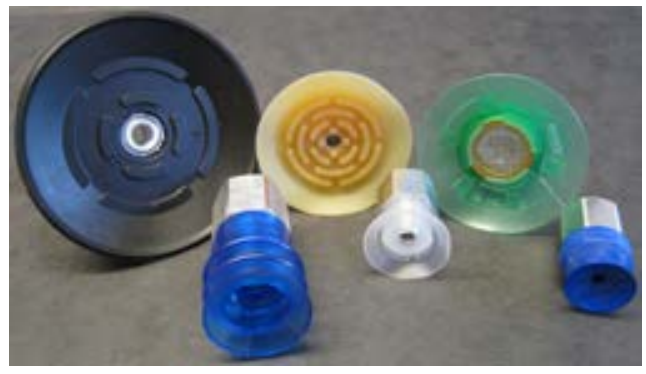

Figure 43: Examples of vacuum suction cups with different sizes, shapes and materials. 
The decision to keep the backing paper attached to the plies during the layup operation naturally suggests the need for developing methods and technologies to remove the prepreg automatically after a ply has been placed onto a laminate. The four end effectors are presented in the following chapter, along with a comparison of the four designs. Next follows a chapter describing two different methods and the required technology for automated removal of the backing paper. More details about the end effectors are provided in Paper III, IV and VI, and more information on automated removal of backing paper can be found in Paper II.

\subsubsection{END EFFECTORS FOR PREPREG LAYUP}

Below follows a presentation of the four end effectors for automated layup of prepreg plies that have been developed in Demonstrators 1-3. After the presentation of the design of each end effector follows a comparison of the different designs based on experiences from the development and layup test. The end effector for Demonstrator 1 (denominated end effector with rigid zones) was mainly developed to show proof of concept for the automated handling of prepreg with backing paper in combination with methods and technologies for the removal of the backing paper. The end effector was tested in manual layup tests where it was shown to fulfill the desired functions, i.e. to be able to pick up all the plies in the ply book from a flat surface and deposit them on another flat surface. Automated layup tests to verify the quality of a laid up laminate were not performed in Demonstrator 1. In Demonstrator 2 and 3, automated layup tests were conducted to evaluate the developed solutions. Prepreg plies were picked up from a flat surface and laid up to form flat laminates using robots equipped with the three different end effectors: the end effector with retractable zones, the reconfigurable end effector and the dual-arm solution. Each layer in the laminates was manually inspected during the tests by an operator with extensive experience from manual prepreg layup. The laminates were compared to the same quality requirements that apply to the manual layup of flat laminates, and were presented in Section 6.2. The tests showed that the automated solutions for prepreg layup in Demonstrators 2 and 3 can fulfill the quality requirements.

\section{END EFFECTOR WITH RIGID ZONES}

The end effector developed in Demonstrator 1 is designed to handle a ply book containing 27 different plies. Figure 44 shows the outlines of all the plies in the ply book, arranged on top of each other, to illustrate all the different ply shapes that must be managed. The different colors indicate the fiber directions of the plies $\left(45^{\circ}, 90^{\circ}\right.$ and $135^{\circ}$ ). The smallest ply is approximately $155 \times 300 \mathrm{~mm}^{2}$, while the largest ply measures about $250 \times 430 \mathrm{~mm}^{2}$. 


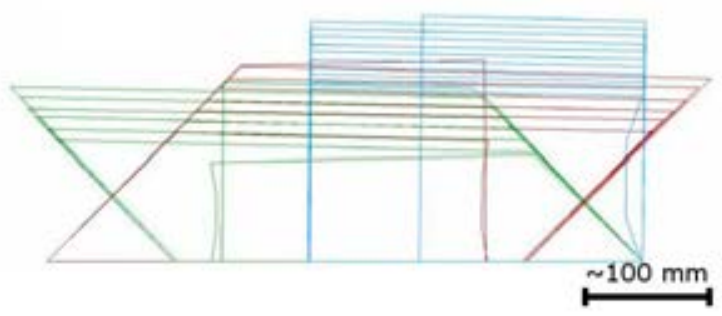

Figure 44: The outlines of the plies in the ply book for Demonstrator 1. Figure from [138].

To handle the 27 plies, 14 vacuum suction cups are used. The vacuum cups have been divided into nine individually controlled zones to reduce the need for pneumatic valves. Several zones can be activated simultaneously to lift one ply. The distribution of the vacuum cups and the division into zones, as illustrated in Figure 45, has been made as a trade-off between using as few vacuum cups as possible and providing enough lift and support to be able to handle the prepreg plies.

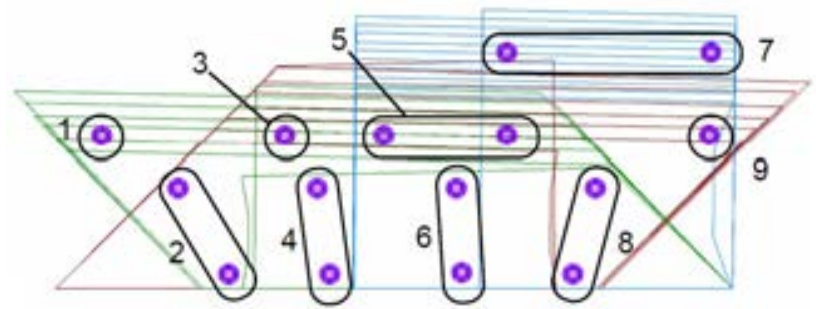

Figure 45: The distribution of the 14 vacuum cups and the division into 9 zones. Figure from [138].

The positions of the vacuum suction cups are fixed, and they are mounted at the same height on a rigid aluminum frame. The entire end effector, shown in Figure 46, weighs approximately $7.3 \mathrm{~kg}$. The end effector also includes a vacuum cup and a mechanical clamp (far right in Figure 46) that are used for removal of the backing paper.

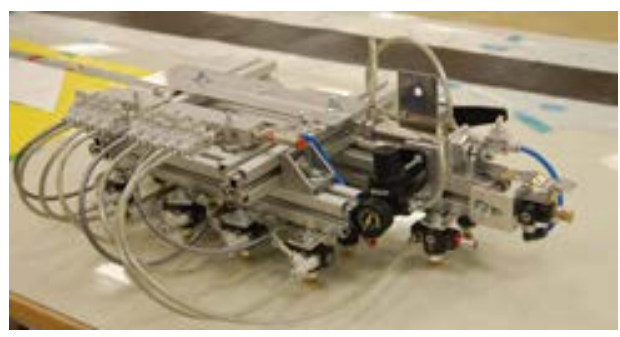

Figure 46: The end effector developed for Demonstrator 1. Figure from [138].

END EFFECTOR WITH RETRACTABLE ZONES

The end effector used for prepreg layup in Demonstrator 2 is developed to handle 11 different plies with fiber directions of $45^{\circ}$ and $135^{\circ}$. The smallest ply is approximately 
$150 \times 80 \mathrm{~mm}^{2}$, while the largest measures about $700 \times 300 \mathrm{~mm}^{2}$. The end effector uses 35 vacuum suction cups mounted on spring levelers to grip the prepreg plies. The vacuum cups are arranged in six zones that can be extended or retracted using pneumatic cylinders. The design of the retractable zones is shown in Figure 47. To grip a ply, one or several zones are extended and the vacuum cups are activated. The vacuum cups that do not correspond to the shape of the ply are retracted. The extend and retract function serves two purposes. First, it allows for pickup of prepreg from a cutting table without the risk of disturbing adjacent material. Second, the retraction also helps to ensure that one corner of the ply can be presented to equipment that separates the prepreg and the backing paper at a corner before layup. This is required to remove the backing paper using the method for automated removal of backing paper used in Demonstrator 2. This process is explained in detail in Section 6.4.2. To decrease zone complexity and the need for tool changes, the end effector has a $\mathrm{V}$-shaped design with a $90^{\circ}$ angle between the two sides that are equipped with the vacuum cups, as shown in Figure 47.
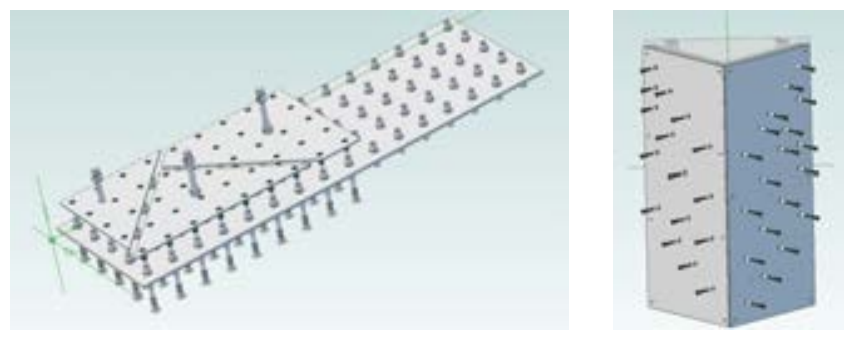

Figure 47: Left: The extend and retract function of the vacuum cups.

Right: The two sides equipped with vacuum cups. Figure from Paper IV.

In addition to the vacuum cups used to handle the plies, the end effector is equipped with a roller to consolidate the prepreg plies onto the laminate once they have been placed (highlighted by the blue oval to the left in Figure 48). It is also equipped with a gripper that is used to remove the backing paper (highlighted by the blue oval to the right in Figure 48). The weight of the end effector is approximately $39.6 \mathrm{~kg}$.
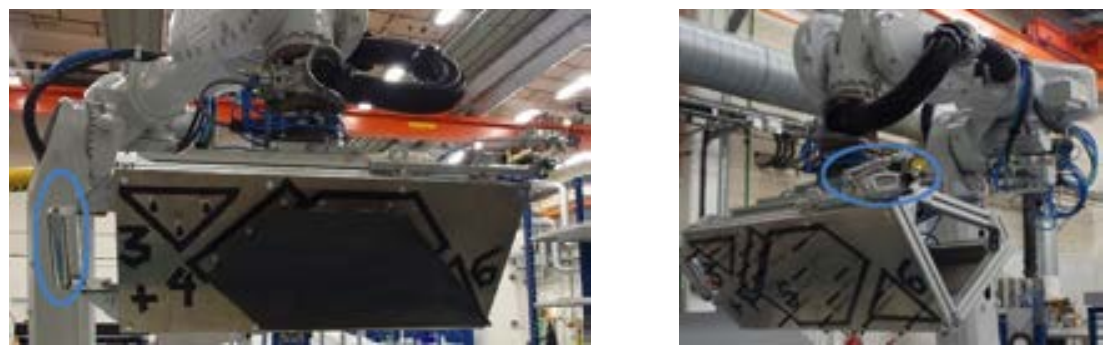

Figure 48: The end effector used for prepreg layup in Demonstrator 2.

The end effector with rigid zones and the end effector with retractable zones presented above were developed to handle fixed ply books with no requirements on flexibility to be able to adapt to changes in the shape and size of the plies. In the first demonstrator, 
an important target was to explore the possibility to design a simple end effector that could handle the ply book and that could be used for automated layup. In the second demonstrator, it was important to implement the pick-and-place approach in a complete cell, where all the steps in the layup process were automated. In both cases, the focus was mainly on designing end effectors that could solve the task of laying up the specified plies onto a flat laminate. The two end effectors presented above can accommodate changes or additions to the ply book if the new plies resemble the plies that they were originally designed to handle. Plies with deviating size and shape will require physical rebuild of the end effectors to accommodate.

As noted in Section 4.9, automated systems for prepreg handling require the ability to handle a multitude of ply shapes and sizes. Therefore, an articulated objective in Demonstrator 3 was to develop end effectors that could manage the plies in the ply book for the demonstrator product, but that also would allow for simple adaptations to changes in ply shapes and sizes to accommodate new plies. Two different solutions for automated prepreg layup, with higher flexibility than the previous two end effectors, were developed and tested in Demonstrator 3. One end effector was designed to be used in combination with a single-arm industrial robot, and the other developed solution used a dual-arm industrial robot equipped with two simple end effectors with similar design.

\section{RECONFIGURABLE END EFFECTOR}

The ply book for Demonstrator 3 contains 12 different plies, some of which are shown in Figure 49. The plies cover the four major fiber directions of $0^{\circ}, 45^{\circ}, 90^{\circ}$ and $135^{\circ}$. The smallest ply measures approximately $300 \times 500 \mathrm{~mm}^{2}$, while the largest ply is circa $400 \times 1100 \mathrm{~mm}^{2}$.
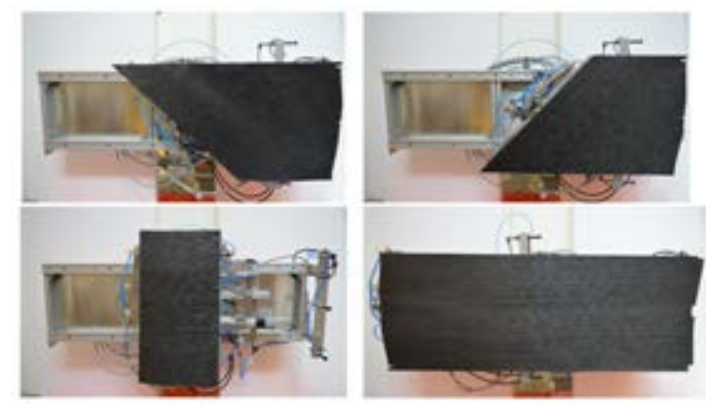

Figure 49: Examples of plies from the ply book held by the reconfigurable end effector developed in Demonstrator 3.

The reconfigurable end effector holding the plies in Figure 49 and shown from the side in Figure 50 consists of an aluminum frame which holds three separate rows of vacuum suction cups. Each row has three vacuum cups mounted on spring levelers. One row has a fixed position (to the right in Figure 50). The two other rows can be moved in a straight line closer and further away from the fixed row. Of the two movable rows, one can be extended and retracted and one can be tilted to adapt to angled plies. In the tiltable row the distance between the vacuum cups can be changed, while the other rows have fixed distances between the cups. The end effector includes a PLC and servo controllers that 
control the motions of the different rows as well as switch the vacuum cups on and off. The PLC is connected to the robot controller to allow the reconfiguration to be initiated by the robot program. The weight of the end effector is about $13 \mathrm{~kg}$.

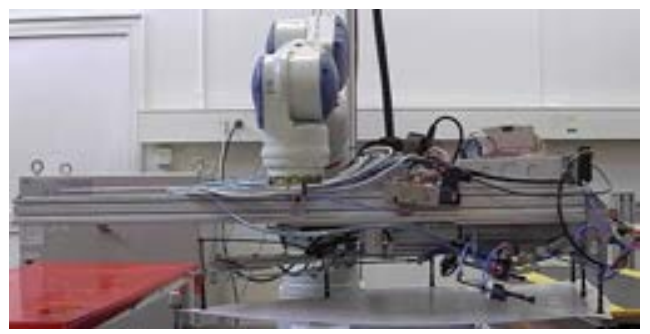

Figure 50: The reconfigurable end effector developed in Demonstrator 3. Figure from Paper VI.

\section{DUAL-ARM END EFFECTORS}

The second solution for automated prepreg layup developed for Demonstrator 3 uses a dual-arm robot equipped with two simple end effectors, shown in Figure 51. The dualarm is developed to handle the same 12 plies as the reconfigurable end effector presented above.

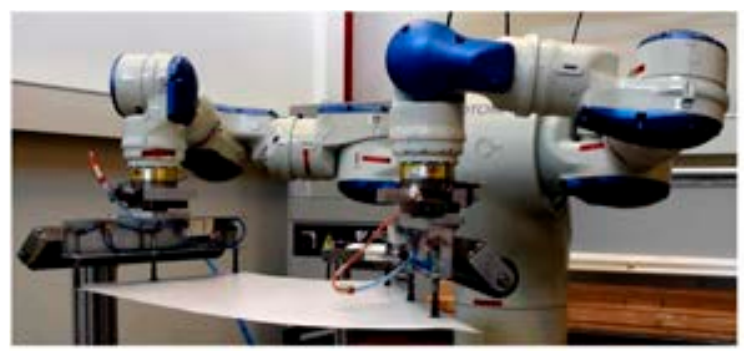

Figure 51: The dual-arm solution for prepreg layup developed in Demonstrator 3. Figure from Paper VI.

The end effectors for the dual-arm robot each consist of three vacuum cups mounted on spring levelers and a roller that is used to consolidate the prepreg. The positions of the vacuum cups are fixed within the end effector. The weight of each end effector is approximately $2.7 \mathrm{~kg}$. The reconfiguration between different ply shapes is realized by reprogramming the relative positions and pose of the robot arms using standard robot programming. For many motions, the two robot arms are moved in coordination where one arm follows the other, maintaining the distance between them during the motion. However, for lay down and pick up sequences the two arms are sometimes moved independently.

\section{COMPARISON BETWEEN THE END EFFECTORS}

As presented in Section 4.7 and more in-depth in Paper VII, solutions for automated handling using a pick-and-place approach can be charted based on analyzing their handling strategies, the selected gripping technology, the distribution of grip points and 
their reconfigurability. In addition, they can also be evaluated based on complexity and cost. A summarizing comparison between the four end effectors developed for Demonstrators 1-3 is presented in Table 11. The comparison is based on empirical data from the development and testing of the end effectors. Below the table follows a more detailed account of each category.

Table 11: A comparison between the end four end effectors.

\begin{tabular}{|l|l|l|l|l|l|l|}
\cline { 2 - 7 } \multicolumn{1}{c|}{} & $\begin{array}{l}\text { Handling } \\
\text { strategy }\end{array}$ & $\begin{array}{l}\text { Gripping } \\
\text { technology }\end{array}$ & $\begin{array}{l}\text { Grip point } \\
\text { distribution }\end{array}$ & $\begin{array}{l}\text { Com- } \\
\text { plexity }\end{array}$ & $\begin{array}{l}\text { Recon- } \\
\text { figurabil- } \\
\text { ity }\end{array}$ & Cost \\
\hline $\begin{array}{l}\text { End effector with } \\
\text { rigid zones }\end{array}$ & 2D $\rightarrow$ 2D & Vacuum & $\begin{array}{l}\text { Over ply } \\
\text { surface }\end{array}$ & Low & Low & Low \\
\hline $\begin{array}{l}\text { End effector with } \\
\text { retractable zones }\end{array}$ & 2D $\rightarrow$ 2D & Vacuum & $\begin{array}{l}\text { Over ply } \\
\text { surface }\end{array}$ & Medium & Low & Medium \\
\hline $\begin{array}{l}\text { Reconfigurable } \\
\text { end effector }\end{array}$ & 2D $\rightarrow$ 2D & Vacuum & Outer edges & High & Medium & High \\
\hline $\begin{array}{l}\text { End effectors for } \\
\text { dual-arm handling }\end{array}$ & 2D $\rightarrow$ 3D & Vacuum & Outer edges & Low & High & Low \\
\hline
\end{tabular}

The four end effectors presented above are all developed for picking prepreg from a flat surface and placing them on a flat surface to form a flat laminate, i.e. they are developed for a pure two-dimensional handling strategy. However, the dual-arm solution provides the ability to move the two end effectors independently, and thereby the ability to perform 3D motions. This ability can for example be used to perform sequential laydown motions when depositing the prepreg onto the layup surface. The sequential laydown is advantageous as it reduces the risk for air enclosures between the prepreg layers. Figure 52 shows a sequential laydown where the robot first places one side of the prepreg ply in contact with the laminate (A). The robot arm then releases the ply and switches to the consolidation roller (B). It then starts to consolidate the prepreg ply to the laminate at the same time as the other arm gradually lowers the other side of the ply until it is in contact with the laminate (C-D). This side is then released and the consolidation is completed (E-F).
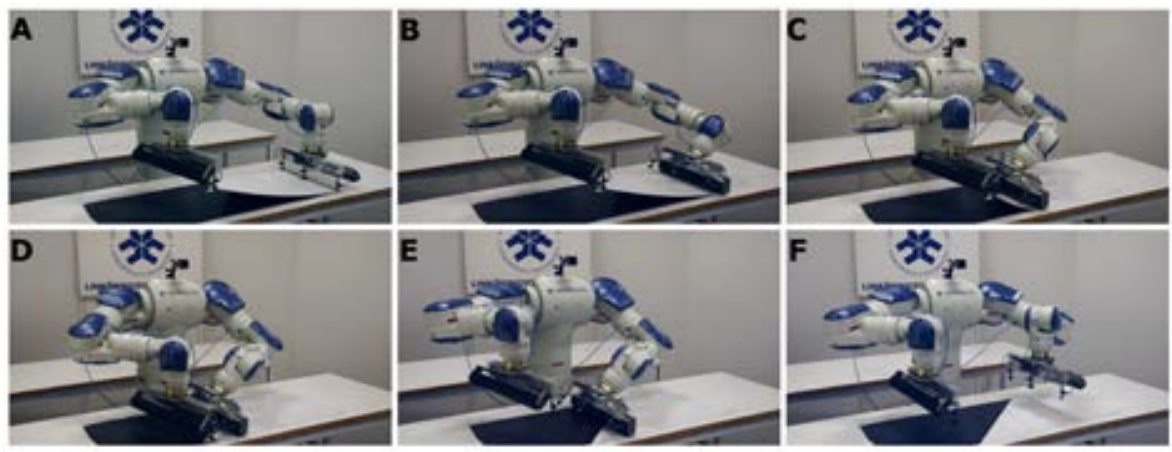

Figure 52: Sequential laydown using the dual-arm solution. 
The possibility of performing a sequential motion has also shown to be useful when removing prepreg that has tacked (formed an adhesive bond) to a surface. To hold the prepreg in place during the robot cutting in Demonstrator 2, a vacuum is drawn through the cutting surface. As the prepreg is cut without any protective film facing downwards the prepreg tacks to the cutting surface, making it difficult to remove the plies after cutting. Lifting plies that had tacked to the surface straight up using the end effector with retractable zones was shown to be an unreliable approach, even with very low lifting speed and pauses to help overcome the tack. The same issue, with the prepreg forming a strong bond to a surface, was also observed in Demonstrator 3, where vacuum was used to hold the laminate in place during layup and removal of the backing paper. In this case, it was possible to remove the laminate from the layup surface by using the dualarm robot to pick up one end of the laminate first and then gently lifting that end in a peeling motion that gradually overcame the adhesive bond between the surface and the prepreg. Manual tests using the end effectors developed for the dual-arm solution showed that they also could be used to remove single plies that have tacked to a cutting surface, if a peeling motion was used.

As described in the introduction of Section 6.4, standard vacuum suction cups are used in all the end effectors to pick up and fix the prepreg during handling. In all the end effectors, the required vacuum is generated using vacuum ejectors. This can cause problems with the exhaust air from the ejectors stirring up dust particles. A vacuum pump located away from the end effector is a more suitable solution in an industrial implementation. For the demonstrators, the use of ejectors has been motivated by their low cost and that they are simple to use.

The gripping points, i.e. the vacuum suction cups, have been distributed along the entire surface of the plies in the end effectors with rigid and retractable zones. The distribution of several grip points across the ply surface provides a strong lift force and a good grip during handling, but is not enough to remove prepreg that has tacked to a surface. The reconfigurable end effector and the dual-arm solution from Demonstrator 3 use fewer grip points, distributed along two sides of the handled prepreg ply. These two solutions provide enough lift and sufficient stability as long as the prepreg has not tacked to the layup surface. In that case, a sequential motion provided by the dual-arm robot can, as described above, be used to remove the prepreg from the surface it has tacked to.

The four end effectors have not been developed to provide solutions for layup onto threedimensional molds, and therefore strategies for draping have not been considered. However, using the same terminology as in the review presented in Section 4.7, the dualarm solution can be classified as a solution that applies active draping. None of the other end effectors can be considered to have an ability to drape material onto contoured molds.

The end effectors take different approaches to switching between the different plies in the ply book. In the end effector with rigid zones, the switch is made by turning on the vacuum cups that correspond to the desired ply shape, while the others are turned off. In the end effector with retractable zones, the vacuum cups corresponding to the desired 
ply shape are turned on and extended, while the other grip points are shut off and retracted. The extend and retract function makes it possible to pick up plies from a cutting table without coming into contact with adjacent material. Contact with surrounding plies on the cutting table poses a risk for disturbing their position, and thereby affects the positional accuracy when they are laid up. The retraction function also helps to provide access to a corner of each ply, which is necessary if the method for automated removal of the backing paper used in Demonstrators 1-3 and described in Section 6.4.2 is used. In the reconfigurable end effector and the dual-arm solution, the position of the grip points are changed so that they correspond to the different plies in the ply book.

The ability to adapt to changes in the ply book or to accommodate additional plies in the ply book shows that the reconfigurability differs greatly between the four end effectors. It is important to remember that the end effector with rigid zones and the end effector with retractable zones were developed for a fixed ply book, while the reconfigurable end effector and the dual-arm solution were developed with reconfigurability as one of the objectives. The end effectors with rigid and retractable zones must be physically rebuilt if a new ply deviates too much from the current ply book. This means that the two end effectors have a low level of reconfigurability. The reconfigurable end effector can accommodate changes in the ply book by means of reprogramming the positions of the three rows of vacuum cups. In this case, the ability to reconfigure is built into the end effector. In the dual-arm solution it is not the end effectors that provide the ability for reconfiguration, but the robot itself. Changes to the ply book are managed by reprogramming the position and pose of the robot arms. This allows for greater changes to the ply book than is possible to manage using the reconfigurable end effector, making the dual-arm solution score highest in the reconfigurability category in Table 11.

A high level of reconfigurability makes the end effector less sensitive to future changes in the ply book. It also makes the end effector more capable to handle a wider set of plies, and therefore better suitable for cases where many different plies must be managed. However, reconfigurability is often a tradeoff to cost and complexity. The complexity of the end effector in Table 11 denotes the design complexity of the end effector itself and considers the number of parts, movable components, and so on. In Table 11, cost is expressed as the estimated cost of one end effector in relation to the others.

\subsubsection{AUTOMATED REMOVAL OF BACKING PAPER}

As described in the introduction of Section 6.4, there are several advantages in keeping the backing paper on the prepreg ply during handling and layup. However, keeping the backing paper requires a solution for automated removal of the backing paper. Only a few of the pick-and-place systems that were presented in Sections 4.7 and 4.8 have raised the issue of automated removal of backing paper. Solutions for automated removal of backing paper, or other types of protective films, and experiences from the development of such solutions that have been found in published sources are presented below to provide in-depth details on the process as well as examples of how it can be 
automated. After the presentation of findings from the literature follows a detailed account of the two solutions that have been developed for the demonstrators.

In a journal paper where Buckingham and Newell [122] present a system for automated layup (summarized in Section 4.8), the authors also present some important empirical findings from a study on the removal of prepreg backing paper. A synthesis of Buckingham and Newell's study [122] is presented in the list below:

- Removal of backing paper is a difficult process to automate.

- The process can be separated into two separate steps, peel initiation and continuation.

- In general, it is the peel initiation that is difficult to automate.

- During the removal of the backing paper, the prepreg ply must be held in place, either by vacuum or by tacking to the mold surface or previous laid up plies.

- Vacuum grippers and needle grippers are effective to use to initiate the removal of the backing paper.

- Peeling should be initiated at a corner of a ply. If that is not possible, the most highly curved edge should be chosen.

- After the initiation, the peeling should continue along the route that provides the shortest peel front.

- Unidirectional materials are especially sensitive to damage. They should be peeled along the direction of the fibers.

- The backing paper should be peeled at an angle of between $90^{\circ}$ and $135^{\circ}$ from the layup surface and at speeds higher than $0.1 \mathrm{~m} / \mathrm{s}$.

- Lowering the temperature of the prepreg is advantageous for the peeling, especially for prepreg materials with a high level of tack.

In a paper from 2013, Ward et al. [94] conclude that the automated removal of protective films from prepreg material is a complex process that pick-and-place systems often fail to achieve in a reliable and fast manner. The authors study manual removal of both polymer films and backing papers from prepreg, and conclude that operators use knives to create an initial separation at a corner of a ply and the removal continues with a peeling motion across the ply, where the protective film is kept as close to the ply surface as possible. Just as Buckingham and Newell [122], Ward et al. [94] note that the removal can be separated into two distinct phases: initiation and propagation. The first phase includes separating a small area, for example a corner, to get a grip on the protective film. The second phase is the peeling motion in which the protective film is removed. The study of manual removal also shows that certain combinations of ply shape and fiber angle can increase the risk for damage of the prepreg during peeling. Ward et al. [94] present different alternatives for separating the protective film and the prepreg. For example, they consider mechanical agitation by bending the prepreg as unsuitable for implementation in a pick-and-place solution, and are instead pursuing solutions that reduce the adhesive bond between the protective film and the prepreg. Heating of the material is tested, but the process is too slow and leads to material degradation. Rapid cooling using liquid nitrogen reduces the tack and makes peeling simple. However, the method is dismissed as there is a clear risk for condensation on the prepreg surface. The 
authors [94] present a solution where cold compressed air is blown onto the edge of a ply at the same time as a vacuum suction cup lifts the corner. The compressed air blowing between the protective film and the prepreg is the exhaust from the vacuum ejector, which provides the vacuum for the suction cup used to lift the film. The air continues to blow during the whole removal process, which aids the peeling. The authors describe the solution as a reasonably reliable process, and tests show no sign of surface condensation. Using this method, peeling can be achieved at the same speed as manual removal. [94]

Another system for the removal of protective films, in this case polymer films from prepreg, is shown in a demonstrator developed in the Armature research project [142]. The system uses a cooling spray to decrease the tack at a corner of a prepreg ply. The protective film at the cooled corner is picked up using a vacuum gripper. Once the other side of the film is accessible, a clamp presses the film towards the vacuum cup to lock it in place before the peeling is continued. An interesting feature of the system is that it is designed to remove protective film from both sides of the ply. To remove the polymer film from the first side, the prepreg ply is placed onto a table and a robot with the end effector containing the cooling spray, the vacuum cup and the clamp removes the ply. The robot then switches to a material handling end effector and picks up the ply from the table and presents it to a stationary piece of equipment that contains cooling spray, a vacuum cup and a clamp. For the second side, the robot moves the prepreg ply away from the stationary equipment to achieve the peeling motion. [142]

\section{Automated Removal OF BACKING PAPER IN DEMONSTRATORS 1-3}

For Demonstrator 1 it was decided to keep the backing paper during the automated layup and remove it after consolidation to simplify the handling operation. Therefore, a method and technologies required to remove the backing paper were developed in parallel with the development of the end effector for the prepreg layup. The method and technologies for removal of the backing paper in Demonstrator 1 were evaluated in manual tests, where they were shown to be a feasible solution for an automated manufacturing cell. The same method and technologies were further refined and used in Demonstrators 2 and 3, where automated removal of backing paper was tested. Below follows an account of the development and tests of the method and the technologies used for the automated removal of backing paper used in Demonstrators 1-3. Additional information on the automated removal of prepreg backing paper can be found in Paper II.

Initial, manual trials showed that a vacuum suction cup does not provide enough lift force to separate the backing paper from a prepreg ply once the ply has been placed on a laminate and consolidated. This of course depends on the prepreg and the backing paper at hand, but for the materials used in all the four demonstrators, the bond between the prepreg and the backing paper was too strong. Gripping technology that can provide a grip with only one accessible side of the material must be used, as only one side of the backing paper is accessible. However, as soon as a corner of the backing paper has been picked up, both sides become accessible for gripping. The gripping can therefore be divided into a pickup procedure where only one side is available, followed by a procedure that locks the backing paper in place and where both sides of the backing 
paper are accessible. Needle grippers, which were used for the backing paper removal in the cell described by Buckingham and Newell [122], were considered unsuitable by the industrial partner that emphasized the risk for needles to break and be left in the prepreg layup. Therefore, alternative approaches to needle grippers were explored.

In the theoretical framework in Section 4.2.1 it was noted that the prepreg tack is dependent on ambient conditions for example temperature and material age. Trials where different combinations of prepreg and backing paper and protective films were manually separated and peeled confirmed that these two parameters affected the prepreg tack, and thereby the bond between the backing paper or protective film and the prepreg. Manual peeling tests also showed that if the backing paper is separated and reattached, the bond between them becomes weaker than before the removal and reattachment. If the backing paper is removed from the prepreg and then manually re-attached in the same location and orientation using a stroking motion, the bond is so weak that a vacuum suction cup can pick up a corner of the backing paper. This discovery led to the idea to develop a two-step process with a separation and a gripping phase. In the separation phase, the prepreg and the backing paper, at a section of each ply, are separated before the ply is consolidated to a laminate. A vacuum cup can then be used to pick up the backing paper at the pre-separated corner once the ply has been consolidated. Several concepts for how to create the separation were considered; some of them are presented in Paper II, along with more details on the manual peeling tests.

The concept for separating the prepreg and the paper at a section of the ply that was selected for further development was based on a well-established approach in manual layup. To separate the prepreg from the backing paper, operators often bend or flick a corner of a ply. Bending a corner of a ply initiates a small separation between the prepreg and the backing paper, at the corner. An automated solution to provide this separation at one corner of a ply was developed and tested in several versions. The tests showed that the automated solution could separate the backing paper and the prepreg at a corner of the ply, and that this was a possible way forward. The process requires access to a corner of each ply to insert it into a small machine that achieves the separation by mechanical bending. This affects the design of the end effector used for handling the prepreg plies during layup. After the separation phase, the prepreg ply is laid up and consolidated to the laminate.

Manual tests verified that it is possible to pick up a pre-separated corner with a vacuum cup, but the tests showed that one single vacuum cup is not enough to hold the backing paper once the peeling motion begins. With a wide peel front, the force required to remove the backing paper from the prepreg is greater than the force provided by the vacuum suction cup, which starts sliding along the smooth surface of the backing paper until eventually the grip is lost. Therefore, the vacuum cup was complemented with a mechanical clamp that locks the backing paper into place; this combined tool is illustrated in Figure 53. The backing paper is peeled from the laminate using a slow robot motion. The angle of the peeling motion away from the corner is determined based on the geometry of the ply and the fiber direction in the prepreg ply. 


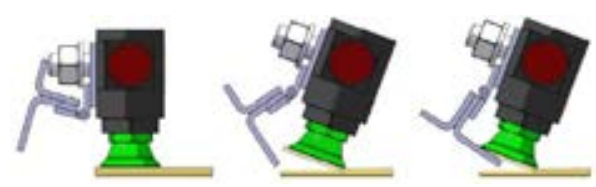

Figure 53: The sequence used to pick up and secure a good grip of a corner of the backing paper. Figure from [138].

The tool used to pick up and hold the backing paper during the removal can either be integrated into the end effector used for the layup as in Demonstrator 2 (Figure 54), or be a separate end effector as in Demonstrator 3 (Figure 55).

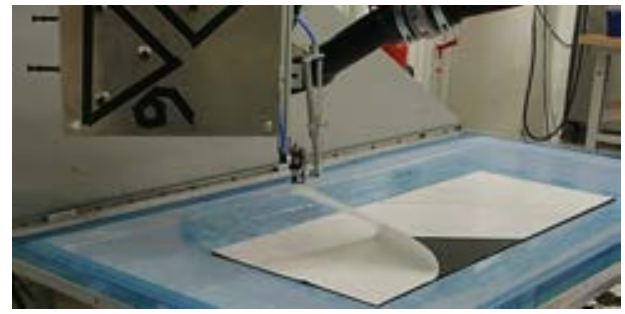

Figure 54: The tool with vacuum cup and clamp integrated into the end effector used for layup.

Figure from Paper VI.

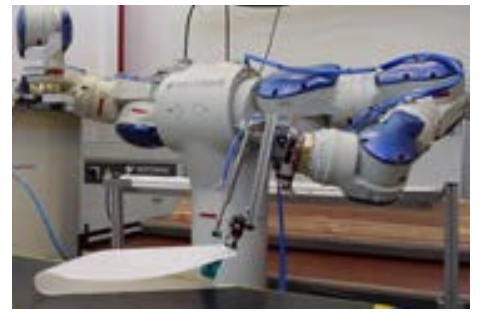

Figure 55: The tool used for removing the backing paper, mounted as a separate end effector.

The method and technologies for removal of backing paper were tested in manual tests during the development of Demonstrator 1. The tests showed that the equipment for separating the backing paper from the prepreg at a corner and the tool for gripping the backing paper were viable solutions for an automated manufacturing cell. Based on the manual tests, the methods and technologies were further refined and redesigned so that they could be implemented in a fully automated manufacturing cell. The refined methods and technologies were implemented in Demonstrators 2 and 3, which were used to test automated removal of the backing paper. In the tests, prepreg plies were, in between being picked up and laid up onto a flat laminate, presented to an external machine that performed the separation. After the plies had been consolidated to the laminate, the backing paper was removed using the tool shown in Figures 54 and 55 that can pick up and hold the backing paper during the removal motion that was performed using a robot. The tests showed that the method and technologies used in Demonstrators 2 and 3 provide a feasible solution for the automated removal of backing paper. However, the method with an extra pre-separation at one corner of the ply has some drawbacks. It sets requirements on the end effectors used for layup; for example, they must be designed so that one corner of every ply is accessible. The pre-separation of a corner also adds an additional process step to the layup, thereby increasing the cycle time for the operation.

\section{Automated Removal of BACKING PAPER In Demonstrator 4}

Based on the experiences from Demonstrators 1-3, a new method and new technology for backing paper removal is in development for Demonstrator 4. The method aims eliminate the need for an extra process step in the layup sequence, where the backing paper and the prepreg are separated. Instead, a process is being developed that ensures 
that the bond between the prepreg and the backing paper is weak enough so that it is possible pick up a corner of the backing paper after a ply has been laid up and consolidated. An advantage is that the process that influences the bond between the prepreg and the backing paper does not add cycle time to the layup, as is the case for the separation of a corner used in Demonstrators 1-3. The development of Demonstrator 4 is an ongoing project and at the moment, prototype equipment that can influence the adhesion between the prepreg and the backing paper has been developed and tested in preliminary tests. The results are promising, but further refinement and testing is required before it can be implemented in the demonstrator. Parallel with the development of the process that influences the adhesion, a tool for removing the backing paper after the ply has been consolidated to the laminate has been developed and tested. The tool for backing paper removal, shown in Figure 56, is a roll with a rubber surface and an integrated vacuum suction cup to pick up and fix the backing paper during removal. The roll is mounted on a spring-loaded bracket that can be attached to a robot arm. Automated removal of backing paper using the tool has been tested. During these tests, the adhesion between the prepreg and the backing paper was influenced using a manual solution. Prepreg plies were consolidated to a laminate and then a robot removed the backing paper using the developed rolling tool and a process described below. The tests show that, with a suitable level of adhesion between the backing paper and the prepreg, a robot can remove the backing paper from a prepreg ply using the rolling tool.

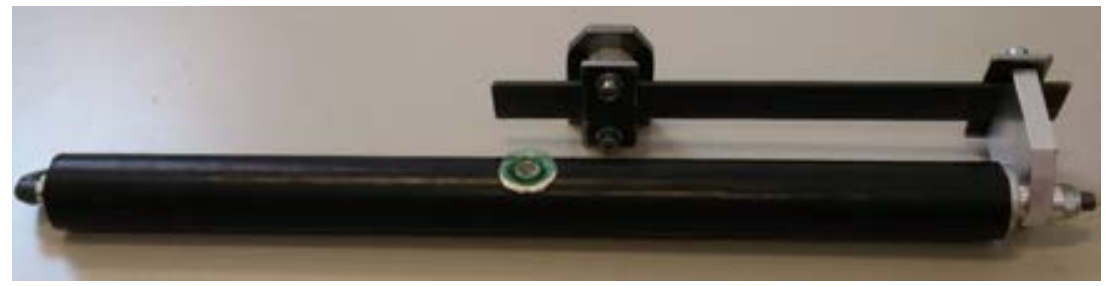

Figure 56: Tool for removal of backing paper using a rolling motion. Figure from [143].

To remove a backing paper using the method developed for Demonstrator 4, the robot switches to the tool shown above and positions the vacuum cup on a corner of the ply, after a ply has been consolidated on the laminate. The vacuum cup lifts the paper from the prepreg and holds the paper in place. The paper is removed by rolling the roller across the ply. Contact between the tool and the ply is maintained during the rolling motion. During the removal of the backing paper, the laminate is held in place using a vacuum. Holding the prepreg laminate to the layup surface is particularly important during the start and the end of the rolling motion. The rolling motion requires less robot reach than the method used in Demonstrators 1-3. For plies that are longer than the width of the rolling tool, the backing paper can be removed using an approach illustrated in Figure 57 and described in the following list: 
- The vacuum cup, at the center of the roll, picks up the backing paper at a corner of the ply. (A)

- A rolling motion is initiated, rolling at a $45^{\circ}$ angle from the corner. (B)

- When the backing paper covers the full width of the roll, the motion is stopped. (C)

- The motion is reversed so that the backing paper is placed back on the laminate and the vacuum cup releases the grip of the backing paper. (D)

- The roll is repositioned along the shorter side of the laminate. (E)

- The vacuum cup is activated to pick up the backing paper and hold it in place, while a rolling motion along the full length of the laminate is executed to remove the backing paper. (F-H)
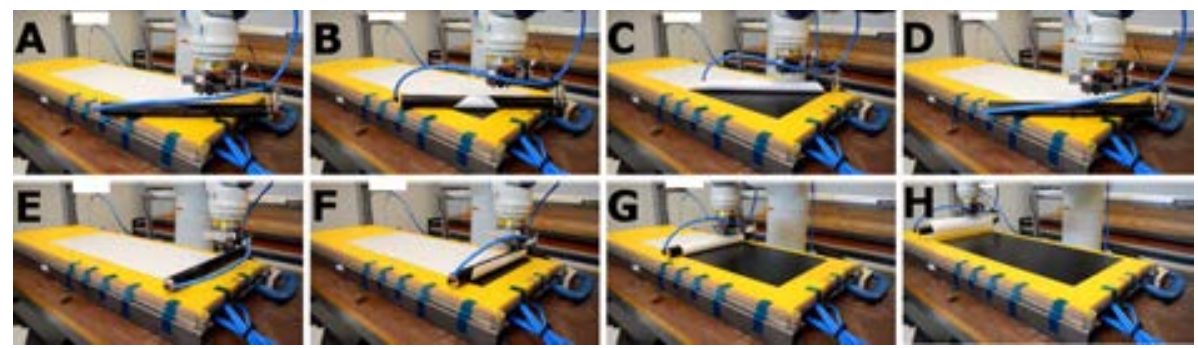

Figure 57: Sequence for removal of long backing papers. Figure from [143].

\section{EXPERIENCES FROM THE TESTS}

Based on the experiences from the tests described in the previous two sections, a few common issues can be identified. A common issue for the methods for automated removal of the backing paper presented above is that the backing paper can tear during the removal. The tear is usually initiated at a weak point, e.g. a cut in the paper highlighted by the red arrow in Figure 58. The result is that a part of the backing paper is left on the laminate, causing FOD. For plies with small notches, often cut to help to align the plies using guiding pins during manual layup, there are generally small cuts in the paper that act as tear initiators, as illustrated in Figure 59. This type of small cut is not necessarily connected to the use of notches; they can also originate from cutting the outline of a ply. This is dependent on the ply geometry.

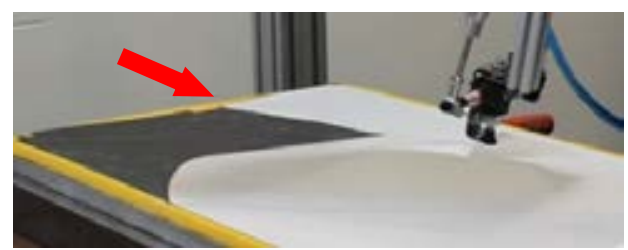

Figure 58: The backing paper tear during the removal. The tear is initiated at a notch, highlighted by the arrow.

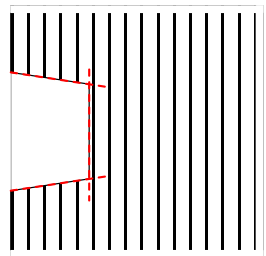

Figure 59: An illustration of how the backing paper is cut (red dotted line) in order to make a notch that helps position the ply during layup.

The automated removal tests described in the previous section indicate that if the rolling solution in Demonstrator 4 is used, it can manage removal of the backing paper with 
small cuts if the rolling direction is at a $45^{\circ}$ angle towards the cut, but not if the cut is in the same direction as the rolling motion. The use of notches that match guide pins is adapted to manual layup, and notches do not provide a function in a solution for automated layup. Eliminating the notches from the plies can reduce the risk of tearing the backing paper during removal. However, in some cases the small cuts that act as tear initiators cannot be removed as they are caused by the cutting of the ply outline. In these cases, removal motion must be adapted to them.

Uncured UD prepreg is a highly fragile material. Removal of the backing paper in the wrong direction, and in cases where the consolidation has not achieved a good bond between the top prepreg plies and the previously placed plies, can lead to the damage shown in Figure 60, where parts of the prepreg remain attached to the backing paper during the removal.

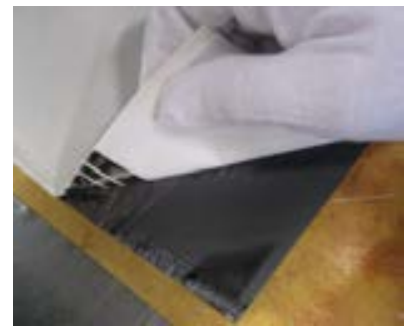

Figure 60: Failure to remove backing paper.

In order to be able to use the two methods for automated removal of backing paper that are described above, the consolidation process is important. The prepreg plies must be properly consolidated so that they fully adhere to the previously placed plies or to the layup surface before the backing paper is removed. The removal process must be adapted to the fiber direction of the prepreg ply, as well as be designed so that the risk for tearing the backing paper is reduced.

\subsubsection{EVALUATION}

The developed methods and technologies for automated prepreg layup and removal of backing paper have been tested and evaluated in isolated tests to evaluate specific methods and technologies, and have also been tested in Demonstrators 2 and 3 using the full demonstrators. In automated layup tests using Demonstrators 2 and 3, prepreg laminates were automatically laid up and each layer in the laminate was manually inspected by an experienced operator. The laminates were compared to the same quality requirements that apply to the manual layup of flat laminates (presented in Section 6.2), and the evaluation showed that the developed methods and technologies for prepreg layup could fulfill the quality requirements.

The method and technologies for the automated removal of backing paper that were developed in Demonstrator 1 were further refined and implemented in the automated manufacturing cells that are Demonstrators 2 and 3. In both Demonstrators 2 and 3, automated removal of the backing paper using the developed methods and technology 
was tested, as described earlier in the previous section. The tests showed that the method and technologies used in Demonstrators 2 and 3 provide a feasible solution for the automated removal of backing paper. However, the tests revealed some drawbacks, in particular the need for an additional separation process that adds cycle time and that affects how an end effector for prepreg layup can be designed. This led to the development of alternative methods and technologies for Demonstrator 4. These methods and technologies are in development but preliminary trials, described earlier in this section, show promising results.

The automated layup tests and tests to automatically remove the backing paper that have been performed using Demonstrators 2 and 3 show proof of concept, i.e. that the methods and technologies are feasible for an automated manufacturing cell. However, more tests and longer tests series are required to show that the methods and technologies can provide the reliable and stabile results required to implement them in an industrial solution.

\subsection{AUTOMATED FORMING OF PREPREG LAMINATES}

In Section 4.4, common forming methods like vacuum forming and HDF were presented. It was noted that the forming of prepreg laminates depends on the temperature of the laminate, the forming speed and the stacking sequence, i.e. the relationship between the fiber directions in the prepreg layers. For forming the $\Omega$-shaped beam that is the demonstrator product in Demonstrator 3, vacuum forming and HDF are unsuitable methods. Instead, an automated sequential forming approach using an industrial robot is selected for the forming in Demonstrator 3. Robot forming has been used to form a spar with a recess area, as reported by Sjölander and Åkermo [81]. The same research team that developed the robot forming for the spar was also responsible for developing the robot forming that was used to form a 20-layer-thick laminate to the shape of a modified U-beam in Demonstrator 2. In both these cases, the robot was equipped with a scraper with a design similar to the type of tools that are commonly used for manual forming. Both the U-shaped beam and the spar have recess areas, making them prone to wrinkling. The demonstrator product in Demonstrator 3 has a geometry that makes it possible to sequentially form thin prepreg laminates to the shape of the beam without wrinkling. The $\Omega$-shaped beam has a cambered head and curved web, and it is formed on a mold with the cross-section illustrated in Figure 61. The development of the forming method and the required technologies used in Demonstrator 3 are described below, and additional details can be found in Paper V. 


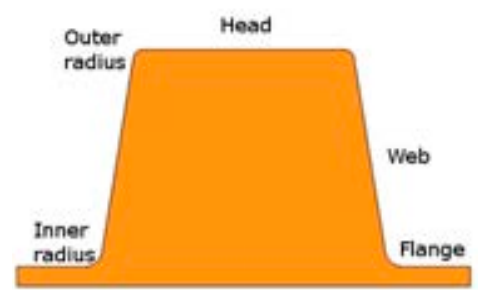

Figure 61: A cross-section of the mold used for the robot forming of a $\Omega$-shaped beam in Demonstrator 3. Figure from Paper V.

The demonstrator product in Demonstrator 3 resembles a part that today is in full-scale production using manual forming. In the manual forming case a thin laminate, usually consisting of two prepreg layers, is formed onto the mold and then vacuum consolidated for ten minutes before the next laminate is formed on top of the first. The process is repeated until the desired thickness has been achieved. One of the main reasons for forming several thin laminates on top of each other instead of forming one thick laminate is that a thick laminate is stiffer and requires a much higher force to press down around the outer and into the inner radius. The high stiffness of a thicker laminate makes the forming operation challenging for manual operations.

In Demonstrator 3, both a single arm and a dual-arm robot are used for the automated layup of prepreg plies. The decision was taken to use the dual-arm robot for the robotforming process as it provided better reach than the single-arm robot. However, the methods and technologies developed for the forming of the $\Omega$-shaped beam in Demonstrator 3 are easily transferrable to a single-arm robot. Figure 62 shows the dualarm forming the demonstrator product.
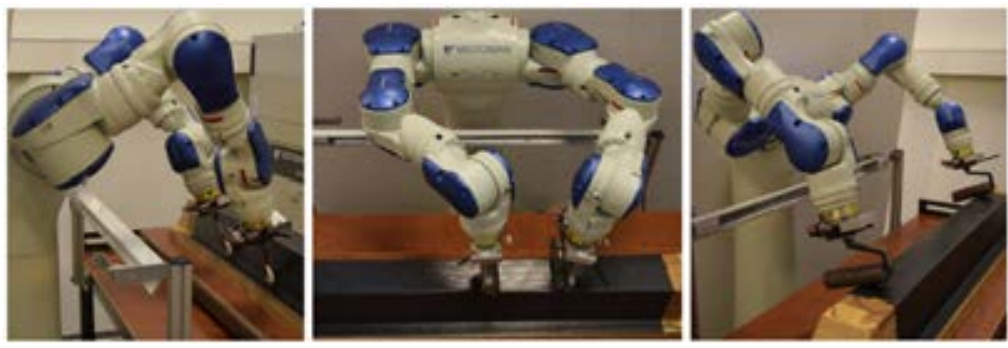

Figure 62: The robot-forming solution developed for Demonstrator 3.

The two major aspects in developing a robust robot forming are the design of the end effectors, referred to as forming tools, and the forming sequence. The two aspects are highly codependent and the tools and the sequence must be jointly developed. Instead of scrapers that had been used in earlier robot-forming applications, rolling tools were explored. For the automated forming of the $\Omega$-shaped beam a number of different forming tools were developed and evaluated in both manual and automated forming tests, where thin laminates were formed onto the mold. These preliminary tests showed that compliancy in the forming tool is an eligible requirement: it reduces the risk for 
damaging the mold, the laminate or the tools and helps to compensate for variations in material thickness as well as deviations in robot path accuracy. The compliancy can either be built into the roller itself by using a roller made from compliant material, or by mounting a rigid roller on a spring-loaded bracket that is attached to the robot arm. The preliminary forming tests showed that wide, compliant rollers were suitable to form the head, outer radius, web and flange of the beam, but not the inner radius. Different types of rollers were tested. Rolls with compliant polymer foam or rubber rolls were used for most of the robot-forming tests described later in this section. The rubber rolls were shown to be more durable, while the softer foam rolls gradually deteriorated with a high number of motions. For the forming of the internal radius, a set of tools with a rigid disk mounted onto a spring-loaded bracket was developed. Both types of tools are shown in Figure 63.
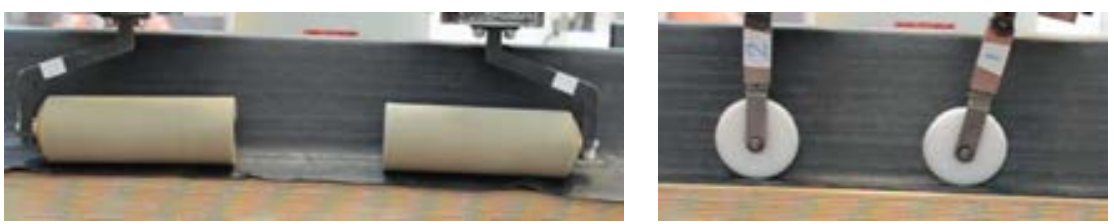

Figure 63: Left: The wide rubber rolls used to form the head, outer radius, web and flange. Right: The tools used for forming the internal radius.

At the same time as the forming tools were designed the forming sequence was established. The starting point was the sequence used for manual forming with scrapers. This sequence was adapted to suite the forming tools and the dual-arm robot. Just as for the development and evaluation of the tools, preliminary tests where thin laminates were formed manually or using the robot were used to establish a forming sequence. The established sequence was then tested in the robot-forming tests described later in this section. The forming sequence used for these robot-forming tests is illustrated in Figure 64 and explained below.
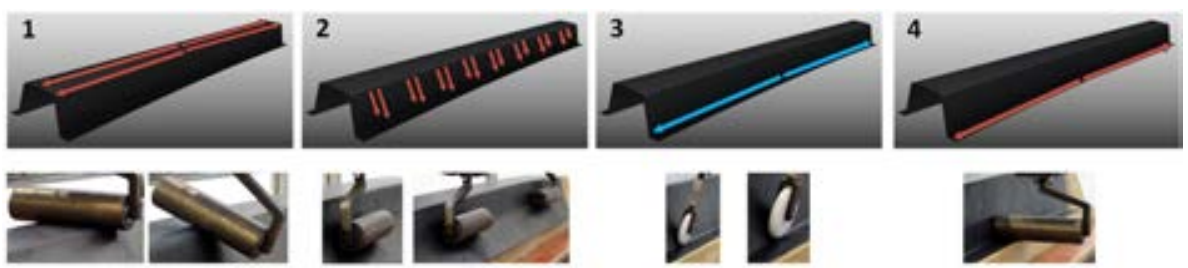

Figure 64: The forming sequence. Figure from Paper V.

1. The wide rollers are first rolled along the head of the beam, starting from the middle and moving outwards to the edges. Once that motion is completed, the wide rollers are positioned so that they press on the outer radius and then are rolled from the center to the edges. One of the robotic arms starts before the other, and as soon as there is room for the tool held by the other arm, it starts rolling in the opposite direction. A small overlap between the motions of the two arms is made. The first 
motion secures the laminate on the mold and the second forms the outer radius, as well as bends the laminate down towards the web for the next step.

2. The rollers are then positioned parallel to the outer radius and rolled down along the web. The motions start in the center and move stepwise towards the edges with a short overlap. The rollers move approximately halfway down along the web. Once the rollers reach the outer edges they start from the center again and repeat the motion. The second time, the rollers move almost all the way down to the inner radius, but without touching the flange.

3. The inner radius is formed using the tools with small rigid disks. The disks are positioned so that they press the laminate into the inner radius. The motion starts at the center of the beam and the tools are moved towards the outer edges. The motion is repeated twice in order to reduce the risk for bridging.

4. In the final step, the wide rollers are rolled along the flange, starting from the center and moving outwards.

Both arms are, as much as possible, used to form the right and the left side of the beam simultaneously to reduce cycle time. The reach of the dual-arm robot is limited, and in order to reach all areas of the beams, both arms must be used. It is also necessary to place the mold on a movable platform that can be moved closer and further away from the robot to allow good access to both the web facing the robot and the opposite side. The sequence described above is first executed to form the head, web and flange facing the robot. Once completed, the mold is moved towards the robot and the full sequence is repeated once more to form the other side. Infra-red heaters were used to heat the laminate during the forming, and a simple control system with a temperature sensor was used to control the heaters.

To evaluate the developed tools and forming sequence robot-forming tests, where thin laminates with two or three layers of prepreg and a slightly thicker laminate containing seven layers, were performed. The results from these robot-forming tests were evaluated based on the requirements that apply for manual forming of similar products. The evaluation was performed by an operator with extensive experience in prepreg layup and forming. According to the quality requirements, the laminate must tightly follow the mold surface, and bridging is not allowed. No wrinkles or other defects are accepted. However, as noted in Section 6.2, this requirement is open to some degree of interpretation.

During the robot-forming tests, three thin laminates were formed on top of each other. Of the three thin laminates, the first could be formed with acceptable quality. In the subsequent laminate, the two prepreg layers had different widths and the area of the laminate that covered the flange was only one layer thick. This laminate could not be formed without severe wrinkling on the flange. The third laminate was formed on top of the other two, and seemed to yield an acceptable quality. Some small defects were noted on the flange, but they were most likely a result of the wrinkles from the previous laminate.

Robot-forming tests using the exact same settings as for the thin laminates showed that different process parameters were required to form the seven-layer laminate. The 
stiffness of the thicker laminate caused the laminate to spring back, in particular when forming the outer radius and the web. This resulted in a small gap between the mold and the laminate just below the outer radius. This is not in accordance with the quality requirements, which specify that the laminate must follow the mold surface tightly. The robot program was altered to increase the pressure on the outer radius as well as lower the forming speed for the radius and the web. However, these changes did not solve the problem. The forming process was altered so that, in addition to the higher pressure and lower speed, the mold was preheated before the forming. This helps to provide a better adhesion between the laminate and the mold, as well as reduce the force needed for the forming. The laminate was also thoroughly heated before the forming sequence was initiated. Unfortunately, the heating system used for the tests could not provide a uniform heating of the laminate and the temperature deviated along the laminate. With these modifications, it was possible to form a beam that almost met the quality requirements. The head and the web on one side clearly fulfilled the quality requirements. For the web on the other side it was not possible to determine, with sufficient certainty, that the laminate followed the mold tightly around the outer radius. To rule out a defect, the outer radius would require more thorough examination than was possible to perform with the applied test setup. The flanges on both sides met the quality requirements. Figure 65 shows the side of the beam that was formed from the sevenlayer laminate with approved quality.

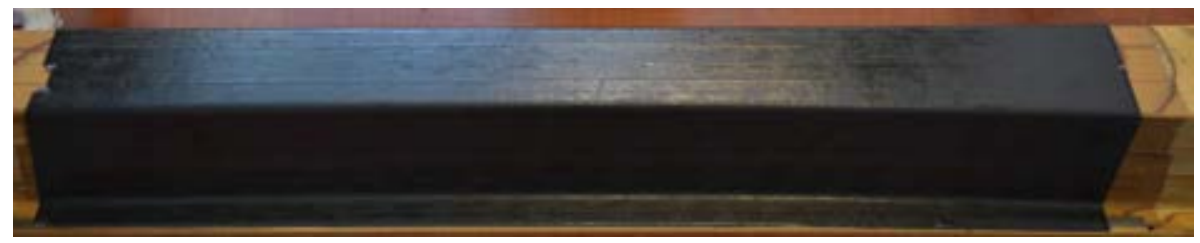

Figure 65: $\Omega$-shaped beam formed from a seven-layer laminate.

Forming a beam from a seven-layer laminate takes 7-8 minutes. This cycle time includes time for tool exchange, which was performed manually. An automated tool exchange system can help in lowering the cycle times. The forming sequence was not developed for short cycle times and there is room for improvements, for example elimination and simplification of some of the robot motions, that also can help to reduce the cycle time. The cycle time above does not include time to heat the mold and the laminate before the forming begins. It also excludes the time required for vacuum consolidation after forming. Forming the seven-layer laminate in one forming operation is highly advantageous in terms of shortening the cycle times for the forming. The cycle time for forming the thick laminate is slightly longer than for forming a thin laminate, but when forming thin laminates on top of each other, the forming must be repeated three times. After each thin laminate is formed, a vacuum consolidation process is required before the next laminate can be formed on top. When forming the thick laminate, this consolidation is only performed once.

From the automated robot-forming tests described above, it could be concluded that robot forming is a complex forming method that depends on a number of different 
process and material parameters. It was shown to depend on the fiber angles and sizes of the plies in the laminate, the temperature of the laminate and the mold during forming, the pressure and the forming speed. Some thin laminates were possible to form with approved quality, but further refinements and tests are required to find a robust forming that works for all the thin laminates as well as for thicker laminates. The tests indicate that this type of robot forming might be possible to use to form prepreg laminates for products with complex shapes, but more tests are required to verify this. An important future development is to improve the heating system so that it can maintain a uniform and constant temperature of the laminate. Also, a heating system included in the mold that can hold a constant mold temperature is an interesting area to further explore. The temperature affects the forming behavior of the laminate and the adhesion to the mold, which is important to reduce the spring back effect observed when forming the thick laminate.

\subsection{Challenges}

Section 4.9 presented some important challenges that affect the development of automated solutions for CFRP products made from prepreg and that have been documented in literature. Among these were detailed quality requirements, for example on ply position and orientation, wrinkles, bridging, fiber angles and FOD. Furthermore, the low rigidity and tack of prepreg material and the need for an automated system to manage a wide array of ply shapes and sizes are also presented. In addition to the challenges outlined in Section 4.9, Paper VII presents a number of challenges associated with the automated handling of prepreg and other materials used in composite manufacturing operations. In Paper VII, these challenges are divided into four different categories based on what aspects they cover. The four categories are quality, material, product and systems. Below follows an account of some of the challenges that affect the design of automated manufacturing systems like the demonstrators. The challenges have been empirically identified during the development and testing of the enabling methods and technologies for the demonstrators, as well as in the realization and testing of the complete demonstrators. Examples of how the challenges might affect the design of automated manufacturing systems are also provided.

\section{QUALITY}

The quality category includes general challenges posed by the high quality level that applies to the aerospace sector. One example of this is the high level of inspections during the manufacturing. During manufacturing of parts that are classified as critical, each step in the manufacturing process must be inspected to ensure that no defects are included in the final product. This can be a requirement even on parts that are subjected to $100 \%$ NDT using ultrasonic scanning after the part has cured. Each step in a manufacturing process is generally described in great detail in production specifications, and process parameters are prescribed in the same type of document.

Another example of how the aerospace quality requirements affect the development and implementation of automated solutions is the requirements on product and process validation. In order to implement a new manufacturing solution, for example a 
manufacturing cell like one of the demonstrators, extensive and costly test and validation programs are required. The high level of validation is of course necessary to safeguard the high safety standards required in aviation. However, it also hampers the implementation of new manufacturing technology.

There are also quality requirements that are more closely related to the use of prepreg materials. These requirements were described in detail in Section 6.2. For example, there are requirements on contamination-free and damage-free handling. Positional accuracy in the layup has both requirements on the outlines of the prepreg plies and in particular on the required gap between prepreg plies. As UD prepreg is used in all the demonstrators, overlaps of the prepreg plies are not allowed and gaps up to $2.5 \mathrm{~mm}$ are accepted. Layup of laminates and forming should be made so that no air is trapped between the prepreg layers, and wrinkles are not allowed. However, defects such as wrinkles are sometimes open to interpretation, and certain types of wrinkles might be acceptable depending on how they look and feel, and also where on the product they originate. This makes evaluation of layup and forming tests a difficult task that requires substantial experience and knowledge of quality evaluation criteria.

The high quality requirements on automated layup and forming require a high level of inspections during manufacturing. This type of requirement either calls for an automated inspection system to be integrated into an automated manufacturing cell for prepreg layup, or for the cell to be designed to allow for continuous or intermediate manual inspection. Despite being well-accepted technologies for prepreg layup, ATL and AFP systems are often monitored by human operators during layup. It is common practice that each layer is inspected by an operator so that no defects or FOD are introduced into the laid up product or laminate. Systems for automated inspection are in development but, as noted in Section 4.5.1, it seems that there is currently no system that can catch all defects with sufficient certainty. The lack of automated quality inspection systems means that manual inspection of each layer in a layup is sometimes required, and that automated solutions must be designed to allow for manual inspection.

\section{MATERIAL}

The dominant material-related challenges are the low rigidity and highly non-isotropic nature of unidirectional prepreg and the tack of the material. The rigidity affects the design of end effectors for material handling as it sets requirements on how many gripping points are required, as well as where they should be located in order to avoid the material folding. The non-isotropic nature of the material affects, for example, in which direction the backing paper should be peeled and how the prepreg can be separated from the backing paper using mechanical bending. The rigidity and nonisotropic behavior, naturally, have a great influence on the automated forming of prepreg laminates.

The tack affects both layup and forming. For example, the problems with prepreg plies or laminates adhering to cutting and layup surfaces, highlighted in Section 6.4.1, is a phenomenon derived from the tack of the prepreg material. The prepreg tack also affects the strength of the bond between the prepreg and the protective backing paper, and 
thereby how the system for automated removal of the backing paper can be designed. In prepreg layup and the forming of laminates, the tack makes error recovery very difficult. Once a prepreg ply or a laminate has tacked to previously placed plies or to an already formed laminate, it is very difficult to remove it without causing damage to the material. This means that layup and forming must be correct on the first attempt; otherwise, the part most likely has to be scrapped.

Another aspect that is challenging for an automated solution is that the level of tack in a prepreg material changes with material age as well as temperature. A system for automated removal of the backing paper might work reliably for prepreg that is a few days old and slightly dry, but struggle with new prepreg with a slightly higher tack level. The robot forming in Demonstrator 3 was shown to be highly dependent on the temperature during forming, as the temperature affects both the tack and the structural rigidity of the laminate. Strict control of the temperature of the prepreg laminate as well as the mold is considered to be one of the key issues for a successful robot-forming operation.

\section{PRODUCT}

For automated layup systems using a pick-and-place approach, the most obvious challenge in the product category is the multitude plies with different shapes and sizes that the system must handle in order to lay up a laminate. This can partly be explained by the use of ply stagger: In prepreg laminates where multiple plies make up one layer in the laminate the joints between plies cannot be repeated on top of each other through the thickness of the laminate, as this impairs the strength of the laminate. Therefore, a stagger is used to shift the joint positions in each layer, which in turn generates a high number of different ply shapes and sizes. Figure 66 shows a thick laminate, where the blue lines illustrate joints between different plies in different layers throughout the laminate thickness. End effectors for automated prepreg layup must be designed to be able to cater to all the plies in the ply book.

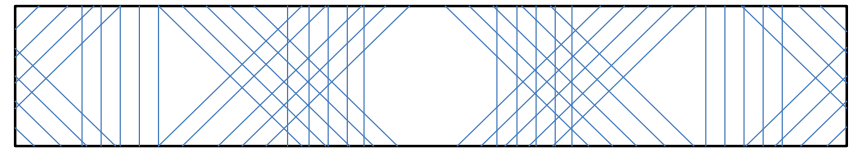

Figure 66: A thick laminate with blue lines illustrating joints between plies within the laminate. Figure adapted from Paper IV.

As the developed solutions all consider the layup of flat laminates, the layup operation is not affected by a complex three-dimensional shape of the final product, although the form of the product has a great influence on the forming process. For simple shapes vacuum forming and HDF suffice, but more complex shapes might require sequential forming methods, and there are shapes where laminate forming is not applicable. The form of the final product also has a big impact on the ability to use systems that can lay up prepreg directly onto a contoured mold, for example ATL, AFP or pick-and-place systems with draping capability. For these types of systems, the form of the product also has a strong influence on the potential productivity of the system. 


\section{SYSTEM}

Several of the challenges within this category are concerned with how one process in an automated manufacturing cell affects the others. One example is the need to pick up cut prepreg plies without disturbing adjacent material. This is highly important in the demonstrators, as the pick-and-place operations are designed with open-loop control based on a good knowledge of the ply positions after cutting. If the position of a ply is slightly affected by the pickup of an adjacent ply, this will introduce a positional error in the laminate when the adjacent ply is laid up.

Another example of how different steps in the automated manufacturing process are interconnected and might hold contradictory requirements is the solutions developed for automated handling of the prepreg plies with backing paper attached and the solutions for the removal of the backing paper. During handling, a strong bond between the prepreg and the backing paper is desirable so that the prepreg does not detach from the paper. For the removal process, a weak bond between the two is desirable as it simplifies the peeling; this is especially important for the solution developed in Demonstrator 4. The challenge is to find a suitable compromise between these two contradictory requirements.

\subsection{GENERAL REFLECTIONS}

The industrial challenge that forms an important basis for the development of the demonstrators is described in Chapter 5 as the need to lower the manufacturing costs in cases where automated manufacturing solutions like ATL and AFP are not suitable, and where the lack of automated alternatives leads to the use of manual manufacturing methods. The aim is to reduce the manufacturing costs as a way to be able to retain manufacturing operations in high-wage countries. The solution to this challenge, put forward in the demonstrators, are systems for automated layup and forming. The focus of the demonstrators has been to identify and develop key enabling methods and technologies that are required to realize such systems. To meet the industrial challenge the demonstrators have been developed with cost-effective manufacturing in mind, but detailed cost estimates have not been performed. It is, as noted in Section 3.1.2, difficult to predict the costs of automation projects, especially when the technology is not well known. Furthermore, in Section 3.1.2 it was noted that it might be difficult to capture all the benefits of automation using traditional financial analysis.

The demonstrators have, to as large extent as possible, been built using off-the-shelf solutions. Standard industrial robots are used for most of the process steps in the demonstrators. Using the methods and technologies developed for the demonstrators, it is possible to build automated manufacturing cells that only require one industrial robot. (Demonstrators 2 and 3 are attended by multiple robots, but the methods and technologies might just as well be applied in a cell with a single robot.) For manufacturing cells designed for low manufacturing volumes, the use of a single robot to perform all the tasks helps to keep the investment costs down; with increasing manufacturing volumes, additional robots can be added. The automated handling of prepreg plies in layup has been greatly simplified by the use of the two-step process, 
with the layup of flat laminates followed by a separate forming operation. The dual-arm solution in Demonstrator 3 shows that it is possible to design a system that is highly reconfigurable in terms of handling a multitude of ply shapes that use very simple end effectors. The dual-arm robot, although less common than the single-arm configuration, is a standard off-the-shelf robot. In solutions for automated handling, high reconfigurability simplifies changes to the ply book as well as the introduction of new products. As long as the reconfigurability does not add significant costs or reduce reliability in a manufacturing cell, the manufacturing of several products in the same manufacturing cell can help to provide cost-effective solutions, as the investment costs can be shared by a greater number of products. With manufacturing volumes of the final products ranging from 3-25 products per week, this can be a suitable strategy. However, as noted in Section 6.1.2, there are some co-cured products that consist of a number of similar parts that can be manufactured using layup and forming, and where the weekly manufacturing volume can reach 100 parts. In this case, a manufacturing cell developed only for the manufacturing of these parts can be a suitable solution.

The studies of the industrial partner's current manufacturing practices have revealed several products where, in addition to the layup of pre-impregnated carbon fibers that make up the bulk of a laminate, small patches of other types of materials such as glass fiber prepreg or adhesive films also are also included in the laminates. It is possible to switch layup heads in ATL and AFP machines to lay up different materials, but the heads that deposit material are complex and costly. An advantage with a pick-and-place approach to lay up flat laminates is the possibility to lay up different materials by using the same end effector for all types of materials. If it is not suitable or possible to design a common end effector for all materials, several different end effectors can be used. The cost for additional end effectors is, compared to the cost of ATL or AFP heads, low.

The sequential forming also uses simple, low-cost end effectors. The wide rolls that are used for most of the steps in the robot forming can likely be used for forming other parts. The small disks used for forming the inner radius are more specialized to a certain product geometry, by they are simple and inexpensive to manufacture. From a robot programming perspective, it is simple to program a forming sequence. However, determining the correct forming sequence and setting the correct parameters, for example speed, pressure and temperature, might require an extensive effort. The work required to develop a suitable forming sequence and to set the correct parameters can probably be facilitated by the use of forming simulation. This type of simulation was employed by Sjölander and Åkermo [81] to develop a suitable forming sequence for robot forming using scrapers that were presented in [81], as well as for the forming that the same research team developed for Demonstrator 2. Simulation was also used by Elkington [75] to determine suitable layup strategies in the two-step pre-shearing and layup process presented in Section 4.10. Further development of forming simulation models that work for robot forming with rolling tools is a highly interesting area to explore, as it might simplify the development of a forming sequence.

An area that has not been considered during the development of the demonstrators is the integration of a quality inspection system in the automated manufacturing cells. The 
focus for the demonstrators has been on developing the key enabling methods and technologies for the automated layup of flat laminates, removal of backing paper and forming. For the manufacturing of critical parts using ATL and AFP it is, as highlighted in Section 4.5.1, common practice to have manual inspections of each prepreg layer during the layup. Considering the strict quality requirements that apply to the manufacturing of the demonstrator products, a need for continuous inspection of each layer, just as for ATL and AFP, cannot be ruled out. The need for inspections requires further investigation, and in cases where it is considered a necessity, two general alternatives can be perceived. One alternative is that the automated manufacturing cells must be designed to allow for manual inspection during layup. This would severely affect the productivity and manufacturing costs, as it would convey frequent stops in the automated manufacturing and also require an operator to be on standby. The other alternative is to integrate an automated quality system that continuously monitors and evaluates the quality during layup. An integrated system for quality inspection reduces the need for frequent human intervention and can therefore improve productivity compared to a system that requires manual inspections. Systems for automated inspection are being developed for ATL and AFP layup, but at the moment there seems to be no system that can detect all the defects required to be inspected. The area of automated inspection is therefore considered a highly important area for further research and development.

As noted in Paper I, it can be a costly and time-consuming endeavor to validate new manufacturing methods and technologies. The extent of a validation can range from theoretically showing that the quality requirements can be fulfilled, all the way to extensive tests series. It is difficult to predict exactly the extensiveness of a validation without a detailed investigation, but as noted in Paper I, it is generally easier to validate technology and methods that are well known and understood. The methods and technologies developed for the demonstrators are not radically new methods, but instead bare resemblance to the manual operations used today. The same ply book can be used and the steps in the process are the same as for manual layup and the forming of laminates. This similarity can be an advantage when it comes to validating the methods and technologies for serial production. However, a more in-depth study is required to determine the validation requirements.

An advantage that is not touched upon earlier is that the automation of layup and forming reduces health hazards. Many types of prepreg that are used in the aerospace industry contain uncured thermoset resins, for example epoxy, that are associated with health hazards. In the case of epoxy resin, direct contact and prolonged exposure to the material can cause contact allergies. Therefore, gloves and protective clothing must be used for the manual handling of these types of materials. Automated layup of laminates reduces the exposure to these allergenic materials. Forming of thick laminates is, as noted in Section 6.5, heavy work, especially for the hands and wrists. The industrial partner points out that one of the advantages of automating the forming operation is that it eliminates the risk for repetitive strain injuries among the staff. 
The methods and technologies for automated layup have, in the demonstrators, been focused on the layup of flat laminates of carbon fiber prepreg ready for forming. The developed pick-and-place solutions can also be possible to use for a number of other handling operations, and to automate the handling of other types of materials. During the studies of the industrial partner's manufacturing system some interesting areas to further explore have been identified.

In Section 6.1.2 it was shown that the automated ply cutting is associated with a lot of manual material handling. The clearing of the cutting table after cutting requires an extensive amount of manual labor. Cut plies are picked from the table and sorted into kits that are transferred to the layup areas. The clearing of cutting tables and sorting of kits is an operation where the solutions for automated layup of prepreg, developed for the demonstrators, could be implemented for a more general material handling operation. However, this operation requires a highly reconfigurable solution that can manage a great variety of ply shapes, and it also requires a large reach. Therefore, a dualarm solution using two cooperating large robots could be a suitable solution for automating this operation.

Studies of the industrial partner's current manufacturing practices indicate that much time is spent on cutting and handling a wide range of auxiliary materials that are used at different stages of a manufacturing process. Among the auxiliary materials are different forms of plastic films and porous fabrics used for debulking and cure assembly. In many cases, operators cut a piece of auxiliary material from broad roll, place it onto the mold and trim the piece to the desired shape in a second cutting operation. For a few products, pre-cut, tailor-made auxiliary materials are used to save time during layup and cure assembly. Examples of tailor-made auxiliary materials that have been identified are adhesive films and vacuum bags. The robot cutting processes and the automated handling processes developed for prepreg layup have the basic functions required to prepare tailored auxiliary materials. This is an interesting area to explore as it holds a possibility to reduce the use of manual labor in layup and cure assembly. Since the material characteristics of the auxiliary materials differ from prepreg, some modifications and specializations will most likely be necessary.

In Section 4.5.1 it was concluded that the scrap rates generally are lower for AFP systems compared to the layup of plies cut from a broad roll of prepreg, but that the costs of AFP material can offset the savings of lower material waste. Prepreg is an expensive material and the scrap generated when cutting the plies must be minimized. One way of reducing the scrap rate is to cut the plies in a sequence that minimizes the scrap, rather than to cut the plies in the sequence that they are used in the layup operation. This approach is referred to as nesting. A system for automated cutting and layup should be designed to allow for nesting, as this can reduce the material waste. The system must therefore be designed with a certain storage capacity, as plies are not cut in the same sequence as they are laid up. 


\section{CONCLUSION AND DISCUSSION}

To conclude the previous sections of the thesis and to connect the results to the research aim presented in the introduction, this chapter starts by briefly answering the four research questions. The conclusion is followed by a discussion and reflections on the scientific and industrial contributions of the presented work. The chapter ends with a brief outlook on future research opportunities. 


\subsection{CONCLUSION}

The research presented in this thesis has been aimed towards exploring automated manufacturing alternatives for low-to-medium volume manufacturing of advanced prepreg-based products for the aerospace industry. The research has been guided by one comprehensive research question (RQ 1) and three more detailed questions (RQs 2-4). To conclude the presented research, the research questions are answered below.

$R Q$ 1: How can automated manufacturing systems for the manufacturing of complex CFRP products made from prepreg be designed so that they meet the needs and requirements of the aerospace industry and are suitable for low and medium production volumes?

The four demonstrators, comprehensively presented in Chapter 5 and explored more indepth in Chapter 6, show four different examples of how manufacturing systems for the automated manufacturing of complex CFRP products made from prepreg can be designed. The four demonstrators are based on a two-step process, where flat laminates are laid up and formed in two separate steps. The two-step process with layup of flat laminates followed by a separate forming process simplifies the automation of the layup compared to automated layup onto a contoured mold, as it transforms the layup from a three-dimensional to two-dimensional problem. This simplifies the design of the required hardware and thereby helps to reduce the costs for the automated manufacturing cell. Tests using the demonstrators show that the automated layup of flat laminates is simplified by keeping the backing paper attached to the prepreg during handling. This calls for a solution for automated removal of the backing paper as part of the layup. Tests using Demonstrators 2 and 3 show that flat laminates that fulfill the quality requirements that apply to the manual layup of laminates can be automated. They also show that the removal of the backing paper can be automated. Tests using Demonstrator 3 indicate that it might be possible to use an industrial robot equipped with rolling tools to form the laid up laminate for a product with a complex shape, in the case of Demonstrator 3 a $\Omega$-shaped beam, but more tests are required to verify this. For simpler shapes, for example U-shaped and rectangular beams, the laminates can be formed using off-theshelf methods such as vacuum forming or HDF.

$R Q 2:$ What key methods and technologies are required to enable the design of the manufacturing system outlined in RQ1?

Key enabling methods and technologies are, in this thesis, defined as methods and technologies required to transform prepreg on a raw material roll to a complex-shaped product, and which require substantial research and development efforts and for which off-the-shelf solutions cannot be applied. It can be concluded that the key enabling methods and technologies are methods and technologies for:

- automated layup of prepreg plies to form a flat laminate,

- automated removal of backing paper, and

- automated forming of prepreg laminates. 
The key enabling methods and technologies are described and discussed in detail in Section 6.3.

\section{RQ 3: How can key enabling methods and technologies be designed in the manufacturing system outlined in RQ1?}

In-depth descriptions of how enabling methods and technology for the automated manufacturing of complex CFRP products can be designed to meet the requirements that apply to the aerospace industry, and that are suitable for low and medium production volumes, are provided in Chapter 6 . Below follows a short summary of how methods and technology for the automated layup of flat laminates, removal of prepreg backing paper and forming of complex shapes can be designed.

Methods and technologies for the automated layup of flat laminates were developed for Demonstrators 1-3. In all three demonstrators, end effectors for prepreg handling that can pick prepreg plies from a flat surface and place them on a flat surface to lay up a laminate are developed. The design of the end effectors is simplified by keeping stiff backing paper attached to the prepreg during the handling. Automated layup tests using Demonstrators 2 and 3 show that it is possible to use industrial robots equipped with the developed end effectors to lay up laminates that meet the quality requirements that apply to the manual layup of flat prepreg laminates.

Two different methods and required technology have been developed for the automated removal of prepreg backing paper. The first method, developed and tested in Demonstrators 1-3, uses an external machine to create a separation between the prepreg and the backing papers at a corner of each ply. After a prepreg ply is placed and firmly attached to the laminate, a gripper with a vacuum cup and a mechanical clamp picks up the backing paper at the separated corner and holds the paper in place while a robot performs a peeling motion that removes the backing paper. This method has been shown to be a working solution for the automated removal of backing paper during tests in Demonstrators 2 and 3. The second method, developed for Demonstrator 4, employs a solution to affect the adhesion between the prepreg and the backing paper so that the paper is lightly attached to the prepreg during the layup. After a prepreg ply has been placed and consolidated to the laminate, the backing paper is removed using a robot equipped with a rolling tool; this method is still in development. So far, preliminary tests have shown that backing paper removal using a rolling tool is a practicable solution if the adhesion between the prepreg and the backing paper is low.

Enabling methods and technologies for the automated forming of products with complex shapes have been developed in Demonstrator 3. In the demonstrator, a robot equipped with simple end effectors is used to sequentially form the prepreg laminate to an $\Omega$ shaped beam. This method is referred to as robot forming. Robot-forming tests in Demonstrator 3 do not prove that the developed methods and technologies can be used to form a complex-shaped product, but indicate that it might be a possible solution that requires further development and testing. 
RQ 4: What challenges affect the development of the key enabling methods and technologies?

Challenges that affect the development of key enabling methods and technologies have been identified in literature reviews as well as empirically when working on the development and testing of the demonstrators. Many of the challenges found in the literature are confirmed by the experiences from the demonstrators. The challenges can be divided into four categories:

- quality,

- material,

- product and

- system.

Examples of challenges in the quality category are the high quality requirements employed in the aerospace industry. There are detailed quality requirements for the outcome from the manufacturing process, for example specifications on fiber angles and wrinkles. There are also extensive requirements that govern the introduction of new manufacturing methods and technologies and how these should be validated in order to make sure that they comply with the quality requirements. Two predominant challenges in the material category are the low rigidity and the tack of prepreg materials. The material-related challenges have been shown to have significant influence on the design of the demonstrators. An important challenge in the product category is the large amount of prepreg plies that can make up a product. The challenges in the systems category generally describe the connection between the different methods and technologies required in an automated manufacturing cell, and how these can set contradictory requirements, for example on the strength of the adhesive bond between the prepreg and the backing paper. More challenges and details on how they affect the design of automated manufacturing systems can be found in Section 6.6.

\subsection{DISCUSSION}

In the broad literature review presented in Paper VII it was noted that there are very few examples of solutions for automated handling of materials used in composite manufacturing that were implemented in industrial applications; almost all the reviewed systems were developed in research projects. Of the six systems for automated prepreg layup presented in Sections 4.7 and 4.8, there seems to be only one, the Hexcel system for layup of flat prepreg laminates, that has seen industrial implementation. The lack of industrial implementation and the reasons for this are debated among the academic community, and no clear evidence for the lack of implementation has so far been presented. Based on in-depth studies of manual layup, Elkington [75] argues that the layup of prepreg on complex-shaped molds is such a complex task that it is probably too challenging to solve using existing technology. Chatzimichali and Potter [12] point to the fact that robotic application companies lack knowledge of the special nature of composite materials, and therefore fail to take this into account when designing automated solutions, as a plausible reason for the lack of implemented systems. Based on the experiences from developing the demonstrators and the studies of current 
manufacturing practices a few thoughts on the lack of automation alternatives, suitable for the manufacturing of complex-shaped products in low and medium manufacturing volumes, are presented below.

In order to develop automated solutions it is necessary to have an in-depth understanding of the possible manufacturing alternatives, the current manufacturing practices and in particular the challenging material characteristics of prepreg materials. Tack and low material rigidity have been shown to have an important impact on the design of solutions for automated prepreg handling. Working with the demonstrators has also shown that many of the steps in a manufacturing process are interconnected, and that different process steps can bring contradictory requirements. The required in-depth understanding of the special nature of prepreg and the interconnected manufacturing methods required in the automated manufacturing of prepreg-based products might be one reason for the limited implementation of this type of automation.

Automated forming of prepreg laminates to complex shapes using robot forming requires extensive knowledge of prepreg forming. The forming operation depends on a number of different process parameters such as temperature, speed and pressure and requires a sequence of motions that must be adapted to the manufactured product. To develop the correct sequence and a working set of process parameters requires extensive work, and it seems to be difficult to develop general settings suitable for a wide range of products. Forming simulation, as shown by Sjölander and Åkermo [81], can aid in the development of a forming sequence. The required level of process knowledge, in combination with the difficulty to develop generic solutions, risks limiting the implementation of robot forming.

For the aerospace industry, another plausible reason for the lack of industrial implementation is the extensive quality requirements. In particular, the requirements on validation of new manufacturing methods and technology risk hampering the introduction of new solutions.

Elkington et al. [77] highlight the importance to understand the techniques and practices used in manual layup when considering the automated layup of complex parts. The developed methods and technologies for automated layup and forming presented in this thesis have to a large extent been based on current manual manufacturing practices. The division into a two-step approach, the layup of flat laminates and robot forming have all been influenced by current manufacturing practices. However, the theoretical background on automation in Section 3.1.2 highlights how existing processes should be broken down into their simplest form, and how all the functions should be reevaluated when designing automated solutions. Furthermore, it was also noted that this reengineering process can provide better automated solutions. In the case of the demonstrators, the enabling methods and technologies have been analyzed in detail, but no new revolutionary solutions have been developed; instead, the development has occurred in solutions mimicking the manual operations. One of the main reasons for this decision is the need for validation and certification of new processes required in the aerospace industry. The study presented in Paper I showed that in some cases, a change 
to a product or manufacturing process can be simplified by showing similarities with already-established practices. It can be simpler to validate a process that is a gradual development of current practices than a radically new process. This, in combination with the request for cost-effective automation, has led to the practice of basing the development of the automated alternatives for layup and forming on already-established manual processes. However, not radically rethinking the processes when developing automated solutions might introduce unnecessary constraints, and thereby risk not realizing the full potential of automation.

Looking at the levels of mechanization presented by Bright [46] and summarized in Table 3, it can be concluded that the highest nine levels require automated measurement and detection, and to reach the top levels requires a system where feedback of data from automated measurements controls the actions of the system. Most resources during the development of the demonstrators have been dedicated to the development and testing of enabling methods and technologies. Automated control of the demonstrators and complete integration of all functions into one control system has not been given the same priority in the development. Using Nof's [43] nomenclature, the focus has primarily been on platform and process and not on the autonomy. None of the demonstrators have been developed to a higher level of autonomy according to Bright's categorization. Demonstrators 2 and 3 reach approximately level six in Bright's automation scale. In order to reach a higher level of automation according to Bright's definition, systems for automated quality inspection would be required.

In Section 3.1.2, goals and reasons for implementing automation, along with advantages and benefits from such implementation, were presented. Some of these clearly apply to the demonstrators. For example, the automated cells can improve worker safety by eliminating or reducing health hazards such as the manual handling of allergenic prepreg material and hard and monotonous work, for instance the manual forming of laminates. Other positive effects from automating the manufacturing are plausible but require further studies to be verified. Layup tests using the demonstrators show that it is possible to lay up flat laminates that comply with the quality requirements that apply to manual layup. Automated layup could help improve product quality as automated solutions provide high repeatability, but more tests are required to verify this. Automation benefits such as reduced operating costs and increased productivity are also likely, but need to be investigated further. As noted in Section 6.7, the demonstrators have been developed with low cost in mind by using as high a degree of off-the-shelf solutions as possible and designing general solutions that can be used for a multitude of products. A key to realizing high productivity and reducing human involvement and thereby labor costs is to be able to run the manufacturing cells for long periods without human intervention. As noted in Section 6.7, this might require the introduction of automated quality systems. Investigating the need for these types of systems, and in case they are required, developing them so that they can be implemented in the manufacturing cells, is therefore of great importance, not only from a quality requirement perspective but also from a cost perspective. 
Each of the demonstrators presented in this thesis is developed to manufacture a specific demonstrator product that is used for evaluation and testing. However, most of the enabling methods and technologies have been developed with greater than required flexibility to be able to manage different products and to allow for new products to be added. Viewing the demonstrators from a flexibility perspective (presented in Section 3.2), it can be noted that most effort has been dedicated to achieve the machine and material handling types of flexibility. These two flexibilities facilitate the desired ability to manufacture different products within the same manufacturing cell. Operation and routing flexibilities have not been considered because manufacturing methods for a specific product are usually strictly regulated, and deviations from established manufacturing processes must usually be validated before they can be implemented. Different, alternative routes within the manufacturing cells are usually not interesting to pursue for the same reason. For the demonstrators, the focus has been on the flexibilities connected to the operational time frame. The considered flexibility dimensions are the systems' abilities to manage manufacturing products containing a great degree of variations in ply shapes and sizes, and to manage changes to material characteristics due to the age of the prepreg or changes in ambient conditions. Although manufacturing is generally performed in a clean room environment with stable conditions, some variations occur and must be managed by an automated system. An automated manufacturing cell with the flexibility to lay up and form a variety of products is an appealing solution, as it can be used to manufacture several products with low manufacturing volumes, and thereby several products can share the cost for automation. The manufacturing cells built to demonstrate automated layup and forming have been designed with the need for the machine, material handling, process and product types of flexibilities in mind. However, no measurements of the systems' flexibility have been conducted.

The demonstrator-centered research approach has helped in attracting a genuine industrial interest for the research, as well as facilitating sharing of the research work among the research partners involved in the demonstrator. For example, different partners involved in the demonstrators have performed detailed development of the methods and technologies. But even though the development of methods and technologies for the demonstrators has been divided among the research and industrial partners, the research has been highly collaborative in nature. Development and evaluation of demonstrator concepts, as well as realization of the demonstrators, have to a large extent been joint work. The results and findings from the development of a demonstrator should therefore be accredited to all in the research team who have contributed to its development and realization.

Working with an industrial partner in developing the demonstrators has provided a good opportunity to study current manufacturing practices. Interviews and on-site observations have provided a detailed understanding of the manual manufacturing processes and the current use of automation, and have helped to understand the industrial challenge that the demonstrators are based on. In-depth studies of current manufacturing practices have mainly been conducted at the composite workshop of one company. Less extensive studies have been conducted at other companies and these, along with findings 
in the literature, support the findings from the more detailed studies that were presented in Section 6.1.2. The understanding of the current manufacturing practices and the industrial challenge has helped to provide industrial relevance to the demonstrators. The demonstrators have been developed in research labs, and not implemented in an industrial context. This has helped to provide the freedom for scientific exploration during the development of the demonstrators, and a greater control over the experiments using the demonstrators.

The use of physical demonstrators, where the enabling methods and technologies are integrated into one manufacturing cell, help to align each enabling method and technology so that they can function together. It drives a system understanding and becomes clear how each method and technology affects the other. A good example of this is the removal of the backing paper in Demonstrator 4, where the methods and technologies for the layup of laminates present contradictory requirements to the methods and technologies used for the removal. The contradictory requirements on the adhesion between the prepreg and the paper severely limit the process window for the process that controls the adhesion. Without the integration step, there is a risk that enabling methods and technologies are developed independently and do not work in an interconnected process.

The use of complex demonstrator products that resemble products in full-scale manufacturing has contributed to developing solutions with an industrial relevance. However, complex demonstrator products have been shown to require substantial resources, both in terms of labor and material. The realization of the demonstrators, i.e. the implementation of the enabling methods and technologies into one manufacturing cell, has also been shown to be highly resource-consuming. Research projects that apply a demonstrator-centered research methodology must consider this when deciding the scope of the demonstrator and choosing a suitable demonstrator product. Small projects can develop a conceptual demonstrator and realize only a few of the required methods and technologies to save resources, as in Demonstrator 1.

\subsection{SCIENTIFIC CONTRIBUTION}

A general review of the area of automated handling of materials used in composite manufacturing shows a multitude of automated solutions for different types of materials. During the work on the literature review, it was noted that no comprehensive review of the field was available. Only a few compilations of previous work could be found, often as background in papers that had as their main focus to present a new method or technology. The review of the field that is presented in Paper VII and summarized in Section 4.7 is, although not seemingly extensive, one of the few reviews of the area. Paper VII presents a classification of the reviewed solutions for automated handling based on design principles for end effectors. This type of classification can simplify future comparisons between solutions for automated handling. The review also presents a mapping of documented challenges that affect the design of systems for automated handling. The challenges, identified in the review, have been supplemented by empirical experiences from the development of the demonstrators. Many of the challenges 
previously documented in the literature and described in Paper VII are confirmed by the empirical data. This thesis adds to the existing knowledge by providing more in-depth descriptions of some of the challenges, and provides examples on how they affect the design of enabling methods and technologies for the automated manufacturing of prepreg-based products.

Studies of the industrial partner's current manufacturing operations have disclosed a number of products like U-shaped, $\Omega$-shaped and rectangular beams and spars that are manufactured using a two-step approach, where flat laminates are laid up and formed. A high level of manual work is today employed to manufacture these products. Development and tests of automated manufacturing cells, in the form of demonstrators presented in Chapters 5 and 6, indicate that the manufacturing of these types of products can be automated using the same type of two-step process of laminate layup and forming as is used in the manual case. During the development of the demonstrators, the key enabling methods and technologies required to realize the automated manufacturing systems have been identified.

The demonstrators and the enabling methods and technologies presented in Chapters 5 and 6 share some commonalities, but also hold some important differences to the automated solutions for prepreg layup found in the literature and which were presented in Section 4.8. In the four demonstrators presented in Chapter 5, the prepreg is covered by protective backing paper during handling, just as in the system designed by Newell, Buckingham and Khodabandehloo [70,122,133], but the same type of solution for automated removal that they used could not be used in the demonstrators. Instead, two new methods have been developed. The work on developing the methods and the required technology have provided an in-depth understanding of the complicated process of automated removal of prepreg backing paper that has added to previously reported data.

The need for systems that can handle a multitude of plies has been identified in the literature [69], and the experiences gained from developing the demonstrators have confirmed this need. Different methods and technologies for achieving a flexible system for automated layup that can handle a multitude of plies have been developed for the demonstrators. The developed methods and technologies have been described in scientific publications, and have added in-depth knowledge to this area.

Robot forming seems to be a novel field, with few documented applications thus far. The work presented herein builds on experiences from Sjölander and Åkermo [81], who developed solutions for the robot forming of U-shaped products with recess areas using scrapers. The methods and technologies for robot forming developed for Demonstrator 3 have contributed with new knowledge on how such a system can be designed. The developed solution shows that compliant rolling tools can be used in robot forming, and indicate that it is possible to form a $\Omega$-shaped geometry.

The research in this thesis has been conducted according to the demonstrator-centered research approach developed by Jonsson [30]. However, some minor additions to the 
research approach have been made. For example, more detailed descriptions of a typical workflow and the different phases encountered when developing a demonstrator are provided in Section 2.5.

\subsection{INDUSTRIAL CONTRIBUTION}

According to Jonsson [30], one of the benefits of using a demonstrator-centered research approach is that it provides an opportunity for the industrial partners to test new ideas within a research project which would have been difficult to explore in an industrial context. This can help to overcome the gap between research and industrial implementation. [30] Experiences from the development of the demonstrators presented in this thesis confirm the view presented by Jonsson [30]. An important reason for the industrial partners to be engaged in the demonstrators has been to be able to experiment with and gain greater knowledge of methods and technology that are not considered ready for implementation in an industrial context, but that might be interesting to implement in a long-term perspective. Working with demonstrators that are decoupled from their original context allows for the testing of new ideas with very low risk to the current production system. The reviews of different methods and technologies that are conducted in the early phases of the demonstrator development have been communicated to the industrial partner, and thereby have provided an insight into previously published research results in the field and ongoing research projects. The demonstrators have shown that it is plausible to implement manufacturing systems based on automated layup and forming into the current production system for prepreg-based parts. They have highlighted areas that require further investigation, for example the need for integrated quality control. Both the information compiled during the literature reviews and the empirical data from the demonstrators have raised the industrial partner's knowledge level on the automated layup and forming of prepreg laminates. This knowledge is valuable for the industrial partner when writing specifications for future development or research projects within this area. It is also important for defining purchase specifications when the time comes to implement some of the methods and technologies from the demonstrators in full-scale production. On a more general level, the collaboration between the industrial partner and the research partners has contributed to bring a general automation perspective to composite manufacturing operations that have strong traditions in manual operations.

\subsection{FUTURE RESEARCH}

The key enabling methods and technologies developed for the four demonstrators have been tested with promising results. The tests using Demonstrator 2 showed that the layup of flat laminates, removal of backing paper and robot forming of the laminates to the form of a U-shaped beam could be performed according to the quality requirements that apply to the manual manufacturing of similar products. Tests using Demonstrator 3 showed that the automated layup of flat laminates, using both types of end effectors developed for the demonstrator, could be performed according to the quality requirements. The tests of the robot-forming process in Demonstrator 3 indicated that it is probably possible to meet the quality requirements, but further tests are required to verify this. The robot-forming tests in Demonstrator 3 showed that the heating of the 
laminate, as well as the mold, have a significant influence on the forming results. Therefore, the heating of the mold and the prepreg laminate during robot forming is an interesting area for future research. Also, the use of simulation to develop suitable forming sequences and to specify process parameters for robot forming is an area that is interesting for future work. Another interesting area for further exploration is the possibility to use force-controlled robotics for the robot forming. Using a force control system to monitor and regulate the force used during the forming can help to ensure a more uniform forming process.

The tests using the demonstrators have, so far, been short test series to show proof of concept; more and longer test series are required to evaluate the robustness of the developed methods and technologies. Further development of the demonstrators can also include work on improving the speed of the automated processes. In the presented research, the main focus has been to evaluate the developed methods and technologies and to investigate if they can meet the quality requirements. Little focus has been dedicated to the improvement of process speed. With more extensive tests series and work on improving the speed, it will be possible to evaluate possible cycle times, which is an important step to be able to perform detailed cost analysis. Further development of the methods and technologies to increase their flexibility so that they can be used for more types of products is also an interesting area to further explore.

In Section 4.5.1, it was noted that it is common practice, for some types of products, to use manual inspections to control the quality of each prepreg layer laid up using ATL and AFP machines. The same type of inspections might be required in a system for the automated layup and forming of prepreg laminates. Recently published results on automated in-process inspection systems for AFP [87] show ongoing work in the development of automated inspection systems, but indicate that further development of the methods and technologies is necessary to achieve systems that can detect all the required defects. Further in-depth investigations are required to determine if automated inspection is required to run manufacturing cells like the demonstrators without human inspections. The development of automated inspection systems that can be integrated into such manufacturing systems is, even if not a strict requirement, an important area for further research, as it can help to increase the level of automation and achieve manufacturing cells that are truly autonomous.

Currently, there seems to be a trend among the calls for research proposals within Swedish manufacturing research to emphasize the development of different types of demonstrators. Several calls for proposals also emphasize collaboration between industrial and research partners. Therefore, it is interesting to further refine and document the demonstrator-centered research approach that was developed by Jonsson [30] and used in this thesis to provide a more comprehensive methodological framework for this type of research. With an increased use of demonstrators in research projects, further refinements of the demonstrator-centered research approach would be a valuable methodological contribution. 


\section{REFERENCES}

1. Danielsson T (1974) Tage Danielssons tankar från roten. Wahlström \& Widstrand, Stockholm

2. Composite. https://www.merriam-webster.com/dictionary/composite. Accessed December 272016

3. Campbell FC (2004) Manufacturing processes for advanced composites. Elsevier Advanced Technology, Oxford

4. Åström BT (2002) Manufacturing of polymer composites [New ed.]. Nelson Thornes, Cheltenham

5. Mallick PK (2007) Fiber-reinforced composites: materials, manufacturing, and design

6. Björnsson A (2014) Enabling Automation of Composite Manufacturing through the Use of Off-The-Shelf Solutions. Licentiate Thesis. Linköping University, Linköping, Sweden 7. McMullen P (1984) Fibre/resin composites for aircraft primary structures: a short history, 1936-1984. Composites 15 (3):222-230

8. Roeseler WG, Sarh B, Kismarton MU (2007) Composite structures: the first 100 years. Paper presented at the 16th International Conference on Composite Materials Kyoto, Japan, July 8-13

9. Dorey G (1987) Carbon fibres and their applications. Journal of Physics D: Applied Physics $20(3): 245-256$

10. Teixeira-Lage PJ (2014) Composite design challenges: Airbus A350XWB wing covers. JEC Composites Magazine.

11. Witten E, Kraus T, Kühnel M (2016) Composites Market Report 2016. http://www.avktv.de/files/20161128 market report 2016 english.pdf

12. Chatzimichali AP, Potter KD (2015) From composite material technologies to composite products: a cross-sectorial reflection on technology transitions and production capability. Translational Materials Research 2 (2)

13. Soutis C (2005) Carbon fiber reinforced plastics in aircraft construction. Materials Science and Engineering: A 412 (1):171-176

14. Grant C (2006) Automated processes for composite aircraft structure. Industrial Robot 33 (2): $117-121$

15. Apostolopoulos P, Kassapoglou C (2002) Recurring cost minimization of composite laminated structures-optimum part size as a function of learning curve effects and assembly. Journal of Composite Materials 36 (4):501-518

16. Potter K (2017) But How Can We Make Something Useful Out of Black String? The Development of Carbon Fibre Composites Manufacturing (1965-2015). The Structural Integrity of Carbon Fiber Composites : Fifty Years of Progress and Achievement of the Science, Development, and Applications. Springer, eBook

17. Lukaszewicz DHJA, Ward C, Potter KD (2012) The engineering aspects of automated prepreg layup: History, present and future. Composites Part B: Engineering 43 (3):997-1009 18. Paton R (2007) Forming technology for thermoset composites. In: Long AC (ed) Composites Forming Technologies. Woodhead Publishing, pp 239-255

19. Williamson K, Burstein F, McKemmish S (2002) Introduction to research in relation to professional practice. In: Williamson K (ed) Research methods for students, academics and professionals : information management and systems. 2 edn. Centre for Information Studies, Wagga Wagga, Australia, pp 5-24

20. Hernon P (1991) The elusive nature of research in LIS. In: McClure CR, Hernon P (eds) Library and information science research : perspectives and strategies for improvement. Ablex Publ. Corp., Norwood, N.J., pp 3-14

21. Leedy PD, Ormrod JE (2009) Practical research : planning and design. 9th edn. Pearson Education, Upper Saddle River, N.J.

22. Williamson K (2002) Research methods for students, academics and professionals :

information management and systems. 2 edn. Centre for Information Studies, Wagga Wagga 
23. Potts C (1993) Software-engineering research revisited. Software, IEEE 10 (5):19-28

24. Oosthuizen MJH (2002) Action research. In: Williamson K (ed) Research methods for students, academics and professionals : information management and systems. 2 edn. Centre for Information Studies, Wagga Wagga, Australia, pp 159-176

25. Dick B (1993) You want to do an action research thesis?

http://www.aral.com.au/resources/arthesis.html. Accessed 17 February 2017

26. Dick B (2000) A beginner's guide to action research.

http://www.aral.com.au/resources/guide.html. Accessed 17 February 2017

27. Dick B (1997) Rigour and relevance in action research.

http://www.aral.com.au/resources/rigour.html. Accessed 17 February 2017

28. Burstein F (2002) System development in information systems research. In: Williamson K (ed) Research methods for students, academics and professionals : information management and systems. 2 edn. Centre for Information Studies, Wagga Wagga, Australia, pp 147-158 29. Nunamaker Jr JF, Chen M, Purdin TDM (1990) Systems Development in Information Systems Research. Journal of Management Information Systems 7 (3):89-106

30. Jonsson M (2013) On Manufacturing Technology as an Enabler of Flexibility : Affordable Reconfigurable Tooling and Force-Controlled Robotics. Linköping University, Linköping, Sweden

31. Darke P, Shanks G (2002) Case study research. In: Williamson K (ed) Research methods for students, academics and professionals : information management and systems. 2 edn.

Centre for Information Studies, Wagga Wagga, Australia, pp 111-124

32. Yin RK (1994) Case study research: Design and methods. Sage, Thousand Oaks, CA, USA

33. Gall MD, Borg WR, Gall JP (1996) Educational research : an introduction. 6 edn.

Longman, White Plains, N.Y.

34. Williamson K, Bow A (2002) Analysis of quantitative and qualitative data. In: Williamson $\mathrm{K}$ (ed) Research methods for students, academics and professionals : information management and systems. 2 edn. Centre for Information Studies, Wagga Wagga, Australia, pp 285-304 35. Maxwell JA (2013) Qualitative research design: An interactive approach. 3 edn. Sage publications, Thousand Oaks, C.A.

36. Tanner K (2002) Experimental research designs. In: Williamson K (ed) Research methods for students, academics and professionals : information management and systems. 2 edn.

Centre for Information Studies, Wagga Wagga, Australia, pp 125-146

37. Merriam S (1995) What Can You Tell From An N of 1?: Issues of validity and reliability in qualitative research. PAACE Journal of lifelong learning 4:51-60

38. Ulrich KT, Eppinger SD (2008) Product design and development. 4 edn. McGrawHill/Irwin, Boston, Mass, USA

39. Groover MP (2008) Automation, production systems, and computer-integrated manufacturing. 3 edn. Prentice Hall, Upper Saddle River, N.J.

40. Wilson M (2015) Implementation of robot systems : an introduction to robotics, automation, and successful systems integration in manufacturing

41. Lamb F (2013) Industrial Automation: Hands On

42. Kandray D (2010) Programmable automation technologies: an introduction to CNC, robotics and PLCs

43. Nof SY (2009) Automation: What it means to us around the world. In: Nof SY (ed)

Springer handbook of automation. Springer, Berlin Heidelberg, Germany, pp 13-52

44. ISO 8373:2012(en) Robots and robotic devices — Vocabulary. (2012) ISO.

https://www.iso.org/obp/ui/\#iso:std:iso:8373:ed-2:v1:en. Accessed 3 February 2017

45. Kalpakjian S, Schmid SR (2005) Manufacturing engineering and technology. Pearson, Upper Saddle River, NJ, USA

46. Bright JR (1958) Automation and management. Division of Research, Graduate School of Business Administration, Harvard University, Boston, USA

47. Ceroni JA (2009) Economic rationalization of automation projects. In: Nof SY (ed)

Springer handbook of automation. Springer, Berlin Heidelberg, Germany, pp 699-713 
48. Upton D (1994) The management of manufacturing flexibility. California management review $36(2): 72-89$

49. Slack N (1987) The flexibility of manufacturing systems. International Journal of Operations \& Production Management 7 (4):35-45

50. Olhager J (1993) Manufacturing flexibility and profitability. International journal of production economics 30:67-78

51. Gerwin D (1993) Manufacturing flexibility: a strategic perspective. Management science 39 (4):395-410

52. Browne J, Dubois D, Rathmill K, Sethi SP, Stecke KE (1984) Classification of flexible manufacturing systems. The FMS magazine 2 (2):114-117

53. Wiendahl HP, ElMaraghy HA, Nyhuis P, Zäh MF, Wiendahl HH, Duffie N, Brieke M (2007) Changeable Manufacturing - Classification, Design and Operation. CIRP Annals Manufacturing Technology 56 (2):783-809

54. Sethi AK, Sethi SP (1990) Flexibility in manufacturing: A survey. International Journal of Flexible Manufacturing Systems 2 (4):289-328

55. Koste LL, Malhotra MK (1999) A theoretical framework for analyzing the dimensions of manufacturing flexibility. Journal of Operations Management 18 (1):75-93

56. Browne J, Dubois D, Rathmill K, Sethi SP, Stecke KE (1984) Types of Flexibilities and Classification of Flexible Manufacturing Systems. vol Working paper No 367. Division of Research, Graduate School of Business Administration, The University of Michigan, Ann Arbor, Michigan

57. Buzacott JA, Mandelbaum M (2008) Flexibility in manufacturing and services:

Achievements, insights and challenges. Flexible Services and Manufacturing Journal 20 (12): $13-58$

58. Stake T (2016) Still leading the way: 787 ramps up rate once again.

59. Kingsley-Jones M (2014) Airbus begins A350 ramp-up towards 10 a month.

60. Three years since the market launch of BMW i. 100,000 electrified BMW on the road.

(2016). BMW Group,

https://www.press.bmwgroup.com/global/article/detail/T0265529EN/three-years-since-themarket-launch-of-bmw-i-100-000-electrified-bmw-on-the-road

61. Mallick PK (1997) Introduction: Definitions, Classifications, and Applications. In: Mallick PK (ed) Composites engineering handbook. Dekker, New York, pp 1-50

62. Bloom L, Elkington M, Ward C, Chatzimichali A, Potter K (2013) On prepreg properties and manufacturability. Paper presented at the 19th International Conference on Composite Materials (ICCM19), Montreal, Quebec, Canada, 24-28 July

63. Putnam J, Seferis J, Pelton T, Wilhelm M (1995) Perceptions of prepreg tack for manufacturability in relation to experimental measures. Science and Engineering of Composite Materials 4 (3): 143-154

64. Dubois O, Le Cam J-B, Beakou A (2010) Experimental analysis of prepreg tack. Experimental Mechanics 50:599-606

65. Nguyen DC, Krombholz C (2016) Influence of Process Parameters and Material Aging on the Adhesion of Prepreg in AFP Processes. Paper presented at the 17th European Conference on Composite Materials (ECCM17), Munich, Germany, 26-30 June

66. Crossley R, Schubel P, Warrior N (2012) The experimental determination of prepreg tack and dynamic stiffness. Composites Part A: Applied Science and Manufacturing 43 (3):423-434 67. Crowley DM, Ward C, Potter K (2013) The Manufacture of Advanced Composite Parts to Rigid Industrial Specifications-Can it be Made? SAE Technical Paper,

68. Kaynak C, Akgül T (2001) Open Mold Processes. Handbook of composite fabrication. Rapra Technology Ltd., Shawbury, U.K

69. Curran JP, Wright EJ, Armstrong PJ (1987) An Intelligent Vacuum Gripper for Robotic Handling. In: Advances in Manufacturing Technology II. Springer, pp 205-209

70. Newell G, Khodabandehloo K (1995) Modelling flexible sheets for automatic handling and lay-up of composite components. Proceedings of the Institution of Mechanical Engineers, Part B: Journal of Engineering Manufacture 209 (6):423-432 
71. Crowley DM, Ward C, Potter K (2013) A status of acceptance criteria and process requirements in advanced composites manufacturing, and whether they are fit for purpose. SAE Technical Paper,

72. Bader MG, Lekakou C (1997) Processing for laminated structures. In: Mallick PK (ed) Composites engineering handbook. Dekker, New York, USA, pp 371-480

73. Strong AB (2008) Fundamentals of composites manufacturing : materials, methods and applications 2nd ed. Society of Manufacturing Engineers, Dearborn, Michigan

74. Horejsi K, Schneiderbauer G, Tauchner J, Schledjewski R, Noisternig J (2014) Production method evaluation for large cylidrical composite parts under a cost perspective. Paper presented at the 16th European Conference on Composite Materials (ECCM16), Seville, Spain, 22-26 June

75. Elkington $\mathrm{M}$ (2015) The evolution and automation of sheet prepreg layup. $\mathrm{PhD}$ thesis, University of Bristol, Bristol

76. Elkington M, Ward C (2016) Time dependence of multi-ply forming over doubly curved shapes. Paper presented at the ECCM17 - 17th European Conference on Composite Materials, Munich, Germany, 26-30 June

77. Elkington M, Bloom D, Ward C, Chatzimichali A, Potter K (2015) Hand layup: understanding the manual process. Advanced Manufacturing: Polymer \& Composites Science $1(3): 138-151$

78. Flogvall E (2014) Investigation of consolidation of stacked prepreg during robot forming. Master Thesis. Kungliga Tekniska Högskolan

79. Åkermo M (2017). Personal communication edn.,

80. Hallander P, Sjölander J, Åkermo M (2015) Forming induced wrinkling of composite laminates with mixed ply material properties; an experimental study. Composites Part A: Applied Science and Manufacturing 78:234-245

81. Sjölander J, Åkermo M Automatic forming of composite aircraft beams. In: Björkman M

(ed) The 5th International Swedish Production Symposium, SPS12, Linköping, 2012. pp 533539

82. Redondo JB (2016) A+ glide forming technology / automatic stringer manufacturing technology. Paper presented at the SAMPE 2016, Long Beach, CA, USA, 23-26 May

83. Sarh B, Moore B, Riedell J (1995) Advanced manufacturing technologies for composite aircraft structures based on prepreg materials. Paper presented at the 40th International SAMPE Symposium, 8-11 May

84. Sloan J (2008) ATL \& AFP: Defining the megatrends in composite aerostructures. High performance composites.

85. Sloan J (2008) ATL and AFP: Signs of evolution in machine process control. High performance composites.

86. Hagnell M, Åkermo M (2015) A composite cost model for the aeronautical industry: Methodology and case study. Composites Part B: Engineering 79:254-261

87. Cemenska J, Rudberg T, Henscheid M (2015) Automated in-process inspection system for afp machines. SAE International Journal of Aerospace 8 (2):303-309

88. Winter D, Crowley D, Williams S, Ward C (2016) Using real-time data for increasing the efficiency of the automated fibre placement process. Paper presented at the 17th European Conference on Composite Materials (ECCM17), Munich, Germany, 26-30 June

89. Rudberg T, Nielson J, Henscheid M, Cemenska J (2014) Improving AFP cell performance. SAE International Journal of Aerospace 7 (2014-01-2272):317-321

90. McPherson A (2013) The $\$ 4$ Million Manufacturing Machine. American Composites Manufacturers Association. http://compositesmanufacturingmagazine.com/2013/01/4-millionmanufacturing-machine/. Accessed 2 April 2017

91. Gates D (2014) Electroimpact to build fiber-laying machines for Boeing's 777X. The Seattle Times. http://www.seattletimes.com/business/electroimpact-to-build-fiber-layingmachines-for-boeingrsquos-777x/. Accessed 2 April 2017 
92. Elkington M, Ward C, Potter K (2016) Automated Layup of Sheet Prepregs on Complex Moulds. Paper presented at the ECCM17 - 17th European Conference on Composite Materials, Munich, Germany, 26-30 June

93. Land P, Crossley R, Branson D, Ratchev S (2015) Technology Review of Thermal Forming Techniques for use in Composite Component Manufacture. SAE International Journal of Materials and Manufacturing 9 (1):81-89

94. Ward C, Bhatnagar V, Potter K (2013) Developing an Automated System for the Removal of Protective Films from Pre-Preg Material, to Remove a Manufacturing Bottleneck in Terms of Pick and Place Automation. Paper presented at the SAMPE SETEC 13, Wuppertal, Germany, 11-12 September

95. Hexcel (2015) Preforms for Compression Molding.

http://www.hexcel.com/products/industries/ipreforms. Accessed 10 February 2016

96. Apmann H (2008) Automatic Handling of CFRP-Material for Frame and Stringer

Production. SAE Technical Paper,

97. Apmann H, Hemmen A, Herkt M (2012) Automatic Handling of Carbon Fiber Preforms for CFRP Parts in Aerospace. SAE Technical Paper,

98. Reinhart G, Straßer G, Ehinger C (2009) Highly flexible automated manufacturing of composite structures consisting of limp carbon fibre textiles. SAE International Journal of Aerospace 2 (1):181-187

99. Angerer A, Ehinger C, Hoffmann A, Reif W, Reinhart G, Strasser G (2010) Automated cutting and handling of carbon fiber fabrics in aerospace industries. Paper presented at the 6th Anual IEEE Conference on Automation Science and Engineering (CASE), Toronto, Canada, August 21-24

100. Reinhart G, Straßer G (2011) Flexible gripping technology for the automated handling of limp technical textiles in composites industry. Production Engineering 5 (3):301-306 101. Reinhold R (2010) Solutions for Sophisticated Fiber-Composite Parts. Kunststoffe international, vol 5 .

102. Snudden J, Horn B, Ward C, Potter K, Drechsler K (2016) Effects of Automated Patch Placement on the Mechanical Performance of Reformed NCF Carbon Fibre. Paper presented at the ECCM17 - 17th European Conference on Composite Materials, Munich, Germany, 26-30 June 2016

103. Kühnel M, Schuster A, Buchheim A, Kießig M, Gerngross T, Kupke M (2014) Automatisiertes endkonturnahes Preforming Carbonfaser-Verstärkter Thermoplaste mittels robotischer Halbzeugablage. Paper presented at the Deutscher Luft- und Raumfahrtkongress 2014, Augsburg, Germany, 16-18 September

104. Kühnel M, Schuster A, Buchheim A, Gerngross T, Kupke M (2014) Automated near-netshape preforming of carbon fiber reinforced thermoplastics (CFRTP). Paper presented at the Innovative Composites Summit, JEC Europe, Paris, France, 11-13 March

105. Kuehnel M, Schuster A, Raehtz C, Kupke M (2016) Tailored Thermoplastic Preforming with Continuously Automated Cutting and Robotic Pick and Place Processes of Various SemiFinished Goods. Paper presented at the ECCM17 - 17th European Conference on Composite Materials, Munich, Germany, 26-30 June 2016

106. FibreMOVE - 2D composite gripper (2016).

http://www.looptechnology.com/pdf/Loop\%20FibreMOVE\%20Brochure.pdf

107. Reinhart G, Ehinger C (2013) Novel robot-based end-effector design for an automated preforming of limb carbon fiber textiles. In: Future Trends in Production Engineering.

Springer, pp 131-142

108. Brecher C, Emonts M, Ozolin B, Schares R (2013) Handling of Preforms and Prepregs for Mass Production of Composites. Paper presented at the 19th International Conference on Composite Mataterials (ICCM19), Montreal, Canada, 26 July - 2 August 2013

109. Kunz H, Löchte C, Fischer F, Dilger K (2013) Form-Flexible Heating Devices for Integration in Preform Gripper. Paper presented at the 19th International Conference on Composite Materials (ICCM19), Montreal, Canada, 26 July - 2 August 2013 
110. Löchte C, Kunz H, Schnurr R, Dietrich F, Raatz A, Dilger K, Dröder K (2013) Formflexible Handling Technology for Automated Preforming. Paper presented at the 19th International Conference on Composite Mataterials (ICCM19), Montreal, Canada, 26 July - 2 August 2013

111. Gerngross T, Nieberl D (2016) Automated manufacturing of large, three-dimensional CFRP parts from dry textiles. CEAS Aeronautical Journal 7 (2):241-257

112. Krebs F, Larsen L, Braun G, Dudenhausen W (2016) Design of a multifunctional cell for aerospace CFRP production. The International Journal of Advanced Manufacturing Technology 85 (1):17-24

113. Eckardt M, Buchheim A, Gerngross T (2016) Investigation of an automated dry fiber preforming process for an aircraft fuselage demonstrator using collaborating robots. CEAS Aeronautical Journal 7 (3):429-440

114. Ehinger C, Reinhart G (2014) Robot-based automation system for the flexible preforming of single-layer cut-outs in composite industry. Production Engineering 8 (5):559-565

115. Handling of Non-rigid Semi-finished Textiles for FRP-production. Internet.

http://www.ipt.fraunhofer.de/content/dam/ipt/en/documents/broschures $/ 220$ Handling $\% 20 \mathrm{of} \%$ 20non-rigid\%20semi-finished\%20textiles\%20for\%20FRP-Production.pdf

116. Linke M, Greb C, Schnabel A, Gries T (2013) Mass production technologies for textile reinforcement structures. Plastics, Rubber and Composites 42 (4):150-156

117. Greb C, Klingele J, Cetin M Automatisierte Fertigung textiler Preforms mit dem ITAPreformcenter. http://www.ita.rwth-aachen.de/1aktuell/highlights/automatisierte\%20Fertigung\%20textiler\%20preforms\%20preforming.pdf 118. Kordi MT, Husing M, Corves B (2007) Development of a multifunctional robot endeffector system for automated manufacture of textile preforms. Paper presented at the 2007 IEEE/ASME international conference on advanced intelligent mechatronics, Zurich,

Switzerland, 4-7 September

119. Integrated Composite Handling \& Drape System. http://www.broetjeautomation.de/en/solutions-customer-benefit/equipment/composite-manufacturing/handlingdrape/. Accessed 9th September 2016

120. Allcock A (2011) Robotic composite fibre lay-up system promises higher productivity for wing manufacture. Machinery Magazine

121. Michl F, Coquel M (2014) Fully-automated production of complex CFRP parts using

Fibre-Patch-Preforming technology. JEC Composites Magazine, vol 87.

122. Buckingham RO, Newell GC (1996) Automating the manufacture of composite

broadgoods. Composites Part A: Applied Science and Manufacturing 27 (3):191-200

123. Szcesny M, Heieck F, Middendorf P, Mezzacasa R, Irastorza X, Sehrschön H,

Schneiderbauer M (2016) LOWFLIP - An Innovative Direct 3D Placement Technology for

Plies and Tapes Paper presented at the ECCM17 - 17th European Conference on Composite Materials, Munich, Germany, 26-30 June

124. Gardiner G (2014) Automating the CH-53K's composite flexbeams. High-Performance

Composites, vol 22. Gardner Business Media Inc., Cincinnati. Ohio

125. Schwanemann P, Modler N, Witschel B, Grüber B, Lenz F (2016) Process Development for Generative Manufacturing of Fiber Thermoplastic Composites Structures - Thermoplastic Patch Placement (TPP). Paper presented at the ECCM17 - 17th European Conference on Composite Materials, Munich, Germany, 26-30 June 2016

126. Faber J, Schmidt-Eisenlohr C (2016) Automated Handling of Auxiliary Materials for Vacuum Bagging in CFRP Fuselage Production. Paper presented at the ECCM17 - 17th European Conference on Composite Materials, Munich, Germany, 26-30th June 127. FibreFORM - A complete composite handling system (2016). http://www.looptechnology.com/pdf/Loop\%20FibreFORM\%20Brochure.pdf

128. Lien TK, Davis PGG (2008) A novel gripper for limp materials based on lateral Coanda ejectors. CIRP Annals-Manufacturing Technology 57 (1):33-36

129. Angerer A, Hoffmann A, Reif W, Ehinger C, Reinhart G, Strasser G (2010) Automated cutting and handling of carbon fiber fabrics in aerospace industries. Paper presented at the 
IEEE International Conference on Automation Science and Engineering, CASE 2010, Toronto, Canada, 21-24 August

130. Stephan J, Seliger G (1999) Handling with ice-the cryo-gripper, a new approach.

Assembly Automation 19 (4):332-337

131. Taylor PM (1995) Presentation and gripping of flexible materials. Assembly Automation $15(3): 33-35$

132. Ozcelik B, Erzincanli F, Findik F (2003) Evaluation of handling results of various materials using a non-contact end-effector. Industrial Robot: An International Journal 30 (4):363-369

133. Newell GC, Buckingham RO, Khodabandehloo K (1996) The automated manufacture of prepreg broadgoods components - A review of literature. Composites Part A: Applied Science and Manufacturing 27 (3):211-217

134. LOWFLIP. http://www.lowflip.eu/. Accessed 14 March 2017

135. Fill lowflip prototype cell for tape laying (2016). Youtube

https://youtu.be/NHtapnUDGe8

136. Fill lowflip multi-functional gripper based on Tecnacompsystem by Tecnalia (2016).

Youtube https://youtu.be/vKxejylkrx4

137. Oberfranz R (1986) Automated systems for the manufacture of Airbus vertical stabilizer spar box in composite materials. Paper presented at the 15 th Congress of the International Council of the Aeronautical Sciences (ICAS), London, United Kingdom, 7-12 September 138. Johansson M, Sundqvist J (2013) Utveckling och design av gripdon för komposithantering. Master of Science, Linköping University, Linköping, Sweden 139. Björnsson A, Johansen K, Alexandersson D (2013) Three-dimensional ultrasonic cutting of RTM-preforms - a part of a high volume production system. Paper presented at the The 19th International Conference on Composite Materials, ICCM19, Montreal, Canada, 28 July 2 August

140. Björnsson A, Johansen K, Thuswaldner M (2014) Automated Composite Manufacturing Using Off-the-shelf Automation Equipment - A Case from the Space Industry. Paper presented at the ECCM16 - the 16th European Conference on Composite Materials, Seville, Spain, June 22-26

141. Lindbäck JE, Björnsson A, Johansen K (2012) New Automated Composite Manufacturing Process: Is it possible to find a cost effective manufacturing method with the use of robotic equipment? Paper presented at the 5th Swedish Production Symposium, SPS12, Linköpig, Sweden, 6-8 November

142. The ARMATURE Project Automated Preforming and Curing Cell. http://www.advancedcomposites.co.uk/armature video_download.html

143. Martinsson F (2016) Automatisk borttagning av skyddspapper från prepreg - En del av att möjliggöra robotiserad tillverkning av komponenter i kolfiberkomposit. Bachelor of Science, Linköping University, Linköping, Sweden 


\section{Papers}

The articles associated with this thesis have been removed for copyright reasons. For more details about these see:

http://urn.kb.se/resolve? urn:nbn:se:liu:diva-137488 